\title{
ACP e LOTOS: um estudo comparativo baseado em conceitos de BPEL e padrões de controle de fluxo
}

\author{
Pedro Losco Takecian
}

\author{
DISSERTAÇÃO APRESENTADA \\ AO \\ INSTITUTO DE MATEMÁTICA E ESTATÍSTICA \\ DA \\ UNIVERSIDADE DE SÃO PAULO \\ PARA \\ OBTENÇÃO DO TÍTULO \\ $\mathrm{DE}$ \\ MESTRE EM CIÊNCIAS
}

Área de Concentração: Ciência da Computação

Orientador: Prof. Dr. João Eduardo Ferreira

- São Paulo, junho de 2008 - 



\section{ACP e LOTOS: um estudo comparativo baseado em conceitos de BPEL e padrões de controle de fluxo}

Este exemplar corresponde à redação final da dissertação devidamente corrigida e defendida por Pedro Losco Takecian e aprovada pela Comissão Julgadora.

São Paulo, 03 de junho de 2008.

Banca Examinadora:

- Prof. Dr. João Eduardo Ferreira (orientador) - IME-USP

- Prof. Dr. José de Jesús Pérez-Alcazar - EACH-USP

- Prof. Dr. Duncan Dubugras Alcoba Ruiz - FACIN-PUCRS 

Aos meus pais, Pedro e Rose. 



\section{Agradecimentos}

Ao meu orientador, professor João Eduardo Ferreira, pela amizade, compreensão, paciência, e por confiar no meu trabalho; pela inestimável ajuda durante todo este percurso; pelo exemplo de pessoa e professor que é, sua simplicidade e humildade.

Aos meus pais, Pedro e Rosemary, minha avó Rachel, meu irmão Alberto e minha cunhada Josiane, pelo carinho, apoio e força que me deram, sem os quais seria impossível a finalização deste trabalho; agradeço, ainda, a meus pais, por todo o esforço para que eu tivesse acesso a uma boa educação e bons estudos.

À minha namorada, Ana Cecília, pelo amor, carinho, paciência, apoio incondicional e compreensão durante todo este período; pela valiosa ajuda; pelas longas conversas, por entender meus receios e me confortar nos momentos difíceis; agradeço também a seus pais, Sr. Roberto e Sra. Eliana pelo apoio e compreensão.

Ao professor Siang Wun Song, pela valiosa ajuda e acompanhamento; aos professores Ana Cristina Vieira de Melo, Calton Pu e José de Jesús Pérez-Alcazar, pela colaboração e preciosas dicas que contribuíram muito para a realização deste trabalho.

Aos amigos, Daniel de Angelis Cordeiro, David da Silva Pires, Grace Anne Pontes Borges, Kelly Rosa Braghetto, Márcio Katsumi Oikawa pelo companheirismo e pelas várias contribuições a este mestrado. Em especial, gostaria de agradecer a Kelly pela grande e importantíssima ajuda durante todo o mestrado.

Aos amigos do IME, à turma do BCC/2000, aos companheiros do Laboratório de Banco de Dados e da Rede Vision e, em especial, aos amigos Daniel André Vaquero, Fernando Mário de Oliveira Filho, Giuliano Mega, João Vítor Baldini Soares, Marcos Eduardo Bolelli Broinizi, que estiveram mais próximos durante a realização do meu mestrado, me incentivando e apoiando.

A todas as outras pessoas que contribuíram e acompanharam, de diferentes formas, este trabalho. 



\section{Resumo}

Recentemente, várias abordagens estão sendo propostas na área de modelagem de processos de negócio. Dentre elas estão as linguagens BPEL e NPDL. BPEL é uma linguagem de representação e execução de processos de negócio que se mostrou bastante expressiva e uma forte candidata a padrão de mercado. NPDL é uma linguagem de definição de processos de negócio baseada em uma extensão de álgebra de processos chamada ACP. NPDL possui uma ferramenta capaz de interpretar e controlar a execução de processos de negócio chamada de NavigationPlanTool.

A tradução de processos BPEL para expressões NPDL tem como objetivo fornecer aos processos descritos em BPEL um ambiente de controle e execução baseado em um formalismo algébrico. Entretanto, isso não é uma tarefa fácil. A presença de conceitos em BPEL que não são mapeáveis para NPDL faz com que grande parte da expressividade de BPEL se perca na tradução. Essa perda se dá pela limitação da própria ACP, na qual NPDL se baseia.

Para sanar essa dificuldade, surgiu a idéia de estender ou trocar a base algébrica da NPDL. Substituindo a ACP por outro arcabouço algébrico ou incorporando idéias de outras álgebras, seria possível tornar a NPDL mais próxima de BPEL, facilitando, assim, o trabalho de mapeamento. Dentre os arcabouços formais disponíveis, LOTOS tem se mostrado uma interessante alternativa à ACP como base para a NPDL. Para comprovar os benefícios da utilização de conceitos de LOTOS na NPDL ou, até mesmo, de uma troca da base algébrica da NPDL de ACP para LOTOS, este trabalho faz um estudo comparativo entre esses dois formalismos algébricos, buscando encontrar a álgebra com maior expressividade e que represente melhor os conceitos presentes em BPEL. Para essa comparação, serão utilizados os principais conceitos existentes na linguagem BPEL, bem como os Padrões de Controle de Fluxo de Workflow. Não pertence ao escopo deste trabalho a implementação da NPDL usando LOTOS como base formal.

Palavras-chave: ACP, BPEL, LOTOS, NPDL, álgebra de processos, Padrões de Workflow. 



\section{Abstract}

Recently, several approaches are being proposed in the business process modeling area. Among them are BPEL and NPDL languages. BPEL is a business process representation and execution language that has showed itself to be very expressive and a strong candidate to market reference. NPDL is a business process definition language based on a process algebra extension called ACP. NPDL has a tool called NavigationPlanTool that is able to interpret and control the business processes execution.

The translation from BPEL processes to NPDL expressions aims to provide to BPEL processes a control and execution environment based on an algebraic foundation. However, this is not an easy task. Due to the translation, the presence of BPEL concepts that can't be mapped to NPDL results in a heavy BPEL expressiveness loss. This loss occurs by the limitation of ACP, in which NPDL is based on.

To solve this problem, the idea of extending or replacing the NPDL algebraic base has appeared. Replacing ACP with other algebraic framework or incorporating ideas from other algebras, could make NPDL closer to BPEL, turning the mapping work easier. Among the formal frameworks available, LOTOS has showed itself an interesting alternative to ACP as an NPDL basis. To prove the benefits of using LOTOS concepts in NPDL, or even exchanging the NPDL algebraic base from ACP to LOTOS, this work presents a comparative study between these two algebraic foundations, trying to find the most expressive algebra and the one that best represents the BPEL concepts. For this comparison, the BPEL main concepts and the Workflow Control-Flow Patterns will be used. The NPDL implementation using LOTOS as formal foundation is out of the scope of this work.

Keywords: ACP, BPEL, LOTOS, NPDL, process algebra, Workflow Patterns. 



\section{Sumário}

Lista de Figuras $\quad v$

Lista de Tabelas

1 Introdução 1

1.1 Contextualização do trabalho . . . . . . . . . . . . . . . . . . . . . . . 1

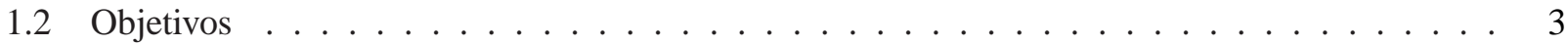

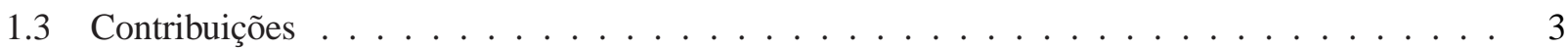

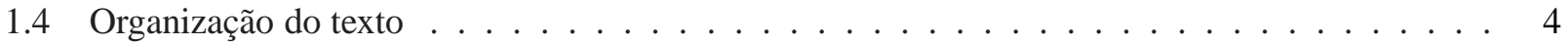

2 Fundamentos algébricos $\quad 5$

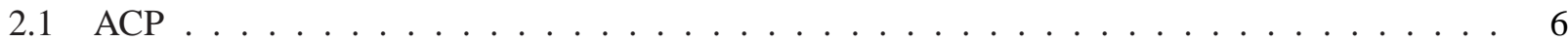

2.1.1 BPA - Álgebra de Processos Básica . . . . . . . . . . . . . . . . . 7

2.1.2 PAP - Álgebra de Processos com Paralelismo . . . . . . . . . . . . . . . . . . 10

2.1.3 ACP - Álgebra de Processos Comunicantes . . . . . . . . . . . . . . . . . . 13

2.1 .4 ACP com recursão . . . . . . . . . . . . . . . . . . . . . . . . . . . 14

2.1.5 Exemplo de especificação de processo . . . . . . . . . . . . . . . . . 15

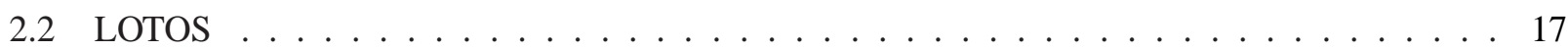

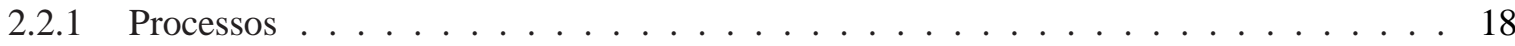


2.2.2 LOTOS básica . . . . . . . . . . . . . . . . . . . . . . 19

2.2 .3 Tipos de dados . . . . . . . . . . . . . . . . . . . 23

2.2 .4 LOTOS completa . . . . . . . . . . . . . . . . . . . . . . 26

2.2.5 Exemplo de especificação de processo . . . . . . . . . . . . . . . . . . 34



3 Trabalhos relacionados $\quad 37$

3.1 Padrões de Controle de Fluxo . . . . . . . . . . . . . . . . . . . . 37



3.2.1 BPEL no contexto de serviços web . . . . . . . . . . . . . . . . . 39

3.2.2 Processos abstratos e processos executáveis . . . . . . . . . . . . . 39

3.2.3 Controle de fluxo em BPEL: a união de dois paradigmas . . . . . . . . . . . . . . 40

3.2.4 Manipulação de dados em BPEL . . . . . . . . . . . . . . . . . . . . . . . . . . . 44

3.2.5 Instâncias de processos: identificação e ciclo de vida . . . . . . . . . . . . . 45

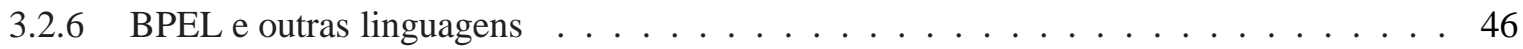

3.2.7 Exemplo de especificação de processo . . . . . . . . . . . . . . . . . 47

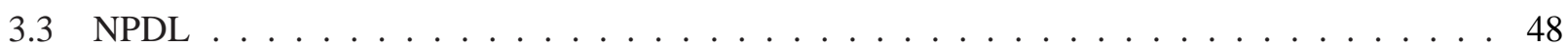

3.3.1 Linguagem para representação e execução de processos . . . . . . . . . . . . . . . . 48

3.3.2 Especificação dos Padrões de Controle de Fluxo em NPDL . . . . . . . . . . . . . . 50

3.3.3 Exemplo de especificação de processo . . . . . . . . . . . . . . . . 51

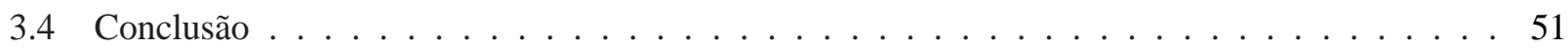

4 Comparando ACP e LOTOS

4.1 Representação dos Padrões de Controle de Fluxo . . . . . . . . . . . . . . . . . . . 54

4.1.1 Padrões básicos de controle de fluxo . . . . . . . . . . . . . . . . . . 56 
4.1.2 Padrões avançados de ramificação e sincronização . . . . . . . . . . . . . . . 61

4.1 .3 Padrões estruturais $\ldots \ldots \ldots \ldots \ldots \ldots \ldots$

4.1 .4 Padrões envolvendo múltiplas instâncias . . . . . . . . . . . . . . . . . . . . . . 69

4.1.5 Padrões baseados em estados . . . . . . . . . . . . . . . . . . . . 73

4.1 .6 Padrões de cancelamento . . . . . . . . . . . . . . . . . . . . 77

4.2 Representação dos conceitos de BPEL . . . . . . . . . . . . . . . . . . . . . . . 79

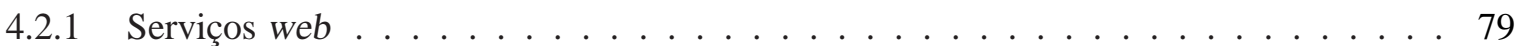

4.2 .2 Atividades . . . . . . . . . . . . . . . . . . . . 79

4.2 .3 Grafos e BPEL . . . . . . . . . . . . . . . . . . . . 90

4.2 .4 Manipulação de dados . . . . . . . . . . . . . . . . . . . . . . . . 93

4.2.5 Manipuladores de falhas, eventos, compensações e terminações . . . . . . . . . . . 93

4.2.6 Identificação e ciclo de vida de instâncias de processos . . . . . . . . . . . . . . . . 94

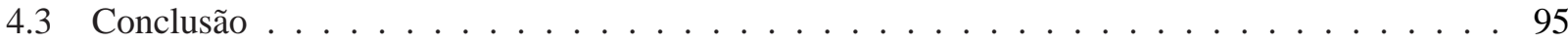

5 Conclusão $\quad 101$

5.1 Principais contribuições . . . . . . . . . . . . . . . . . . . 101

5.2 Sugestões para pesquisas futuras . . . . . . . . . . . . . . . . . . . 102

$\begin{array}{lc}\text { A Atividades BPEL } & 103\end{array}$

$\begin{array}{ll}\text { B Processo LOTOS } & 107\end{array}$

Referências Bibliográficas $\quad 111$ 



\section{Lista de Figuras}

2.1 Análise de equivalências . . . . . . . . . . . . . . . . . . . . . 9

2.2 Exemplo de processo: processamento de pedido . . . . . . . . . . . . . . . 16



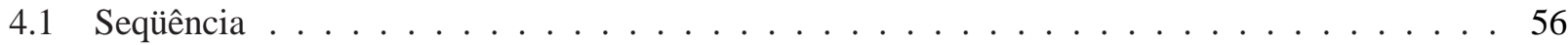

4.2 Divisão Paralela . . . . . . . . . . . . . . . . . . . . . . . . . . . 57

4.3 Sincronização . . . . . . . . . . . . . . . . . . . . . 58

4.4 Escolha Exclusiva . . . . . . . . . . . . . . . . . . . . . . . 59

4.5 Junção Simples . . . . . . . . . . . . . . . . . . . . . . . . . . . . . 60

4.6 Escolha Múltipla . . . . . . . . . . . . . . . . . . . . . . 61

4.7 Junção Sincronizada . . . . . . . . . . . . . . . . . . . . . . 63

4.8 Junção Múltipla . . . . . . . . . . . . . . . . . . . . . . . . . . . . . . . . . 64

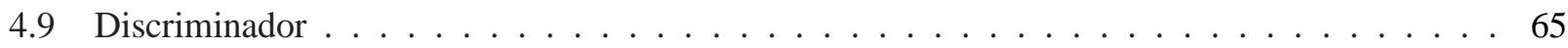

4.10 Ciclo Arbitrário . . . . . . . . . . . . . . . . . . . . . . . 67

4.11 MI com Conhecimento Prévio em Tempo de Projeto $\ldots \ldots \ldots \ldots$

4.12 MI com Conhecimento Prévio em Tempo de Execução . . . . . . . . . . . . . . . . . 71

4.13 MI sem Conhecimento Prévio em Tempo de Execução . . . . . . . . . . . . . . . . . 72

4.14 Escolha Postergada . . . . . . . . . . . . . . . . . . 73 
4.15 Roteamento Paralelo Entrelaçado . . . . . . . . . . . . . . . . . . . . . 74



4.17 Marco envolvendo linhas paralelas . . . . . . . . . . . . . . . . 76

4.18 Atividade Cancelável . . . . . . . . . . . . . . . . . . . . . . . . 78 


\section{Lista de Tabelas}

2.1 Regras de transição para BPA. . . . . . . . . . . . . . . . . . . . 8

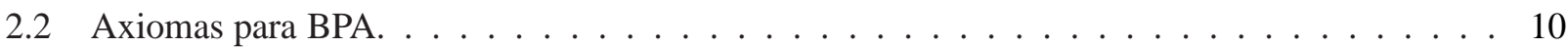

2.3 Regras de transição para entrelaçamento. . . . . . . . . . . . . . . . . . . . 11

2.4 Regras de transição para entrelaçamento envolvendo comunicação. . . . . . . . . . . . . . . 11

2.5 Regras de transição para o entrelaçamento à esquerda. . . . . . . . . . . . . . . . . . . . . 12

2.6 Regras de transição para entrelaçamento com comunicação. . . . . . . . . . . . . . . . . . 12

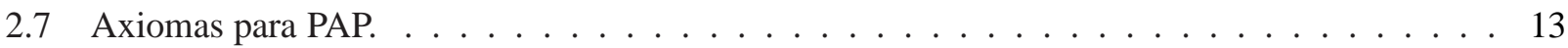

2.8 Regras de transição para o encapsulamento. . . . . . . . . . . . . . . . . . . . . . 14

2.9 Axiomas para impasse e encapsulamento. . . . . . . . . . . . . . . . . . . . 14

2.10 Regras de transição para recursão . . . . . . . . . . . . . . . . . . . . . . 15

4.1 ACP e LOTOS: comparação baseada nos padrões. . . . . . . . . . . . . . . . . . . . . 98

4.2 ACP e LOTOS: comparação baseada nos conceitos BPEL. . . . . . . . . . . . . . . . . . . 99 



\section{Capítulo 1}

\section{Introdução}

Antes da década de 70, os computadores eram pouco utilizados nos processos produtivos, devido ao alto custo que representavam e à dificuldade em operá-los. Com o passar dos anos, a utilização deles começou a aumentar, automatizando tarefas repetitivas, substituindo pessoas e barateando o custo total de produção. Apesar de os passos da produção tornarem-se individualmente mais automatizados, havia uma grande dificuldade em melhorar a coordenação das diversas tarefas.

Já na década de 70, algumas pessoas como Skip Ellis, Anatol Holt e Michael Zisman começaram a se preocupar com o problema da coordenação de tarefas, iniciando o trabalho com modelagem de processos nos chamados Office Information Systems [1]. Apesar do otimismo inicial relacionado à aplicabilidade desses sistemas, a maioria das aplicações desenvolvidas fracassou, levando a uma estagnação da tecnologia e da pesquisa relacionada à área.

O interesse pelo assunto voltou apenas nos anos 90, retomando-se as pesquisas, que agora davam maior ênfase ao gerenciamento de processos de negócio. Atualmente, existem vários produtos comerciais disponíveis nessa área. Entretanto, problemas conceituais ainda persistem, tais como a falta de padronização para a modelagem de processos de negócio e a rigidez excessiva imposta aos processos quando utilizados em ambientes reais de trabalho [1].

\subsection{Contextualização do trabalho}

Recentemente, várias abordagens estão sendo propostas na área de processos de negócio. A representação e execução de passos de negócio têm gerado vários desafios. Entre eles, destacam-se a questão da escolha da melhor fundamentação matemática e a melhor linguagem para representação de processos de negócio. 
Para a manipulação matemática, execução e simulação de processos de negócio, duas abordagens são comumente usadas. A primeira delas utiliza redes de Petri [2]. Já a outra baseia-se em álgebra de processos [3]. Dentre as vantagens da primeira, estão o forte apelo visual e a representação explícita de estados. Na segunda opção, temos como vantagem a representação de processos por meio de expressões algébricas, de caráter textual e composicional. As redes de Petri têm como desvantagem o fato de produzirem modelos muito grandes para processos complexos. Isso ocorre devido à explosão combinatória de estados inerente à técnica. Já na álgebra de processos, tem-se a dificuldade em se compreender processos complexos descritos utilizando expressões algébricas. Existem diversas álgebras de processos e extensões. Dentre as mais importantes, estão: ACP [4], CCS [5], CSP [6], $\pi$-calculus [7] e LOTOS [8]. Elas utilizam diferentes abordagens para representação de processos. Essas diferenças culminam em diferentes capacidades expressivas.

Apesar de serem escassas na literatura, as tentativas de produzir ferramentas que utilizem como arcabouço formal a álgebra de processos vêm se mostrando boas alternativas às redes de Petri para a execução de processos de negócio, devido ao caráter textual da álgebra, de fácil manipulação computacional, quando comparada às redes de Petri. Dentre os trabalhos baseados em álgebras de processos, está a NPDL [9]. NPDL é uma linguagem baseada na ACP. Ela possui uma ferramenta capaz de interpretar e controlar a execução de processos de negócio chamada de NavigationPlanTool.

A escolha da melhor linguagem para representação de processos de negócio é outra questão bastante relevante no cenário atual. Recentemente, muitas linguagens foram criadas com esta finalidade. Como exemplo, tem-se: WSCI [10], BPML [11], BPEL [12-14], XLANG [15], WSFL [16], YAWL [17]. Muitas dessas linguagens utilizam conceitos de composição de serviços $w^{1} b^{1}$ [18], abordagem bastante utilizada nas visões orientadas a processos. Apesar do surgimento de um vasto número de linguagens para esse fim, havia pouco esforço em compará-las de uma maneira mais formal. Diante dessa lacuna, surgiram os Workflow Patterns [19] como uma maneira de avaliar essas linguagens com relação à semântica e à expressividade, permitindo, assim, compará-las.

Workflow Patterns são o resultado de pesquisas de W. M. P. van der Aalst e de outros pesquisadores de seu grupo. Eles tentaram achar uma maneira de comparar as diversas linguagens existentes, ao mesmo tempo em que tentaram identificar quais os requisitos que as linguagens de representação de processos deveriam satisfazer. Assim, os Workflow Patterns tentam representar as diversas situações recorrentes em processos de negócio, identificando-as como possíveis requisitos de um sistema gerenciador de processos. Esses padrões buscam a independência de qualquer linguagem específica, servindo, também, para comparação entre

\footnotetext{
${ }^{1}$ Neste trabalho, o termo serviço web será utilizado para substituir o termo web service, mantendo o significado original.
} 
formalismos matemáticos existentes na área de processos.

Dentre as diversas linguagens existentes, a BPEL vem se destacando das demais, devido a sua grande capacidade expressiva, resultado da convergência das idéias presentes em duas outras linguagens preexistentes: XLANG e WSFL. Com o passar do tempo, ela vem ganhando destaque nos cenários das grandes empresas, tornando-se uma forte candidata a padrão de mercado.

\subsection{Objetivos}

Apesar de promissora e bastante expressiva, BPEL não está baseada em um formalismo matemático que propicie facilidades de verificação, validação e execução de processos. A tradução de processos BPEL para expressões NPDL tem, justamente, o objetivo de fornecer aos processos descritos em BPEL um ambiente de controle e execução baseado em um formalismo algébrico. Entretanto, isso não é uma tarefa fácil. A presença de conceitos em BPEL que não são mapeáveis para NPDL faz com que grande parte da expressividade de BPEL se perca na tradução. Esta perda se dá pela limitação da própria ACP, na qual NPDL se baseia.

Com o intuito de facilitar esse processo de tradução, surgiu a idéia de estender ou trocar a base algébrica da NPDL. Substituindo a ACP por outro arcabouço algébrico ou incorporando idéias de outras álgebras, seria possível tornar a NPDL mais próxima de BPEL, facilitando, assim, o trabalho de mapeamento. Dentre os arcabouços formais disponíveis, LOTOS tem se mostrado uma interessante alternativa à ACP como base para a NPDL. Para comprovar os benefícios da utilização de conceitos de LOTOS na NPDL ou, até mesmo, de uma troca da base algébrica da NPDL (de ACP para LOTOS), este trabalho faz um estudo comparativo entre esses dois fundamentos algébricos, buscando encontrar a álgebra com maior expressividade e que represente melhor os conceitos presentes em BPEL. Para essa comparação, serão utilizados os principais conceitos existentes na linguagem BPEL, bem como os Padrões de Controle de Fluxo de Workflow.

\subsection{Contribuições}

As principais contribuições deste trabalho estão discriminadas abaixo:

- Desenvolvimento de uma representação dos Padrões de Controle de Fluxo de Workflow utilizando a linguagem LOTOS;

- Estudo sobre a relação entre os principais conceitos de BPEL e as suas respectivas representações utilizando LOTOS e ACP;

- Comparação entre as linguagens LOTOS e ACP utilizando os Padrões de Controle de Fluxo de Workflow e 
os conceitos básicos de BPEL.

\subsection{Organização do texto}

No Capítulo 2, são apresentados os fundamentos das duas teorias algébricas utilizadas neste trabalho: ACP e LOTOS. Nesse capítulo estão os principais operadores dessas álgebras, de grande importância para o entendimento deste trabalho. No Capítulo 3, encontram-se os trabalhos relacionados. Os Padrões de Controle de Fluxo e a linguagem BPEL serão usados como bases comparativas para os fundamentos algébricos vistos no capítulo anterior. A linguagem NPDL também é descrita nesse capítulo. O Capítulo 4 contém os mapeamentos desenvolvidos e a comparação entre ACP e LOTOS proposta pelo trabalho. Finalmente,

no Capítulo 5, a conclusão do trabalho é apresentada. No Apêndice A, encontram-se descrições sucintas das atividades definidas por BPEL e no Apêndice B, um exemplo de processo LOTOS. 


\section{Capítulo 2}

\section{Fundamentos algébricos}

Os parágrafos seguintes abordam uma introdução à álgebra de processos. Eles são baseados em [20] e no capítulo introdutório de [3].

Todo sistema possui um comportamento. Por comportamento, entende-se a totalidade de eventos ou ações que um sistema pode desempenhar, bem como a ordem em que eles podem ser executados, além de outros aspectos, como, por exemplo, as probabilidades de execução. Para descrever um comportamento de um sistema, são necessários dois tipos de elementos: os processos e os dados. Os processos, dinâmicos e ativos, são os mecanismos de controle para a manipulação dos dados, estáticos e passivos. Um comportamento de um sistema tende a ser formado por vários processos que executam concorrentemente. Esses processos podem trocar dados entre si, influenciando a execução uns dos outros.

Para representar um comportamento de um sistema, primeiramente, extrai-se uma visão simplificada desse comportamento, que descreve alguns aspectos relevantes e desconsidera outros que não são necessários. Posteriormente, utiliza-se algum método de representação para expressar esta simplificação. Existem várias maneiras de representar o comportamento de um sistema. Uma delas é a utilização de um Sistema de Transições Rotuladas (STR). Um STR é um grafo dirigido formado por um conjunto de nós, que representam os diferentes estados de um sistema, e arestas rotuladas entre os nós, que representam as transições de estados. Um STR que possui um estado, escolhido entre os demais, para ser o estado inicial recebe o nome de grafo de processo. Em um grafo de processo, a existência de uma aresta que liga o estado $s$ ao estado $s^{\prime}$, com rótulo $a$ (representada por $s \stackrel{a}{\rightarrow} s^{\prime}$ ), indica que o grafo de processo pode evoluir do estado $s$ para o estado $s^{\prime}$ através da execução da ação $a$.

Entretanto, para fins de análise matemática, muitas vezes é conveniente representar grafos de processos algebricamente, por meio de termos algébricos. A especificação e a manipulação de termos algébricos que 
representam comportamentos de sistemas são o enfoque da álgebra de processos. Os fundamentos da álgebra de processos começaram a ser desenvolvidos ainda na década de 70, grande parte independentemente, por Robin Milner e C.A.R. Hoare. Os trabalhos de Milner resultaram na teoria de álgebra de processos chamada Calculus of Communicating Systems (CCS) [5]. Paralelamente a Milner, Hoare também trabalhava em uma teoria de processos, que posteriormente resultou na CSP (Communicating Sequential Processes) [6]. Durante o desenvolvimento da CCS e da CSP, houve uma troca de idéias que contribuiu para o amadurecimento desses trabalhos. Em 1982, Jan Bergstra e Jan Willem Klop começaram a desenvolver outra álgebra de processos. A ela, deram o nome de ACP (Algebra of Communicating Processes) [4]. Esses dois pesquisadores foram os responsáveis pela enfatização do aspecto algébrico do modelo desenvolvido por eles e introduziram o termo "álgebra de processos" para descrevê-lo. Até então, o termo "cálculo de processos" era utilizado com este fim. Nesta dissertação, o termo "álgebra de processos" será utilizado para se referir a todas essas teorias, sem distinção, para fins de simplificação. CCS, CSP e a ACP constituem, assim, as álgebras fundamentais, nas quais a maioria das álgebras mais recentes se baseiam, como é o caso de LOTOS [8] e de $\pi$-calculus [7].

Apesar da grande variedade de álgebras de processos existentes na atualidade, elas costumam ser semelhantes em vários pontos. Por exemplo: a existência de operadores básicos para a construção de processos finitos; a noção de recursão para representar processos de comportamento infinito; a existência de lógicas equacionais para igualar termos de processos quando estes possuem grafos de processos comportamentalmente equivalentes; a existência da formalização das semânticas operacionais; a capacidade de estendê-las, adicionando novos operadores e funcionalidades. Entretanto, existem significativas diferenças entre elas, que levam a diferentes poderes de expressividade. Assim, dependendo das funcionalidades que se deseja representar, uma álgebra mostra-se mais apropriada do que a outra. Essas diferenças são ocasionadas pela existência de diferentes operadores e diferentes maneiras de tratar a comunicação entre processos, além de outros fatores.

No restante deste capítulo, serão descritas duas teorias algébricas, ACP e LOTOS, que serão comparadas no Capítulo 4. Para cada álgebra estudada, o enfoque será dado aos elementos que influenciam de alguma maneira o poder de representação e expressividade dela. Esse é o caso de vários operadores, da definição de elementos básicos (como ações) e, ainda, da comunicação entre processos.

\subsection{ACP}

Dentre as três álgebras de processos mais conhecidas (CCS, CSP e ACP), a ACP é o formalismo com maior ênfase no aspecto algébrico. Apresentada por Jan Bergstra e Jan Willem Klop em 1982 [21], a ACP é uma teoria elegante e madura, que possui um poderoso arcabouço axiomático, proporcionando o formalismo necessário à descrição da igualdade de processos. 
A ACP foi definida como uma extensão do que foi denominada Álgebra de Processos Básica (BPA Basic Process Algebra). Na Álgebra de Processos Básica, apenas os operadores básicos foram definidos. Assim, tem-se apenas os operadores de composição seqüencial e composição alternativa. Aqui, nesta primeira abordagem, a comunicação entre processos não é considerada. Nessa teoria básica, novos operadores foram introduzidos com a finalidade de representar a comunicação entre processos. À BPA incrementada com alguns aspectos de comunicação, dá-se o nome de Álgebra de Processos com Paralelismo (PAP - Process Algebra with Paralelism). Por fim, também foram adicionados à PAP os conceitos de impasse e encapsulamento, completando assim a extensão que constitui a ACP.

A seguir, serão descritas a Álgebra de Processos Básica e a sua extensão, que constitui a ACP. Além disso, será descrita, de maneira sucinta, a ACP com recursão (ACP with guarded recursion). Esta especificação é uma maneira de aumentar a expressividade da álgebra, adicionando o poder de representar sistemas com comportamentos que podem ser ilimitados. A ACP com recursão é a álgebra utilizada na linguagem NPDL (ver Seção 3.3). O restante desta seção foi baseado em [3], livro escrito por Wan Fokkink. As regras, axiomas de igualdade, definições e figuras a seguir foram retiradas desse livro.

\subsubsection{BPA - Álgebra de Processos Básica}

Os processos finitos podem ser representados por termos fechados, construídos a partir de um conjunto de elementos. Esses elementos são ações atômicas e dois operadores, que juntos constituem o arcabouço básico para a álgebra de processos. Assim, tem-se:

- Conjunto de ações: conjunto finito e não vazio $A$ de ações atômicas, representando comportamentos indivisíveis. Cada ação atômica $a(a \in A)$ é uma constante que pode se executar. Após a execução, a ação $a$ termina com sucesso.

- Operador de composição alternativa: operador binário "+". Se os termos $t_{1}$ e $t_{2}$ representam processos $p_{1}$ e $p_{2}$, respectivamente, então o termo $t_{1}+t_{2}$ representa o processo que executa ou $p_{1}$ ou $p_{2}$. Ou seja, o grafo de processos de $t_{1}+t_{2}$ é obtido pela junção de $p_{1}$ e $p_{2}$ pelos seus estados iniciais.

- Operador de composição seqüencial: operador binário “.”. Se os termos $t_{1}$ e $t_{2}$ representam processos $p_{1}$ e $p_{2}$, então o termo fechado $t_{1} \cdot t_{2}$ representa o processo que executa primeiro $p_{1}$ e depois $p_{2}$. O grafo de processo de $t_{1} \cdot t_{2}$ é obtido pela substituição em $p_{1}$ de cada término com sucesso na forma $s \stackrel{a}{\rightarrow} \sqrt{ }(\stackrel{a}{\rightarrow} \sqrt{ }$ representa um término bem-sucedido depois da execução da ação $a$ ) pela transição $s \stackrel{a}{\rightarrow} s^{\prime}$, em que $s^{\prime}$ é o estado inicial de $p_{2}$. 
Por convenção, assume-se que o operador "." tem maior precedência que o operador " + ". Assim, $a+b \cdot c$ representa $a+(b \cdot c)$. Muitas vezes, a ocorrência do operador “.” é omitida dos termos, ficando implícita a sua presença $(a b$ denota $a \cdot b)$.

\section{Regras de transição para BPA}

Até agora, foi apresentada a sintaxe dos termos da álgebra de processos básica juntamente com uma noção informal do significado dos operadores básicos apresentados. É necessário agora formalizar a semântica operacional. Esta formalização é feita por meio da especificação de um conjunto de regras de transição. Essas regras de transição envolvem relações de transição. Uma relação de transição $x \stackrel{a}{\rightarrow} x^{\prime}$ expressa que o termo $x$ pode evoluir para o termo $x^{\prime}$ por meio da execução da ação $a$. Uma relação de transição $x \stackrel{a}{\rightarrow} \sqrt{ }$ expressa que o termo x pode terminar com sucesso com a execução da ação $a$. As relações de transição para BPA estão descritas na Tabela 2.1. As variáveis $x, x^{\prime}, y$ e $y^{\prime}$ nas regras de transição são termos básicos de processo, enquanto $v$ é uma ação atômica.

$$
\begin{gathered}
\frac{\vdots}{v \stackrel{v}{\rightarrow} \sqrt{ }} \\
\frac{\stackrel{v}{\rightarrow} \sqrt{ }}{x+y \stackrel{v}{\rightarrow} \sqrt{ }} \frac{x \stackrel{v}{\rightarrow} x^{\prime}}{x+y \stackrel{v}{\rightarrow} x^{\prime}} \quad \frac{y \stackrel{v}{\rightarrow} \sqrt{ }}{x+y \stackrel{v}{\rightarrow} \sqrt{ }} \quad \frac{y \stackrel{v}{\rightarrow} y^{\prime}}{x+y \stackrel{v}{\rightarrow} y^{\prime}} \\
\frac{x \stackrel{v}{\rightarrow} \sqrt{ }}{x \cdot y \stackrel{v}{\rightarrow} y} \quad \frac{x \stackrel{v}{\rightarrow} x^{\prime}}{x \cdot y \stackrel{v}{\rightarrow} x^{\prime} \cdot y}
\end{gathered}
$$

Tabela 2.1: Regras de transição para BPA. Extraída de [3].

Na Tabela 2.1, a primeira regra expressa que cada ação atômica $v$ termina com sucesso executando a si mesma. As próximas quatro regras expressam que $x+y$ executa ou $x$ ou $y$. As duas últimas regras expressam que $x \cdot y$ executa $x$ até um término bem-sucedido e depois executa $y$.

\section{Equivalência entre grafos de processos (bissimulação)}

Os processos vêm sendo estudados desde os anos 60. Nesses estudos, a equivalência de processos era, em geral, baseada na chamada equivalência por rastros (trace equivalence). Nela, dois processos são ditos equivalentes se eles podem executar exatamente as mesmas cadeias de ações. Porém, para o comportamento de sistemas, essa equivalência nem sempre é satisfatória, como mostrado na Figura 2.1. 

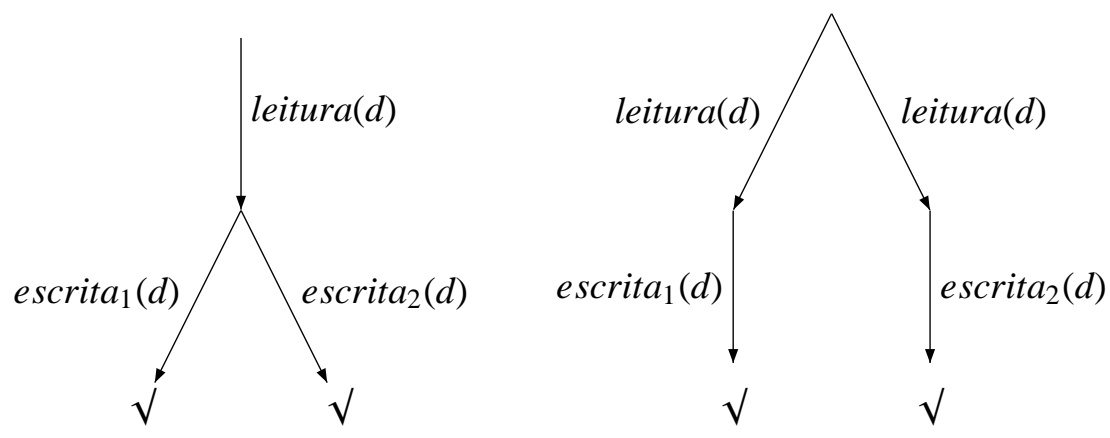

Figura 2.1: Análise de equivalências. Extraída de [3].

Na Figura 2.1, o processo da esquerda primeiro lê o dado $d$ e então decide se $d$ será escrito no disco 1 ou no disco 2. No processo da direita, a escolha pelo disco 1 ou disco 2 é feita antes mesmo da leitura do dado $d$.

Quanto à equivalência por rastros, ambos os processos são equivalentes. Isto ocorre pois os processos podem executar exatamente as mesmas cadeias de ações (leitura $(d)-$ escrita $_{1}(d)$ e leitura $(d)-$ escrita $_{2}(d)$ ). Porém, existe uma diferença entre os dois processos que se torna aparente se, por exemplo, o disco 1 quebra. Nesse caso, o processo da esquerda sempre salva $d$ no disco 2, enquanto o processo da direita pode travar devido a um impasse (deadlock).

Para diferenciar os processos de uma maneira melhor do que ocorre na equivalência por rastros, discriminando mais os processos, foi definida a equivalência por bissimulação. Por ela, se dois processos são equivalentes (ou bissimilares), então não só podem executar exatamente as mesmas cadeias de ações como também possuem a mesma estrutura de ramificação. Segue a definição.

Definição. Uma relação de bissimulação $\beta$ é uma relação binária entre processos tal que:

1. se $p \beta q$ e $p \stackrel{a}{\rightarrow} p^{\prime}$, então $q \stackrel{a}{\rightarrow} q^{\prime} \operatorname{com} p^{\prime} \beta q^{\prime}$;

2. se $p \beta q$ e $q \stackrel{a}{\rightarrow} q^{\prime}$, então $p \stackrel{a}{\rightarrow} p^{\prime} \operatorname{com} p^{\prime} \beta q^{\prime}$;

3. se $p \beta q$ e $p \stackrel{a}{\rightarrow} \sqrt{ }$, então $q \stackrel{a}{\rightarrow} \sqrt{ }$;

4. se $p \beta q$ e $q \stackrel{a}{\rightarrow} \sqrt{ }$, então $p \stackrel{a}{\rightarrow} \sqrt{ }$;

\section{Axiomas para BPA}

Com o objetivo de igualar termos de processos que são bissimilares, facilitando assim a automatização de algumas tarefas envolvendo processos, alguns axiomas foram derivados a partir das regras de transição e da 
definição de bissimilaridade. Nesses axiomas, a igualdade caracteriza a equivalência de processos por meio da relação de bissimulação. Eles estão representados na Tabela 2.2.

$$
\begin{array}{cc}
A 1 & x+y=y+x \\
A 2 & (x+y)+z=x+(y+z) \\
A 3 & x+x=x \\
A 4 & (x+y) \cdot z=x \cdot z+y \cdot z \\
A 5 & (x \cdot y) \cdot z=x \cdot(y \cdot z)
\end{array}
$$

Tabela 2.2: Axiomas para BPA. Extraída de [3].

\subsubsection{PAP - Álgebra de Processos com Paralelismo}

Até aqui, as estruturas apresentadas para a construção de termos algébricos foram as ações atômicas, o operador de composição alternativa e o operador de composição seqüencial. Entretanto, nenhum aspecto de comunicação interprocessos foi introduzido neste primeiro momento. Nesta seção, serão definidos novos operadores que expressam paralelismo e concorrência, introduzindo a comunicação e aumentando, assim, a expressividade da álgebra de processos.

\section{Paralelismo e comunicação}

No mundo real, vários processadores costumam trabalhar conjuntamente, executando vários processos ao mesmo tempo. Esses processos executados em entidades distintas podem influenciar uns aos outros com relação à execução. Essa influência se dá por meio da troca de dados entre processos. Para modelar este cenário, no qual existe concorrência e comunicação entre processos, Milner [22] apresentou o operador chamado entrelaçamento (merge). O entrelaçamento é um operador binário que executa dois termos de processo em paralelo. Assim, considerando $x$ e $y$ termos de processo, o termo $x \| y$ permite que tanto a primeira transição de $x$, como a primeira transição de $y$ possam ser executadas. Esse comportamento é formalizado por meio das regras de transição descritas na Tabela 2.3 (considerando as variáveis $x, x^{\prime}, y, y^{\prime}$ como termos de um processo e $v$ como ação atômica).

$\mathrm{Na}$ Tabela 2.3, as duas primeiras regras expressam que $x \| y$ pode começar com uma transição inicial de $x$, e então, executar paralelamente $x^{\prime}$ e $y$ (ou apenas $y$ caso $x$ tenha terminado). As duas últimas regras expressam que $x \| y$ pode começar com uma transição inicial de $y$, e então, executar paralelamente $x$ e $y^{\prime}$ (ou apenas $x$ caso $y$ tenha terminado). 


$$
\begin{aligned}
& \frac{x \stackrel{v}{\rightarrow} \sqrt{ }}{x \| y \stackrel{v}{\rightarrow} y} \quad \frac{x \stackrel{v}{\rightarrow} x^{\prime}}{x\left\|y \stackrel{v}{\rightarrow} x^{\prime}\right\| y} \\
& \frac{y \stackrel{v}{\rightarrow} \sqrt{ }}{x \| y \stackrel{v}{\rightarrow} x} \quad \frac{y \stackrel{v}{\rightarrow} y^{\prime}}{x\|y \stackrel{v}{\rightarrow} x\| y^{\prime}}
\end{aligned}
$$

Tabela 2.3: Regras de transição para entrelaçamento. Extraída de [3].

Além destas opções, $x \| y$ pode escolher executar a comunicação entre as transições iniciais de $x$ e $y$. Para esse propósito, define-se a função comunicação $\gamma: A \times A \rightarrow A$ (em que $A$ é o conjunto de ações atômicas), que produz para cada par de ações atômicas $a$ e $b$ sua comunicação $\gamma(a, b)$. Essa função precisa ser comutativa e associativa, isto é, para $a, b, c \in A$,

$$
\begin{aligned}
& \gamma(a, b) \equiv \gamma(b, a) \\
& \gamma(\gamma(a, b), c) \equiv \gamma(a, \gamma(b, c)) .
\end{aligned}
$$

As quatro regras existentes na Tabela 2.4 para o entrelaçamento expressam que $x \| y$ pode escolher executar a comunicação das transições iniciais de $x$ e $y$ (considerando as variáveis $x, x^{\prime}, y, y^{\prime}$ como termos de um processo e $v$ e $w$ como ações atômicas).

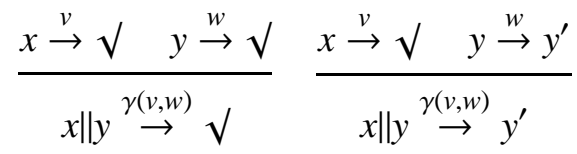

$$
\begin{aligned}
& \frac{x \stackrel{v}{\rightarrow} x^{\prime} \quad y \stackrel{w}{\rightarrow} \sqrt{ }}{x \| y \stackrel{\gamma(v, w)}{\rightarrow} x^{\prime}} \frac{x \stackrel{v}{\rightarrow} x^{\prime} \quad y \stackrel{w}{\rightarrow} y^{\prime}}{x\left\|y \stackrel{\gamma(v, w)}{\rightarrow} x^{\prime}\right\| y^{\prime}}
\end{aligned}
$$

Tabela 2.4: Regras de transição para entrelaçamento envolvendo comunicação. Extraída de [3].

\section{Entrelaçamento à esquerda e entrelaçamento com comunicação}

Para suprir uma deficiência [23] na axiomatização de BPA quando acrescido do operador entrelaçamento, dois outros operadores foram definidos: o entrelaçamento à esquerda (left merge) e o entrelaçamento com comunicação (communication merge). Cada um deles captura parte do comportamento do operador entrelaçamento. O operador entrelaçamento à esquerda (“Џ”), quando aplicado ao termo $x \llbracket y$, sendo $x$ e $y$ termos de processo, toma a sua transição inicial do processo $x$ (ação $v$ ) e depois comporta-se como o entrelaçamento. Na 
Tabela 2.5, estão as regras de transição para o entrelaçamento à esquerda, que correspondem às duas primeiras regras para o entrelaçamento, vistos na Tabela 2.3.

$$
\frac{x \stackrel{v}{\rightarrow} \sqrt{ }}{x\lfloor y \stackrel{v}{\rightarrow} y} \quad \frac{x \stackrel{v}{\rightarrow} x^{\prime}}{x \llbracket y \stackrel{v}{\rightarrow} x^{\prime} \| y}
$$

Tabela 2.5: Regras de transição para o entrelaçamento à esquerda. Extraída de [3].

O operador entrelaçamento com comunicação ("“"), quando aplicado ao termo $x \mid y$, com $x$ e $y$ termos de processos, executa como transição inicial uma comunicação entre as transições iniciais dos termos $x$ e $y$ e então se comporta como o operador entrelaçamento padrão (“|l”). Na Tabela 2.6, encontram-se as regras de transição para o entrelaçamento com comunicação, que correspondem às quatro últimas regras de transição para o entrelaçamento.

$$
\begin{aligned}
& \frac{x \stackrel{v}{\rightarrow} \sqrt{ } y \stackrel{w}{\rightarrow} \sqrt{ }}{x \mid y \stackrel{\gamma(v, w)}{\rightarrow} \sqrt{ }} \frac{x \stackrel{v}{\rightarrow} \sqrt{ } y \stackrel{w}{\rightarrow} y^{\prime}}{x \mid y \stackrel{\gamma(v, w)}{\rightarrow} y^{\prime}} \\
& \frac{x \stackrel{v}{\rightarrow} x^{\prime} \quad y \stackrel{w}{\rightarrow} \sqrt{ }}{x \mid y \stackrel{\gamma(v, w)}{\rightarrow} x^{\prime}} \frac{x \stackrel{v}{\rightarrow} x^{\prime} \quad y \stackrel{w}{\rightarrow} y^{\prime}}{x \mid y \stackrel{\gamma(v, w)}{\rightarrow} x^{\prime} \| y^{\prime}}
\end{aligned}
$$

Tabela 2.6: Regras de transição para entrelaçamento com comunicação. Extraída de [3].

Por convenção, assume-se que "|l”, “Џ”, e “|” tem maior precedência do que "+". Por exemplo, $a\lfloor b+a$ representa $(a\lfloor b)+a$. Porém, a precedência do operador "." ainda é maior do que a de todos os outros operadores.

À BPA estendida com os três operadores "ll", “U” e "l”, dá-se o nome de PAP (Process Algebra with Paralelism). Os operadores entrelaçamento à esquerda e entrelaçamento com comunicação, juntos, cobrem o comportamento do entrelaçamento, no sentido de que $x \| y=(x\lfloor y+y \llbracket x)+x \mid y$ para todos os termos $x$ e $y$ em PAP.

\section{Axiomas para PAP}

Além dos axiomas para BPA apresentados anteriormente, outros axiomas foram derivados da BPA acrescidos dos três novos operadores. Da mesma forma que os outros axiomas, a igualdade significa a equivalência por bissimilaridade entre os termos. Os axiomas encontram-se na Tabela 2.7. As variáveis $x, y$ e $z$ correspon- 
dem a termos de processos, enquanto $v$ e $w$ correspondem a ações atômicas.

$\begin{array}{cc}\text { M1 } & x \| y=(x \llbracket y+y \llbracket x)+x \mid y \\ \text { LM2 } & v \llbracket y=v \cdot y \\ \text { LM3 } & (v \cdot x)\lfloor y=v \cdot(x \| y) \\ \text { LM4 } & (x+y) \llbracket z=x \llbracket z+y \llbracket z \\ \text { CM5 } & v \mid w=\gamma(v, w) \\ \text { CM6 } & v \mid(w \cdot y)=\gamma(v, w) \cdot y \\ \text { CM7 } & (v \cdot x) \mid w=\gamma(v, w) \cdot x \\ \text { CM8 } & (v \cdot x) \mid(w \cdot y)=\gamma(v, w) \cdot(x \| y) \\ \text { CM9 } & (x+y)|z=x| z+y \mid z \\ \text { CM10 } & x|(y+z)=x| y+x \mid z\end{array}$

Tabela 2.7: Axiomas para PAP. Extraída de [3].

\subsubsection{ACP - Álgebra de Processos Comunicantes}

Na Álgebra de Processos com Paralelismo, serão introduzidos os conceitos de impasse e encapsulamento. Com esses conceitos, completa-se a extensão da álgebra denominada ACP.

\section{Impasse e encapsulamento}

Nos casos em que a comunicação entre duas ações ( $a$ e $b$ ) é possível, ela é representada por meio de uma nova ação $\gamma(a, b)$, em que $\gamma: A \times A \rightarrow A$ e $A$ é o conjunto de ações atômicas. Porém, existem casos em que pares de ações não se comunicam. Para representar tal comportamento, foi introduzida a constante $\delta$, chamada de impasse ou deadlock. Assim, se as ações $a$ e $b$ não se comunicam, pode-se dizer que $\gamma(a, b) \triangleq \delta$. A função de comunicação $\gamma$ é então estendida para que a comunicação entre duas ações atômicas possa resultar no impasse. Assim, tem-se agora que: $\gamma: A \times A \rightarrow A \cup\{\delta\}$. A constante $\delta$ é especial pela ausência de comportamento. Assim, não existem regras de transição para o impasse.

Com a inserção desta constante na função de comunicação, as regras de transição para o entrelaçamento (Tabela 2.4) e para o entrelaçamento com comunicação (Tabela 2.6) que envolvem a função $\gamma$ devem ser levemente alteradas com a adição da restrição $\gamma(v, w) \not \equiv \delta$, para que continuem com o sentido correto. Na Tabela 2.9, estão presentes alguns axiomas envolvendo o impasse. Eles demostram de que maneira a sua presença interfere em uma expressão. 
Juntamente ao impasse, foi definido também o operador unário de encapsulamento $\partial_{H}$, em que $H$ é um conjunto de ações atômicas. Quando aplicado a um termo de um processo, este operador renomeia todas as ações do termo que estão presentes no conjunto $H$ para a constante $\delta$ do impasse. Portanto, se $x$ é um termo de um processo, o termo $\partial_{H}(x)$ pode executar somente as ações de $x$ que não estão no conjunto $H$. Este comportamento é formalizado por meio das regras de transição descritas na Tabela 2.8 (considerando as variáveis $x$ e $x^{\prime}$ como termos de um processo e $v$ como ação atômica).

$$
\frac{x \stackrel{v}{\rightarrow} \sqrt{ }}{\partial_{H}(x) \stackrel{v}{\rightarrow}} \sqrt{ } v \notin H \quad \frac{x \stackrel{v}{\rightarrow} x^{\prime}}{\partial_{H}(x) \stackrel{v}{\rightarrow} \partial_{H}\left(x^{\prime}\right)} v \notin H
$$

Tabela 2.8: Regras de transição para o encapsulamento. Extraída de [3].

Na Tabela 2.9 estão presentes os axiomas relacionados ao encapsulamento. Nela, estão explicitadas a influência do operador em uma expressão, bem como a sua relação com a constante do impasse $\delta$.

$\begin{array}{ccc}A 6 & x+\delta=x \\ A 7 & & \delta \cdot x=\delta \\ D 1 & v \notin H & \partial_{H}(v)=v \\ D 2 & v \in H & \partial_{H}(v)=\delta \\ D 3 & & \partial_{H}(\delta)=\delta \\ D 4 & \partial_{H}(x+y)=\partial_{H}(x)+\partial_{H}(y) \\ D 5 & \partial_{H}(x \cdot y)=\partial_{H}(x) \cdot \partial_{H}(y) \\ L M 11 & \delta\lfloor x=\delta \\ C M 12 & \delta \mid x=\delta \\ C M 13 & x \mid \delta=\delta\end{array}$

Tabela 2.9: Axiomas para impasse e encapsulamento. Extraída de [3].

Adicionando-se o impasse e o encapsulamento à PAP, tem-se a álgebra denominada ACP.

\subsubsection{ACP com recursão}

Até aqui, todos os processos vistos eram finitos. A ACP, sozinha, não oferece uma maneira de se representar sistemas com comportamentos ilimitados. Visando a representação desse tipo de comportamento, uma especificação recursiva pode ser utilizada para estender a ACP.

Definição. Especificação recursiva é um conjunto finito de equações recursivas do tipo 


$$
\begin{aligned}
& X_{1}=t_{1}\left(X_{1}, \ldots, X_{n}\right) \\
& \vdots \\
& X_{n}=t_{n}\left(X_{1}, \ldots, X_{n}\right)
\end{aligned}
$$

em que, do lado esquerdo, temos variáveis de recursão $X_{i}$ e do lado direito temos termos de processo $t_{i}\left(X_{1}, \ldots, X_{n}\right)$, em ACP, com possível ocorrência de variáveis de recursão $X_{1}, \ldots, X_{n}$.

\section{Exemplos.}

$$
\left\{\begin{array}{l}
\mathrm{X}=\mathrm{aY} \\
\mathrm{Y}=\mathrm{bX}
\end{array} \quad M=a \cdot(b \cdot M+a \cdot M)\right.
$$

Existem especificações recursivas que possuem apenas uma única solução módulo equivalência por bissimulação (ver guarded recursive especification em [3]). Se $E$ é uma especificação recursiva com esta característica, e $X$ uma variável de recursão em $E$, então $\langle X \mid E\rangle$ denota o processo que deve ser substituído por $X$ na solução para $E$. Assim, mais duas regras de transição foram adicionadas para expressar este tipo de comportamento. Elas estão descritas na Tabela 2.10.

$$
\frac{t_{i}\left(\left\langle X_{1} \mid E\right\rangle, \ldots,\left\langle X_{n} \mid E\right\rangle\right) \stackrel{v}{\rightarrow} \sqrt{ }}{\left\langle X_{i} \mid E\right\rangle \stackrel{v}{\rightarrow} \sqrt{ }} \frac{t_{i}\left(\left\langle X_{1} \mid E\right\rangle, \ldots,\left\langle X_{n} \mid E\right\rangle\right) \stackrel{v}{\rightarrow} y}{\left\langle X_{i} \mid E\right\rangle \stackrel{v}{\rightarrow} y}
$$

Tabela 2.10: Regras de transição para recursão. Extraída de [3].

As regras descritas na Tabela 2.10 expressam que o comportamento das soluções $\left\langle X_{i} \mid E\right\rangle$ para as variáveis recursivas $X_{i}$ em $E$, para $i \in 1 \ldots n$, é exatamente o comportamento dos termos do lado direito da especificação $t_{i}\left(X_{1}, \ldots, X_{n}\right)$.

\subsubsection{Exemplo de especificação de processo}

Segue um exemplo para ilustrar o modo como a ACP pode ser usada para especificar processos. Esse mesmo exemplo será usado ao final de cada seção dos Capítulos 2 e 3 (exceto na Seção 3.1) para mostrar como as linguagens e fundamentos apresentados neste trabalho podem ser usados para especificar processos. Trata-se de um exemplo simples, fictício, colocado somente para facilitar o entendimento das teorias apresentadas. Suas especificações também serão simplificadas, de modo a retirar a complexidade desnecessária para o entendimento do que realmente importa no contexto deste trabalho. 
É importante notar que, para viabilizar a representação de processos de negócio na ACP, o operador de entrelaçamento utilizado no exemplo não inclui o conceito de comunicação. Assim, deve ser considerado simplesmente como um operador de paralelismo. Maiores informações podem ser encontradas na Capítulo 4.

Exemplo. Seja Processamento de pedido um processo responsável por processar pedidos de compra de clientes. Para processar os pedidos, o processo é formado pelas seguintes tarefas:

- A: processo recebe um pedido de um cliente;

- $B$ : o preço começa a ser calculado somando os valores dos produtos requisitados;

- $C$ : o sistema decide qual a transportadora que será utilizada para enviar os produtos ao cliente;

- $D$ : o preço final do pedido é calculado somando o valor dos produtos ao preço do frete;

- $E$ : a transportadora é notificada sobre a existência de uma entrega;

- F: ocorre a confirmação da data de entrega;

- $G$ : o cliente é notificado com o valor total do pedido e a data da entrega.

Essas tarefas estão relacionadas do modo descrito na Figura 2.2. Primeiramente, tem-se uma dependência seqüencial das tarefas $A, B$ e $C$. Em seguida, uma divisão paralela ocorre ( $A N D$ 1), dividindo o processo em dois fluxos, permitindo que a tarefa $D$ rode paralelamente às tarefas $E$ e $F$. Por fim, existe uma união dos dois fluxos (AND 2), sincronizando-os. Após a sincronização, a tarefa $G$ poderá ser executada.

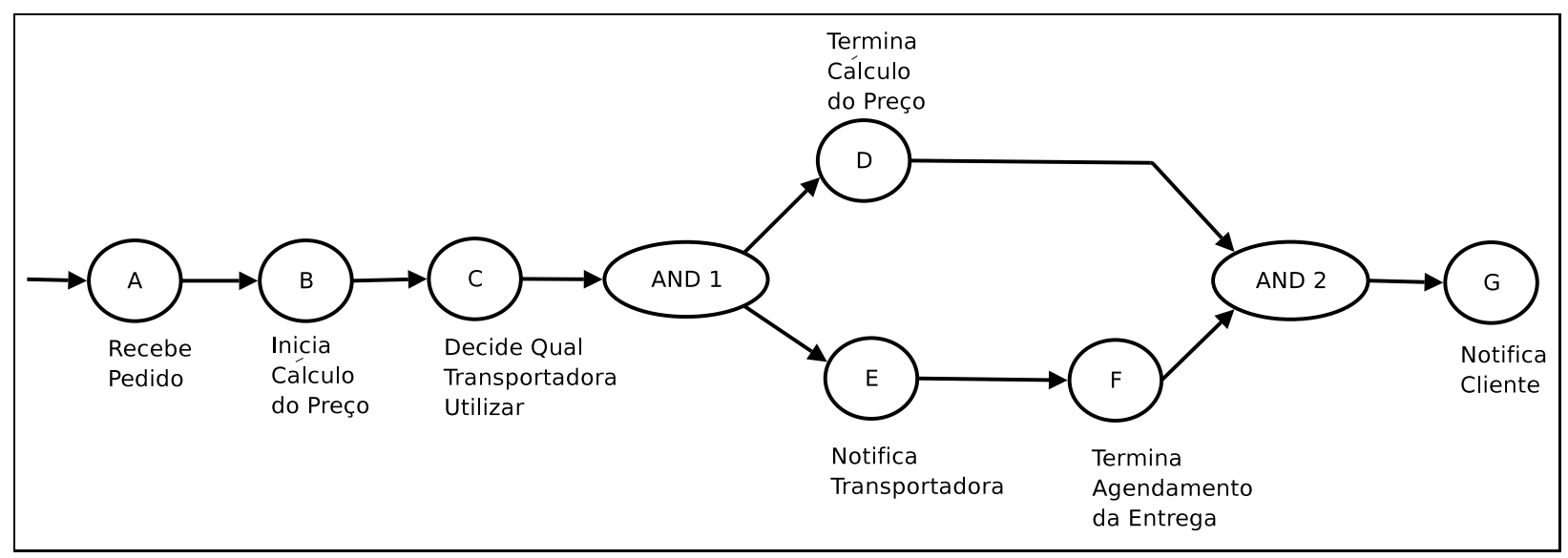

Figura 2.2: Exemplo de processo: processamento de pedido. 
Para representar este processo na ACP, cada tarefa deve ser mapeada para uma ação atômica da ACP. As ações serão identificadas pelas mesmas letras (porém minúsculas) usadas para a identificação das tarefas. Assim, chamando de $P$ o processo, tem-se:

$$
P: a \cdot b \cdot c \cdot(d \| e \cdot f) \cdot g
$$

\subsection{LOTOS}

LOTOS (Language of Temporal Ordering Specification ou Linguagem para Especificação de Ordenação Temporal) é uma linguagem para especificação de sistemas concorrentes e distribuídos. Ela foi desenvolvida para suprir a necessidade da ISO (International Standards Organization) de especificar, de uma forma clara, precisa e independente de implementação, seus padrões da arquitetura OSI (Open Systems Interconnection). Além da clareza e precisão, buscava-se também uma linguagem que servisse como documentação e que, além disso, fosse suficientemente formal para permitir a realização de verificações e validações dos sistemas descritos.

Baseada em teorias algébricas, LOTOS não se limitou à arquitetura OSI, mostrando-se útil para a descrição de sistemas concorrentes e distribuídos em geral. Em 1988, depois de quase uma década de trabalho e aprimoramento, a linguagem se tornou um padrão internacional da ISO.

Basicamente, LOTOS é composta por dois componentes distintos. O primeiro componente lida com descrições do comportamento de processos, definindo a relação temporal entre as interações que ocorrem no sistema. Para fazer tais descrições, a linguagem se apóia na teoria de álgebras de processos, principalmente nas álgebras conhecidas como CCS [22] e CSP [6]. O segundo componente é responsável por adicionar à linguagem o poder da utilização de estruturas de dados na forma de tipos abstratos de dados, variáveis e expressões matemáticas. Muitos conceitos desse segundo componente foram baseados na linguagem algébrica ACT-ONE [24]. Dá-se o nome de LOTOS básica (basic LOTOS) ao subconjunto da linguagem LOTOS que engloba apenas o primeiro componente, com foco na sincronização e interação entre processos. Essa visão simplificada de LOTOS não leva em consideração a troca de dados entre processos. Assim, é possível se concentrar no poder expressivo dos operadores de LOTOS. Ao adicionar à linguagem a definição de dados e a troca destes entre processos, tem-se a chamada LOTOS completa (full LOTOS), ou apenas LOTOS, que agora une os dois componentes citados.

Nos próximos tópicos, será fornecida primeiramente uma visão inicial sobre processos em LOTOS. Em seguida, serão explicitados os conceitos principais de LOTOS básica. Posteriormente, será introduzida a noção 
de definição de dados na linguagem e, por fim, a integração entre os componentes, culminando na linguagem LOTOS completa.

\subsubsection{Processos}

Em LOTOS, um sistema concorrente é descrito por meio de um processo. Esse processo pode ser constituído por vários subprocessos. Cada um dos subprocessos é, por sua vez, um processo. É possível considerar, portanto, um sistema concorrente descrito em LOTOS como uma hierarquia de definições de processos.

Um processo tem a capacidade de interagir com outros processos e também de desempenhar ações internas, não observáveis. As interações com outros processos são feitas de maneira síncrona, por meio de unidades atômicas de sincronização chamadas de eventos ou ações observáveis. Interações mais complexas são construídas a partir dessas interações atômicas. As interações entre processos LOTOS podem ou não envolver troca de dados. Os processos interagem por meio de pontos de interação, chamados de portas. Para LOTOS, não existe a distinção entre componentes ativos e passivos de uma interação, sendo ambos "participantes" dela. Assim, uma interação entre processos é identificada pelo nome da ação observável. Para ocorrer uma sincronização, as ações observáveis precisam ter o mesmo nome. Se um processo está pronto para uma interação por meio de uma determinada ação observável $a$, diz-se que ele oferece uma ação (observável) $a$ ao ambiente.

Para um processo $P$, o conjunto dos processos com os quais ele interage é chamado de ambiente de $P$. No ambiente de $P$, inclui-se também um processo cuja função é observar qualquer comportamento observável do sistema. Esse processo tem como finalidade modelar possíveis intervenções externas que possam ocorrer (como, por exemplo, a intervenção humana), tratando uma observação como se fosse uma interação.

Além das ações observáveis, responsáveis pela sincronização e comunicação entre processos, as ações internas, não-observáveis, também integram a descrição de processos em LOTOS. Uma ação interna é uma maneira de representar alguma decisão interna ao sistema, que não pode ser influenciada pelo ambiente. Ela é uma maneira de representar o não-determinismo na descrição, podendo influenciar passos subseqüentes no comportamento do processo, dependendo das escolhas que foram feitas internamente. Não se diferencia ações internas por nomes, sendo todas elas representadas pela letra $i$.

Neste texto, o termo ação será utilizado para se referir genericamente a uma ação, não importando se ela é observável ou interna. Quando essa distinção for necessária, os termos ação observável ou evento serão usados para as ações que podem sincronizar e os termos ação interna ou ação não-observável para representar os comportamentos internos. Essa distinção poderá ser feita também pelo nome da ação. Assim, ação $a$ refere- 
se a uma sincronização, ao contrário de ação $i$. O contexto também poderá ser usado para diferenciar as ações: ao utilizar-se, por exemplo, os termos oferecimento ou sincronização ligados a uma ação, deve-se entender que a ação é observável.

\subsubsection{LOTOS básica}

Para servir como linguagem de especificação de sistemas reais, LOTOS engloba alguns recursos que aumentam a expressividade da linguagem. Porém, à medida que os recursos são adicionados, a complexidade da linguagem também cresce, aumentando a dificuldade em entendê-la. Com o intuito de enfatizar a importância dos operadores algébricos de LOTOS, simplificar a notação e facilitar o desenvolvimento da teoria de equivalência de processos, foi feita uma simplificação da linguagem, chamada de LOTOS básica. Nessa forma simplificada, não existe troca de dados entre processos, ocorrendo apenas a sincronização entre eles. Com isso, a especificação de um processo em LOTOS básica se concentra em descrever a ordem temporal das ações, isto é, a ordem relativa das ações no tempo. Nessa descrição, os eventos são identificados pelos nomes das portas nas quais são oferecidos, e essa nomenclatura é suficiente para o estabelecimento das sincronizações. Assim, se um evento é oferecido por meio da porta de nome sinc, o evento será também reconhecido pelo nome sinc.

Para descrever a ordem temporal das ações, faz-se necessário definir, por meio da linguagem, os processos que compõem o sistema. A parte mais importante da definição de um processo é a expressão algébrica que define o seu comportamento. A essas expressões algébricas, dá-se o nome de expressões de comportamento (behaviour expressions). Uma expressão de comportamento é construída aplicando-se operadores a outras expressões de comportamento. As expressões de comportamento também podem incluir instâncias de outros processos (cujos comportamentos são definidos de forma separada da expressão do processo que os instancia) ou até mesmo do próprio processo, permitindo a definição de um comportamento recursivo.

\section{Expressões e operadores}

Com o intuito de mostrar, informalmente, a maneira de construir expressões de comportamento em LOTOS, seguem algumas expressões de comportamento que servem como base para a elaboração de expressões mais complexas, e também os operadores que podem ser utilizados na construção de expressões. Neste trabalho, no contexto de LOTOS, as letras em caixa alta serão utilizadas para representar expressões de comportamento (Ex: $\left.E, E_{1}, E_{2}\right)$. A letra $i$ será utilizada para representar uma ação interna, não-observável. As demais letras minúsculas representarão ações observáveis (nomes de portas). As palavras reservadas de LOTOS estarão destacadas em negrito. Maiores detalhes a respeito das expressões de comportamento e dos operadores 
LOTOS podem ser encontrados em [8].

- Inatividade ou ausência de ação: "stop"

A expressão de comportamento mais simples que existe é a que representa a ausência de ação ou a inatividade. Ela é representada pela palavra stop. O processo representado por esta expressão não oferece nenhuma ação ao ambiente e não faz nada. É utilizada para, além de representar a ausência de ação, representar uma situação de impasse.

- Sequiência ou prefixação de ação: “;”

O operador de seqüência é utilizado para prefixar uma ação antes de uma expressão de comportamento $(E)$. A ação prefixada pode ser observável $(a ; E)$ ou interna $(i ; E)$. Este operador estabelece uma seqüência de execução das ações. Assim, em $a ; E$, a expressão $E$ ficará habilitada para execução somente quando houver uma sincronização pela porta de nome $a$. No caso da prefixação de uma ação interna, a sua execução se dará anteriormente à habilitação de $E$.

- Escolha: "[ ]"

O operador de escolha introduz na linguagem a escolha entre comportamentos distintos para um mesmo processo. Na expressão $E_{1}[] E_{2}$, o operador permite que o processo se comporte como descrito pela expressão $E_{1}$ ou como descrito pela expressão $E_{2}$. O ambiente será o responsável pela decisão de qual comportamento será adotado pelo processo. Se o ambiente oferecer uma ação observável que corresponde a uma ação inicialmente oferecida por $E_{1}$, então $E_{1}$ será selecionada como a expressão de comportamento do processo. Se o ambiente oferecer uma ação observável que corresponde a uma ação inicialmente oferecida por $E_{2}$, então $E_{2}$ será selecionada como a expressão de comportamento do processo. Se a ação oferecida pelo ambiente corresponder a uma ação inicialmente oferecida tanto por $E_{1}$ quanto por $E_{2}$, o comportamento do processo é indeterminado.

- Paralelismo: “|[...]|", “||", “|||"

Os operadores de paralelismo são usados quando se deseja expressar comportamentos compostos por duas expressões que podem executar simultaneamente as suas ações. Esse paralelismo pode ocorrer com independência completa entre as ações das duas expressões, ou ainda com a exigência de um sincronismo total ou parcial entre elas. O caso no qual há independência completa entre as expressões de comportamento $E_{1}$ e $E_{2}$ é chamado de intercalação, sendo representado por $E_{1} \| \mid E_{2}$. Nesse caso, os eventos podem ser oferecidos em qualquer ordem, sem que haja dependência entre eles. Se houver a necessidade de sincronizar 
as expressões em alguns eventos, é necessário descrever quais são esses eventos. Assim, utilizando-se a notação $E_{1}\left|\left[p_{1}, \ldots, p_{n}\right]\right| E_{2}$, descreve-se um processo que tem as expressões $E_{1}$ e $E_{2}$ em paralelo, mas, nos eventos $p_{1}, \ldots, p_{n}$ presentes em ambas as expressões, a sincronização entre $E_{1}$ e $E_{2}$ deve ocorrer. Quando a lista de eventos que devem ser sincronizados coincide com a lista de todos os eventos presentes em $E_{1} \mathrm{e}$ também em $E_{2}$, ocorre uma sincronização completa. Esse caso é representado por $E_{1} \| E_{2}$. Independentemente do operador de paralelismo utilizado, as expressões concorrentes sempre irão sincronizar no término das suas execuções, que devem ser todas bem-sucedidas (ver item exit). Esse sincronismo ocorre por meio do evento interno $\delta$ que deve ser gerado por todas as linhas de execução.

- Terminação bem sucedida: "exit"

Se um processo é representado pela expressão $a$; $b$; stop, após o oferecimento das ações $a$ e $b$, ele entrará em um estado de inatividade, representado pela expressão stop. Entretanto, em certos casos, é interessante representar o término bem-sucedido de um processo. Com esse intuito, foi criada a expressão de comportamento exit. Essa expressão oferece um evento especial, denominado $\delta$ e, em seguida, comporta-se como um stop. O evento $\delta$ faz parte do modelo matemático interno da linguagem LOTOS e não pode ser oferecido como os outros eventos. A sua emissão representa a terminação bem-sucedida de um processo, podendo ser utilizado implicitamente, como acontece no paralelismo, na composição seqüencial e na desativação.

- Composição seqüencial: ">>”

O operador de composição sequiencial é utilizado para colocar, em sequiência, duas expressões de comportamento. Na expressão $E_{1}>E_{2}$, se a execução da expressão $E_{1}$ for bem-sucedida, então a expressão $E_{2}$ será habilitada para execução logo após o término de $E_{1}$. Pode-se considerar que $E_{2}$ "consome" o evento $\delta$ produzido pelo término de $E_{1}$. Caso $E_{1}$ não termine com sucesso, $E_{2}$ nunca será executada.

- Desativação: “[>”

O operador de desativação possibilita a realização de um comportamento muitas vezes necessário na especificação de processos: a interrupção de um comportamento e a sua substituição por outro. Em uma expressão $E_{1}\left[>E_{2}\right.$, o operador "[>" permite que o comportamento descrito pela expressão $E_{2}$ interrompa a execução do comportamento descrito pela expressão $E_{1}$, e funciona da seguinte forma: enquanto estão sendo executadas ações de $E_{1}, E_{2}$ continua existindo, porém não está habilitada. Caso $E_{1}$ atinja uma terminação bem-sucedida, $E_{2}$ é descartada, e o processo termina a sua execução com sucesso. Nesses casos anteriores, não houve desativação de $E_{1}$. Porém, se durante a execução de $E_{1}$ alguma ação de $E_{2}$ for executada, a execução de $E_{1}$ é irreversivelmente interrompida, e $E_{2}$ toma o seu lugar como expressão de comportamento do processo. 
- Encobrimento: "hide"

Quando utilizado em uma expressão da forma hide $p_{1}, \ldots, p_{n}$ in $E$, o operador de encobrimento tem a capacidade de transformar as ações observáveis $p_{1}, \ldots, p_{n}$ da expressão $E$ em ações não-observáveis $(i)$, escondendo detalhes que não devem ser expostos em níveis mais altos de abstração. Assim, supondo que, na expressão $(a ; b ; \boldsymbol{e x i t})|[b]|(b ; c ;$ exit $)$ se queira manter privada a sincronização que ocorre em $b$, é possível a utilização do encobrimento. A expressão resultante seria hide $b$ in $((a ; b ; \boldsymbol{e x i t})|[b]|(b ; c ; \boldsymbol{e x i t}))$, transformando $b$ em uma ação não-observável.

Vistos os principais operadores de LOTOS, seguem as suas precedências [25] (operadores à esquerda têm precedência mais alta do que à direita):

\section{$; \rightarrow[]|[]|[>>>$ hide choice let}

Os operadores de paralelismo estão representados genericamente pelo símbolo |[ ]|. Alguns dos operadores acima ainda não foram apresentados, mas serão no decorrer do texto. Os operadores de prioridades iguais devem ser associados à direita.

\section{Definição de processos}

Uma vez definidas as expressões de comportamento básicas e os operadores, é possível agora descrever como é feita a definição de um processo em LOTOS básica. De maneira geral, a seguinte estrutura é utilizada:

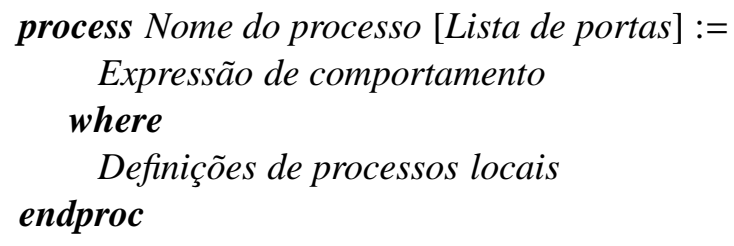

em que nome do processo refere-se ao nome do processo que está sendo definido; lista de portas refere-se às portas do processo definido que são externamente observáveis, separadas por vírgula; expressão de comportamento diz respeito à expressão que descreve o comportamento do processo, podendo conter referências a outros processos definidos localmente, bem como referenciar a si mesma; por fim, em definições de processos locais, pode-se definir processos locais, referenciados na expressão de comportamento do processo que os engloba. Suas definições seguem os mesmos moldes da definição que os contém. 
Exemplo. Para ilustrar, segue uma definição de um processo LOTOS.

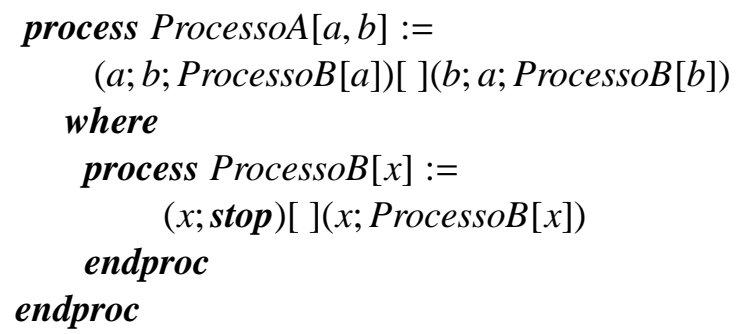

\subsubsection{Tipos de dados}

Até aqui, foram vistas apenas descrições do comportamento de processos, baseadas na ordem temporal das ações. Nesta seção, será abordada a possibilidade de se declarar tipos de dados, que poderão ser utilizados juntamente às descrições dos comportamentos dos processos. A maneira de representar estruturas de dados em LOTOS se originou do método algébrico de especificação de tipos abstratos de dados presente na linguagem ACT ONE [24]. Um tipo abstrato de dados (também chamado de ADT, do inglês Abstract Data Type) é uma especificação de um tipo de dado de maneira independente de sua implementação, representando apenas as propriedades essenciais dos dados e operações.

Para definir um tipo de dados em LOTOS, é necessário definir uma álgebra. Para tanto, é preciso determinar os conjuntos de elementos e as operações associadas, bem como propriedades envolvendo os elementos e as operações, responsáveis pelo valor semântico da álgebra. Esses conjuntos e as operações associadas são definidos por meio de uma assinatura. Já as propriedades são explicitadas por meio de equações.

\section{Assinatura}

Um tipo de dados LOTOS possui um ou mais conjuntos de dados. Esses conjuntos de dados contêm os elementos sobre os quais as operações serão definidas. Uma operação LOTOS é uma função total, cujo domínio é formado por zero ou mais conjuntos. Já o contradomínio dessa função deve ser constituído por um único conjunto. Uma operação que tem $n$ argumentos é chamada de uma operação $n$-ária. Uma constante é definida como uma operação que não recebe argumentos, isto é, uma operação 0-ária. Os conjuntos de dados LOTOS são identificados por meio de nomes, chamados de sorts. As operações também ganham nomes, pelos quais serão identificadas. Em LOTOS, utiliza-se a abreviação opns para se referir às operações de um tipo de dados. Os sorts e as opns de um tipo de dados constituem a assinatura deste tipo.

Exemplo. Para ilustrar um tipo de dados LOTOS, segue um exemplo extraído de [8], que define os números 
naturais juntamente com a operação de soma. Por enquanto, apenas uma assinatura constitui o tipo. A semântica associada não é explorada neste momento.

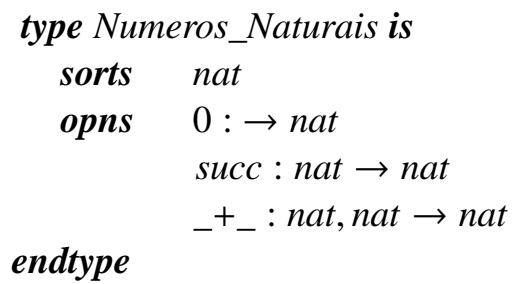

Nesse exemplo, tem-se a definição de um conjunto de nome nat. Além do conjunto, três operações são definidas. A primeira delas define uma constante (0) como parte do conjunto nat. Já a segunda define uma operação de sucessão no conjunto, construindo os termos relativos aos outros elementos do conjunto dos números naturais. A terceira operação define a soma entre elementos do conjunto nat. Por ela, fica garantido que a soma de dois elementos de nat deve ser um elemento de nat. É importante notar os tipos diferentes de notações possíveis para a definição de operações. É possível utilizar a notação op $: s_{1}, s_{2}, \ldots, s_{n} \rightarrow s$, em que $o p$ é o nome do operador e $s, s_{1}, s_{2}, \ldots, s_{n}$ são sorts, tal que $s_{1}, s_{2}, \ldots, s_{n}$ constituem o domínio e $s$, o contradomínio. Por ela, $o p\left(s_{1}, s_{2}, \ldots, s_{n}\right)$ é um termo referente a um elemento do conjunto $s$. Também é possível utilizar uma notação em que o símbolo “_” é utilizado para marcar a posição dos operandos com relação ao operador. Assim, é possível especificar operadores infixos, como é o caso da operação de adição vista anteriormente. Neste caso, termos como $0+1$ ou $0+\operatorname{succ}(0)$ são termos referentes a elementos do conjunto nat.

\section{Equações}

Com a presença da assinatura, tem-se a definição sintática do tipo de dados que está sendo definido. Porém, é necessário ainda especificar a semântica envolvida nas operações. Com o intuito de expressar as propriedades das operações, existem as equações. A finalidade das equações é dizer quando dois termos que são sintaticamente diferentes representam o mesmo elemento e, portanto, podem ser substituídos. Para definir as propriedades das operações, várias equações podem ser utilizadas. Nessas equações, é possível utilizar variáveis livres para representar os elementos dos conjuntos.

Exemplo. Para ilustrar o uso de equações, segue o exemplo anterior acompanhado pelas equações que estabelecem as propriedades das operações de soma e sucessão dos números naturais. 




Nesse exemplo, tem-se a introdução de duas equações que inserem propriedades sobre as operações definidas. Essas equações tratam de termos pertencentes ao conjunto nat. Esse fato é explicitado pela declaração ofsort nat. Além disso, esses termos usam duas variáveis livres, $x$ e $y$, que representam elementos de nat. Isso é representado pela declaração forall $x, y$ : nat.

Existem, ainda, equações condicionais, prefixadas por condições Booleanas ou por equações, que condicionam a validade de certas propriedades à avaliação de outras. Maiores detalhes podem ser encontrados em [26].

\section{Extensões, combinações e renomeações de tipos de dados}

Além de definir novos tipos de dados em LOTOS, ainda é possível usar alguns artifícios da linguagem para reutilizar tipos de dados já existentes. A combinação de tipos pré-definidos é um deles. É possível combinar diversos tipos de dados previamente definidos, formando um novo tipo, composto pelo agrupamento dos conjuntos, operações e equações dos tipos base. Também é possível estender um tipo existente, adicionando a ele novos elementos, operações e equações. LOTOS permite também estender uma combinação de diversos tipos, unindo os dois artifícios citados. Ainda é possível especificar parcialmente um tipo, de modo que, preenchendo lacunas, ele sirva de base para especificações que realmente serão utilizadas. Por fim, a renomeação de tipos de dados também pode ser feita, permitindo reutilizar a mesma estrutura em contextos diferentes.

Mais informações sobre a maneira como esses artifícios são utilizados, bem como maiores detalhes sobre eles podem ser vistos em [8]. 


\subsubsection{LOTOS completa}

$\mathrm{Na}$ Seção 2.2.2, referente a LOTOS básica, foi visto um subconjunto de LOTOS, que incluía as principais características da linguagem, porém não lidava com a utilização de valores nos processos, nem com a passagem destes entre processos. Na Seção 2.2.3 foi introduzida uma forma de representação de tipos de dados em LOTOS, característica essencial para o tratamento de valores pela linguagem. Nesta seção, serão apresentadas as principais características da integração entre LOTOS básica e o tratamento de valores e variáveis. A essa versão integrada da linguagem, com maior poder de expressividade, dá-se o nome de LOTOS completa. Nas seções a seguir, serão apresentadas as principais características e conseqüências dessa integração.

\section{Interações envolvendo valores e variáveis}

Em LOTOS básica, as ações são identificadas pelos nomes das portas. Basta que os nomes das ações e, portanto, das portas sejam iguais para indicar quais ações podem sincronizar. Em LOTOS completa, a idéia de identificação das ações por nomes iguais continua a mesma. Porém, de algum modo, é necessário incluir manipulação de valores. Com isso, a identificação de uma ação apenas por meio do nome da porta em que ela é oferecida não é mais suficiente para a representação requerida. Em LOTOS completa as ações são compostas pelos nomes das portas acrescidos de uma lista de valores oferecidos naquela porta. Por exemplo, $\operatorname{sinc}\langle 5\rangle$ e $p\langle$ 'teste', 17〉 são ações válidas. O sincronismo é possível apenas quando houver coincidência das ações, portanto, mesmas portas e mesmas listas de valores. Essas ações não são inseridas diretamente nas expressões de comportamento da linguagem. Para representar tais ações, uma estrutura chamada de denotação de ação (do inglês action denotation) é utilizada. O que será visto a seguir é a apresentação dessa estrutura e quais são as ações geradas a partir dela.

Definição. Uma denotação de ação é uma estrutura composta por um nome de porta $p$ seguido de uma lista de atributos $\left(\alpha_{1}, \alpha_{2}, \ldots, \alpha_{n}\right)$, na forma $p \alpha_{1} \alpha_{2} \ldots \alpha_{n}$, em que os atributos podem ser de dois tipos distintos: declarações de valores ou declarações de variáveis.

Uma declaração de valor utiliza a notação “! $E$ ”, em que $E$ é uma expressão que descreve um valor. Portanto, !5, !'lotos', ! $(x+y+4)$ são declarações válidas. Ao colocar um atributo de declaração de valor $\alpha$ na lista de atributos de uma porta $p$, o valor da expressão de $\alpha$ será oferecido por meio da porta $p$. Se a expressão contiver variáveis, como é o caso de ! $(x+y+4)$, elas serão substituídas por valores de acordo com o contexto e o valor resultante da expressão será oferecido. O oferecimento de um valor $v$ pela porta $p$ resulta na representação de uma ação denominada $p\langle v\rangle$. 
Exemplo. Na estrutura sinc !(6-2), a porta de nome sinc possui a expressão (6-2), que descreve o valor 4. Este valor será oferecido pela porta sinc. Esta ação é representada por $\operatorname{sinc}\langle 4\rangle$.

Uma declaração de variável utiliza a notação "? $x: t$ ", em que $x$ é o nome da variável e $t$ é o nome de um conjunto de dados (sort), visto na Seção 2.2.3, e representa o conjunto de valores que podem ser atribuídos a $x$. Portanto, ?y:char e ?x:nat são declarações válidas. Ao associar uma declaração de variável ?x:t a uma porta $p$, descreve-se um conjunto de ações $\{p\langle v\rangle \mid v \in t\}$. Portanto, torna-se possível a sincronização com qualquer ação de mesmo nome de porta e um valor no domínio da variável. Ao fixar na variável $x$ o valor $v$, a ação $p\langle v\rangle$ passa a ser oferecida. Além disso, na expressão de comportamento que se segue a essa ação, se houver alguma ocorrência da variável $x$, ela será automaticamente substituída pelo valor $v$. Esse comportamento pode ser generalizado da seguinte maneira (usando uma notação introduzida em [8] e lembrando que $B(x)$ representa o escopo em que vale a substituição da variável $x$ pelo valor $v$ ):

$$
p ? x: t ; B(x) \stackrel{p\langle v\rangle}{\longrightarrow} B(v) .
$$

Exemplo. Supondo que port é o nome de uma porta de sincronização, $x$ é uma variável que pode receber valores do conjunto dos números naturais, e $B(x)$ simboliza uma expressão de comportamento $B$ que possui a variável $x$ na sua composição, é possível ter a seguinte expressão de comportamento:

$$
\text { port ?x:nat; } B(x) \text {. }
$$

Essa denotação de ação descreve o conjunto de ações $\operatorname{port}\langle n\rangle$, para todo $n$ natural. Supondo que $n$ receba o valor 5, a ação oferecida será port $\langle 5\rangle$. Essa expressão de comportamento evoluiria para $B(5)$, isto é, todas as ocorrências de $x$ dentro da expressão de comportamento $B$ seriam substituídas pelo valor 5 .

Ao ter uma lista de declarações de valor e declarações de variáveis associadas a uma porta, os valores resultantes e as variáveis substituídas pelo valor farão parte da lista de valores resultantes, na ordem em que foram apresentadas na estrutura. Assim, algumas possíveis ações resultantes de $p$ ?x:nat ?y:char ! $(3+1)$ seriam $p\langle 2, ' a$ ', 4$\rangle$ ou $p\langle 3, ' b$ ', 4$\rangle$.

\section{Sincronização entre processos}

Assim como ocorre em LOTOS básica, dois processos LOTOS rodando em paralelo podem sincronizar por meio de ações que possuem o mesmo nome (mesma porta e mesmos valores, considerando a ordem em 
que aparecem). Porém, em virtude da introdução da declaração de valores e variáveis, a sincronização passa a ter três casos distintos, avaliados a seguir:

- Passagem de valores: $p ! E|[p]| p$ ?x:t, em que $p$ é uma porta, $E$ é uma expressão de declaração de valor, $x$ é uma variável de declaração de variável e $t$ o seu domínio. Nesse caso, a única condição existente para ocorrer a sincronização é a verificação da inclusão do valor de $E$ no conjunto $t$. Caso esteja incluso, a sincronização ocorre (basta escolher o valor de $x$ como sendo o valor de $E$, gerando, assim, ações iguais). Após a sincronização, a variável $x$ passa a ter o valor da expressão $E$.

- Comparação de valores: $p ! E_{1}|[p]| p ! E_{2}$,

em que $p$ é uma porta, e $E_{1}$ e $E_{2}$ são expressões de declarações de valor. Neste caso, não há nenhuma troca de valores. O que ocorre, apenas, é a verificação da igualdade das ações, para ver se a sincronização acontece ou não. A sincronização ocorrerá desde que o valor da expressão $E_{1}$ seja igual ao valor da expressão E2.

- Negociação de valores: $p$ ?x:t $|[p]| p$ ?y:s, em que $p$ é uma porta, $x$ e $y$ são variáveis de declarações de variáveis e $t$ e $s$ são os domínios das respectivas variáveis. A condição para haver sincronização nesse caso é a igualdade dos conjuntos $t$ e $s$. Caso sejam iguais, algum valor $v$, pertencente a $t$ (ou $s$, pois são iguais), é utilizado como escolha para o valor de $x$, e também para o valor de $y$. Com isso, a sincronização ocorre, pois as ações passam a ser iguais.

Caso a sincronização entre duas portas contenha mais de uma declaração, elas são avaliadas aos pares, respeitando a ordem em que elas aparecem. A sincronização somente ocorrerá se todas as declarações puderem ser sincronizadas de acordo com as regras anteriores.

\section{Condições e expressões de comportamento}

A partir do momento em que as ações de LOTOS passam a considerar valores na sua estrutura, tornase possível associar condições baseadas nesses valores às expressões de comportamento. Em LOTOS, uma condição (ou predicado) é expressa por meio de equações entre duas expressões. Se os valores resultantes da avaliação das duas expressões forem iguais, a condição é satisfeita. Uma condição também pode ser expressa por meio de uma expressão Booleana. Nesse caso, quando a expressão for verdadeira, a condição é satisfeita. 
$\mathrm{Na}$ linguagem, as condições vêm envolvidas por colchetes: "[condição]". As condições podem ser utilizadas de duas maneiras distintas: como predicados de seleção ou guardas de expressões.

Uma denotação de ação, além do nome da porta e da lista de declarações de valores e variáveis, pode conter, no final da estrutura, um predicado. Nesses predicados, as variáveis que foram declaradas podem ser utilizadas para formar condições. Nesse caso, o papel de uma condição é impor restrições sobre valores que, por meio de sincronizações, podem ser associados a essas variáveis. Com essa finalidade, as condições são chamadas de predicados de seleção.

Exemplo. A estrutura a seguir ilustra a idéia de predicado de seleção:

$$
\text { p?:nat !'teste’ }[x<3] \text {. }
$$

Aqui, o predicado $[x<3]$ restringe os valores que podem ser atribuídos à variável $x$. Apenas os valores $0,1 \mathrm{e}$ 2 serão aceitos e apenas as ações $p\langle 0$, 'teste' $\rangle, p\langle 1$, 'teste' $\rangle$ e $p\langle 2$, 'teste' $\rangle$ poderão ser oferecidas.

Além de predicados de seleção, as condições podem ser utilizadas como guardas de expressões. Em LOTOS, as expressões de comportamento podem vir precedidas por um predicado (utilizando a sintaxe "[predicado] $\rightarrow$ expressão de comportamento"). Caso a condição de guarda seja satisfeita, então o comportamento descrito pela expressão é possível. Caso contrário, a expressão em questão torna-se equivalente à expressão stop. Utilizada conjuntamente com o operador de escolha, a linguagem permite fazer escolhas entre várias expressões.

Exemplo. Estrutura que ilustra o uso de guardas de expressões:

$$
[x<10] \rightarrow p !(10-x)[][x>=10] \rightarrow p !(x-10) .
$$

Apesar de o exemplo tratar de condições mutuamente exclusivas, isso não é obrigatório na especificação das condições.

\section{Generalização do operador de escolha}

A inclusão de variáveis nas expressões de comportamento faz com que, mesmo mantendo inalterada a estrutura das expressões, possam existir infinitas opções de comportamento, bastando, para isso, atribuir valores diferentes às variáveis das quais as expressões dependem. Assim, uma expressão $E(x)$, que tem a variável $x$ 
do tipo $t$ na sua composição, pode assumir infinitas alternativas. Essas alternativas podem ser representadas por $\{E(v) \mid v \in t\}$, em que $v$ representa um valor pertencente ao tipo $t$.

O operador de escolha ("[ ]”) de LOTOS básica possui uma limitação importante. Esse operador permite que uma escolha seja feita apenas entre um número finito de alternativas distintas. Como fazer então para representar uma escolha entre infinitas alternativas com o envolvimento de variáveis? Com essa finalidade, foi criado um novo operador de escolha, denominado choice.

Sejam $x_{1}, x_{2}, \ldots, x_{n}$ variáveis dos tipos $t_{1}, t_{2}, \ldots, t_{n}$, respectivamente. Seja $E\left(x_{1}, x_{2}, \ldots, x_{n}\right)$ uma expressão que contém as variáveis $x_{1}, x_{2}, \ldots, x_{n}$ na sua composição. Então

$$
\text { choice } x_{1}: t_{1}, x_{2}: t_{2}, \ldots, x_{n}: t_{n}[] E\left(x_{1}, x_{2}, \ldots, x_{n}\right)
$$

representa uma escolha entre todos os processos $E\left(v_{1}, v_{2}, \ldots, v_{n}\right)$, para todos os valores que $x_{1}, x_{2}, \ldots, x_{n}$ possam assumir.

É importante notar que, pela definição do operador choice, surge uma nova maneira de expressar uma declaração de variável. Para declarar uma variável $x$ do tipo $t$ oferecida na porta $p$, seguida por uma expressão $E(x)$, que antes era declarada como $p ? x: t ; E(x)$, pode-se utilizar agora a expressão equivalente

$$
\text { choice } x: t[] p ! x ; E(x)
$$

\section{Definição e instanciação de processos paramétricos}

Na definição de processos de LOTOS básica, os únicos parâmetros utilizados eram os nomes das portas. Em LOTOS completa, é possível, além dos nomes de portas, parametrizar os processos com uma lista de declarações de variáveis. Essas variáveis podem ser utilizadas como variáveis livres, na composição das expressões de comportamento. Para definir tais processos, a seguinte sintaxe é utilizada:

process Nome do processo [Lista de portas] (Lista de variáveis) := $\cdots$

endproc

em que nome do processo refere-se ao nome do processo que está sendo definido; lista de portas refere-se às portas do processo definido que são externamente observáveis e lista de variáveis diz respeito a uma lista 
de declarações de variáveis, na forma $x_{1}: t_{1}, x_{2}: t_{2}, \ldots, x_{n}: t_{n}$, com $x_{1}, \ldots, x_{n}$ correspondendo aos nomes das variáveis e $t_{1}, \ldots t_{n}$ aos seus respectivos tipos.

Exemplo. Segue um exemplo de definição de um processo paramétrico.

$$
\begin{aligned}
& \text { process Emite_xy }[p, q](x: \text { nat }):= \\
& \quad p \text { ?y:nat; } \\
& \quad([y>0] \rightarrow q !(x * y)[] \\
& \quad[y<=0] \rightarrow q ! 0) \\
& \text { endproc }
\end{aligned}
$$

$\mathrm{Na}$ instanciação de processos paramétricos, as variáveis são substituídas por expressões que correspondem, uma a uma, às variáveis declaradas. Essas expressões, por sua vez, podem conter as suas próprias variáveis. A única restrição existente diz respeito ao valor resultante da expressão, que deve ter o mesmo tipo da variável correspondente.

Existe, ainda, uma outra maneira de associar expressões a variáveis livres de expressões de comportamento. Essa associação é feita utilizando a palavra reservada let, como segue:

$$
\text { let } x_{1}: t_{1}=E_{1}, \ldots, x_{n}: t_{n}=E_{n} \text { in } B\left(x_{1}, \ldots, x_{n}\right) \text {, }
$$

em que $E_{1}, \ldots, E_{n}$ se referem a expressões cujos valores serão substitutos para as variáveis na expressão de comportamento $B$.

\section{Composição seqüencial com passagem de valores}

O operador de composição seqüencial ">>" é utilizado para colocar, em seqüência, duas expressões de comportamento $\left(E_{1}>>E_{2}\right)$. Com a introdução de valores e variáveis na linguagem, seria interessante que informações pudessem ser passadas do primeiro processo $\left(E_{1}\right)$ para o segundo processo da composição $\left(E_{2}\right)$. Para permitir esse fluxo de dados, algumas alterações precisam ser inseridas na linguagem. A seguir, serão descritas algumas dessas modificações, bem como o mecanismo desenvolvido para permitir tal característica.

A primeira modificação necessária é a extensão do conceito de terminação bem-sucedida. A terminação bem-sucedida é especificada por meio da utilização da expressão exit. Em LOTOS básica, essa expressão simplesmente oferece um evento especial (ou uma porta especial), denominado $\delta$ e, em seguida, comporta-se como um stop. Em LOTOS completa, a expressão exit ganha uma lista finita de expressões associada a ela. 
Os valores dessas expressões serão oferecidos por meio de $\delta$, ficando disponíveis para utilização pelo processo subseqüente.

Exemplo. Uma expressão com uma terminação válida seria

$$
\text { p?x:nat; exit }(3, \text { true },(x+1)) \text {. }
$$

Juntamente com a extensão da terminação bem-sucedida, vem um conceito denominado funcionalidade (do inglês functionality) da terminação. A funcionalidade de uma expressão de comportamento é constituída por uma lista dos sorts dos valores oferecidos na sua terminação bem-sucedida. A funcionalidade de um processo é a mesma da sua expressão de comportamento. A funcionalidade é uma maneira existente na linguagem de detectar, de maneira estática, processos (ou expressões) que não podem terminar de maneira bem-sucedida. É importante perceber que existem casos de terminações sem sucesso que não podem ser detectados por meio da funcionalidade.

No exemplo anterior, a funcionalidade da terminação seria a lista $\langle$ nat, bool, nat $\rangle$, referindo-se a um número natural, um Booleano e outro número natural. Para expressões que terminam de maneira bem-sucedida, mas que não passam valores, a funcionalidade exit é atribuída. A funcionalidade também é definida para expressões que não terminam de maneira bem-sucedida, isto é, terminam com stop. Nesse caso, a funcionalidade noexit é atribuída para essa expressão. Porém, nem sempre é uma tarefa trivial atribuir uma funcionalidade a uma expressão de comportamento. É o caso, por exemplo, de composições paralelas ou alternativas. Da necessidade de determinar as funcionalidades desses casos mais complexos, foram criadas algumas regras, cujos detalhes podem ser consultados em [8].

Além da extensão do conceito de terminação bem-sucedida e da criação do conceito de funcionalidade, foi criada uma estrutura para representar a passagem de valores entre processos subseqüentes em uma composição seqüencial. Assim, a construção

$$
E_{1}>>\text { accept } x_{1}: t_{1}, \ldots, x_{n}: t_{n} \text { in } E_{2}
$$

usa as variáveis $x_{1}, \ldots, x_{n}$ da expressão de comportamento $E_{2}$ para receber os valores passados pela terminação bem-sucedida da expressão de comportamento $E_{1}$. Dessa forma, $E_{1}$ será executado até o seu término. Após o término de $E_{1}$, as variáveis $x_{1}, \ldots, x_{n}$ de $E_{2}$ serão substituídas pelos valores da lista da terminação de $E_{1}$. Para utilizar essa estrutura, existe o requisito da funcionalidade de $E_{1}$ casar com a lista dos sorts $t_{1}, \ldots, t_{n}$ referentes às variáveis utilizadas. 


\section{Definição de processos e especificação}

Apresentadas as principais mudanças que a inserção de dados trouxe à linguagem, é possível adequar a declaração de processos LOTOS para este novo cenário. A declaração de processos em LOTOS completa não apresenta muitas diferenças, se comparada com a declaração de processos em LOTOS básica. A estrutura se mantém basicamente a mesma, salvo algumas poucas alterações com o propósito de inserir as novas características referentes a dados no contexto dos processos. Segue a estrutura utilizada.

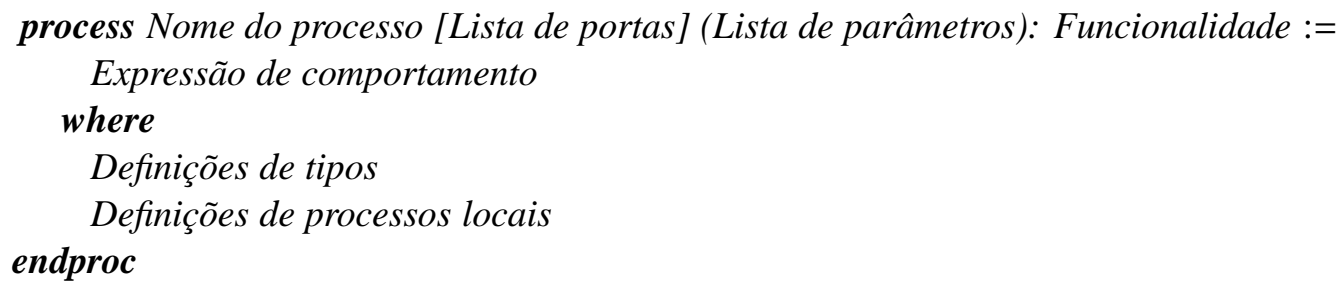

Comparando com a definição de processos em LOTOS básica, as principais diferenças são: a inclusão de uma lista de parâmetros, com as variáveis e tipos para a definição de processos paramétricos; a inclusão da funcionalidade, que contém uma lista de valores associados à terminação do processo; e, por fim, a inclusão de definições de tipos de dados, da maneira explicitada na Seção 2.2.3.

Além da estrutura para definição de processos, é possível, ainda, definir uma estrutura bastante similar, chamada especificação. Uma especificação contém o comportamento global do sistema, podendo ser vista como a definição do processo que representa o sistema. Basicamente, não há grandes mudanças se comparada a uma definição de processo usual. Existem algumas pequenas mudanças de sintaxe, como é o caso da palavra reservada behaviour, em vez do símbolo ':=', utilizado na definição de processos. Há uma diferença significativa que diz respeito às definições de tipos feitas antes da declaração da expressão de comportamento. Esses tipos declarados possuem um caráter global, podendo, inclusive, ser utilizados pelo ambiente responsável pela execução da especificação. Esse tipo de definição não pode ser feita nas declarações de processos usuais.

Segue a estrutura de uma definição de especificação. 
specification Nome da especificação [Lista de portas] (Lista de parâmetros) : Funcionalidade

Definições de tipos globais

\section{behaviour}

Expressão de comportamento

where

Definições de tipos

Definições de processos

endspec

\subsubsection{Exemplo de especificação de processo}

Para ilustrar a maneira como o controle de fluxo pode ser representado por uma especificação LOTOS, o exemplo da Seção 2.1.5 será descrito, agora, por meio da sintaxe LOTOS.

Exemplo. Segue o trecho de código referente à especificação na linguagem LOTOS. Neste exemplo, apenas o controle de fluxo foi representado, permitindo comparar as especificações. Ele retrata como seria especificar um processo do modo como é feito em ACP e NPDL, porém usando a sintaxe LOTOS. Entretanto, ao contrário da ACP, em LOTOS é possível inserir dados do processo no controle de fluxo, gerando uma especificação mais completa. Para ilustrar como seria o processo referente a esse exemplo com a inserção de dados, foi gerada a sua especificação. Devido ao seu tamanho e à sua complexidade, ela foi colocada separadamente, no Apêndice B.

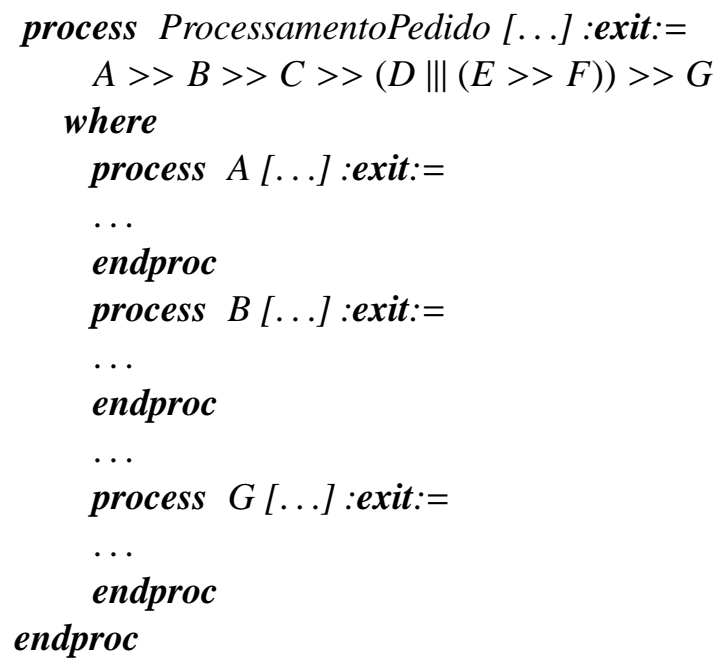

em que $A, B, \ldots G$ são as tarefas do exemplo (ver Seção 2.1.5) mapeadas para subprocessos LOTOS que 
representam a execução dessas tarefas. Assim, a letra $A$ indica um processo LOTOS de nome $A$, escrito com uma notação simplificada (sem portas, parâmetros, etc), que realiza a tarefa $A$, da mesma maneira que a ação atômica $A$ de ACP. Maiores detalhes sobre esse mapeamento podem ser vistos na Seção 4.1.

\subsection{Conclusão}

Neste capítulo, foram apresentados a ACP e LOTOS, formalismos algébricos que serão comparados neste trabalho. No próximo capítulo serão introduzidos os Padrões de Controle de Fluxo e a linguagem BPEL, bases da comparação feita no Capítulo 4. Além disso, será apresentada a linguagem NPDL, motivo da realização dessa comparação. 



\section{Capítulo 3}

\section{Trabalhos relacionados}

Neste capítulo serão apresentados os Padrões de Controle de Fluxo, a linguagem BPEL e a linguagem NPDL. Os Padrões de Controle de Fluxo serão brevemente introduzidos aqui. As suas descrições individuais encontram-se na Seção 4.1. Com relação a BPEL, o enfoque será dado aos principais conceitos da linguagem. Por fim, a linguagem NPDL será introduzida e os seus operadores, apresentados. As especificações dos padrões em NPDL encontram-se na Seção 4.1, juntamente com as especificações em ACP e LOTOS.

\subsection{Padrões de Controle de Fluxo}

É notável o fato de que existem muitas linguagens que podem ser utilizadas para descrever processos. Mas será que todas elas oferecem o mesmo poder de expressividade? Será que existem casos que podem ser facilmente descritos com uma linguagem e que, com outras, torna-se uma tarefa complexa? Existe uma linguagem mais "completa" que as outras? Nesse contexto, W. M. P. van der Aalst e outros pesquisadores de seu grupo começaram a pesquisar uma maneira de comparar as diversas linguagens existentes ao mesmo tempo em que tentavam identificar quais eram os requisitos que as linguagens de representação de processos deveriam satisfazer.

Dessa pesquisa nasceu a idéia dos Workflow Patterns [19]. Da mesma forma que no livro Design Patterns [27] um padrão é "a abstração de uma forma concreta que se mantém recorrente em contextos específicos e não arbitrários", os Workflow Patterns tentam representar as diversas situações recorrentes em processos de negócio, colocando-as como requisitos de um sistema gerenciador de workflows. Ainda da mesma maneira, esses padrões buscam a independência de qualquer linguagem específica. Eles são divididos em quatro categorias: controle de fluxo, dados, recursos e tratamento de exceções. Para a comparação proposta neste trabalho, foi utilizado um conjunto de vinte padrões de controle de fluxo. Esse conjunto corresponde aos primeiros 
padrões propostos por Aalst e constitui o cerne do controle de fluxo nos processos de negócio. Recentemente, os padrões de controle de fluxo foram revisitados e os vinte padrões iniciais foram fragmentados, dando origem a vinte e três novos padrões, que se somaram aos anteriores. Essa subdivisão tinha como finalidade tirar algumas ambigüidades existentes em alguns padrões, tornando-os mais restritivos. Porém, esse aumento no rigor acabou por inserir detalhes de implementação na descrição dos padrões, desviando-os de seu propósito inicial. Esse foi um importante fator na decisão de se usar neste trabalho apenas os padrões originais como base para comparação.

Cada padrão possui, entre outras informações, a descrição com as condições que devem vigorar para que o padrão seja aplicável, exemplos em situações reais de negócio, possíveis problemas encontrados na realização desses padrões em linguagens específicas existentes e algumas soluções de implementação.

Para facilitar o entendimento deste trabalho, bem como sintetizar as informações contidas nele, a descrição individual dos padrões utilizados é feita somente na Seção 4.1, momento em que são usados na comparação proposta. Ali, são apresentadas as descrições dos padrões e algumas observações pertinentes. Alguns dos padrões são ilustrados graficamente com o objetivo de facilitar o seu entendimento. Mais detalhes podem ser vistos em [19].

\subsection{BPEL}

Business Process Execution Language (BPEL) [12-14] é uma linguagem utilizada para definir processos de negócio no contexto de serviços web. Ela é o resultado da convergência das idéias presentes em duas linguagens preexistentes: WSFL (Web Services Flow Language) [16], da IBM, e XLANG [15] (Web Services for Business Process Design), da Microsoft. BPEL se propôs a unir a estruturação hierárquica de atividades presente na linguagem XLANG com o controle baseado em grafos da WSFL. Assim, em julho de 2002, a Microsoft e a IBM, conjuntamente com a BEA Systems, lançaram a especificação da linguagem que batizaram com o nome BPEL4WS 1.0 (Business Process Execution Language for Web Services) [12]. Em abril de 2003, essas empresas, juntamente com a SAP e Siebel Systems, lançaram uma segunda versão pública da especificação da linguagem; a ela deram o nome de BPEL4WS 1.1 [13]. Essa especificação foi submetida à organização denominada OASIS (Organization for the Advancement for Structured Information Standards), um consórcio global que dirige o desenvolvimento, a convergência e a adoção de padrões ligados à área de serviços web e comércio eletrônico. Com essa atitude, buscava-se obter um padrão aberto e ainda uma aceitação maior na indústria. Com seu amadurecimento, a especificação passou por várias mudanças significativas e, em setembro de 2004, o comitê responsável pela linguagem na OASIS resolveu mudar o nome da especificação para WS-BPEL 2.0 (Web Services Business Process Execution Language) [14]. Em setembro de 
2006, essa especificação ficou disponível para revisão pública, ficando neste estado até abril de 2007, data em que foi lançada como um padrão OASIS. Apesar das diversas versões e modificações feitas no decorrer do processo, as diretrizes básicas [28] da linguagem permaneceram as mesmas. São essas idéias principais que serão abordadas nesta seção. Por não se tratar, na maioria dos casos, de assuntos específicos a uma versão da linguagem, será utilizada aqui a sigla BPEL para genericamente representá-la.

\subsubsection{BPEL no contexto de serviços web}

BPEL é uma linguagem baseada em XML [29], desenvolvida para ser utilizada dentro do contexto de serviços web. Um processo descrito em BPEL é construído baseado no modelo de serviço definido pela especificação WSDL 1.1 [30]. Com isso, um processo BPEL se comporta como um serviço web, descrito por meio de uma especificação WSDL. Todas as interações externas realizadas pelo processo ocorrem por meio de interfaces WSDL de serviços web. Um processo de negócio escrito em BPEL define como coordenar as interações entre as diversas instâncias do processo e os serviços web com os quais se comunicam. Assim, uma instância de processo sabe quando deve mandar ou receber uma mensagem. Entretanto, para realizar efetivamente a comunicação, recorre-se às interfaces WSDL disponibilizadas pelos diversos serviços web.

Uma especificação de processo BPEL separa as referências concretas aos serviços reais das representações abstratas das interações entre os serviços. Para isso, utiliza os recursos de abstração providos pelo modelo WSDL (como port types e operations). A desvinculação entre o comportamento do processo e o ambiente de execução dá ao processo BPEL a característica de ser reutilizável e simples, retirando da especificação as restrições desnecessárias.

O fato de um processo BPEL ficar disponível como um serviço web traz ainda o caráter modular ao processo, pois um serviço web pode ser chamado de dentro de outro.

\subsubsection{Processos abstratos e processos executáveis}

Em BPEL, existem duas maneiras de descrever processos de negócio: por meio de processos executáveis (executable processes) e por meio de processos abstratos (abstract processes). Essas diferentes formas de descrição têm finalidades distintas, exploradas a seguir.

Segundo [31], um processo executável "define a ordem de execução de um conjunto de atividades, as partes envolvidas no processo, as mensagens trocadas entre elas, bem como os eventos e tratamento de exceções, especificando qual(is) o(s) tratamento(s) quando eventos específicos ou falhas ocorrem". Um processo executável pode existir independentemente de um processo abstrato. O seu objetivo é representar todos os 
detalhes de um processo BPEL, possibilitando a sua execução.

Já um processo abstrato não é especificado para execução. Segundo [31], "um processo abstrato é uma especificação do comportamento de uma classe de serviços, que captura restrições quanto à ordenação das mensagens que são enviadas para um serviço ou recebidas de um serviço". Assim, processos abstratos descrevem as interfaces públicas e as regras associadas a essas interfaces.

Nota-se que, diferentemente do arquivo WSDL, que somente descreve as interfaces utilizadas, no processo abstrato é possível descrever a seqüência das comunicações ou a dependência entre as mensagens. Existem vários casos de uso em que o processo abstrato se aplica. Entre eles estão a validação de um processo, garantindo que ele obedeça a uma especificação estabelecida; a função de prover um modelo que auxilie no desenvolvimento da implementação de um processo que seja executável; ou ainda a possibilidade de divulgar aspectos públicos de um processo sem que, para isso, seja necessário revelar decisões internas para os utilizadores do processo.

Neste trabalho, a atenção estará voltada aos processos executáveis, que contêm descrições completas dos processos de negócio.

\subsubsection{Controle de fluxo em BPEL: a união de dois paradigmas}

O modo como BPEL lida com o controle de fluxo de seus processos está intimamente relacionado à maneira como suas linguagens predecessoras, XLANG [15] e WSFL [16], tratam o assunto. Elas utilizam diferentes paradigmas para estabelecer o controle dos fluxos. WSFL utiliza uma estrutura de grafos, aliada a algumas condições, para controlar o fluxo de seus processos. Já XLANG utiliza uma estrutura hierárquica formada por "blocos" que representam conceitos especiais, como while e sequence, lembrando bastante uma linguagem de programação usual. Dependendo do tipo de processo que se quer modelar, uma das duas abordagens se mostra mais natural que a outra. BPEL foi desenvolvida de modo a combinar as duas linguagens, tentando extrair o melhor delas, facilitando a naturalidade da representação.

Um processo BPEL relaciona diversas atividades, que podem ser divididas em duas categorias: atividades básicas e estruturadas. Atividades básicas são aquelas que descrevem ações atômicas do comportamento do processo. Já as atividades estruturadas são aquelas que envolvem lógica de controle de fluxo, podendo conter outras atividades dentro delas, sejam básicas ou estruturadas, de um modo recursivo. As atividades estruturadas impõem regras de comportamento e restrições sobre a execução das atividades que elas contêm, ditando a ordem com que essas atividades serão executadas. Juntamente às atividades, BPEL também inclui os conceitos de eventos, falhas, compensações e terminações, que possuem seus respectivos manipuladores. 


\section{Atividades básicas}

A seguir, serão apresentadas as atividades básicas fornecidas pela linguagem. Para mais detalhes sobre elas, ver o Apêndice A.

- invoke: faz uma chamada a algum dos serviços web disponibilizados;

- receive: espera por uma mensagem de um agente externo;

- reply: manda uma resposta referente a uma requisição previamente aceita;

- wait: aguarda por um tempo determinado ou então até que determinado marco final seja atingido;

- assign: copia dados entre variáveis ou os insere por meio de expressões;

- throw: sinaliza explicitamente uma falha interna na execução;

- compensate e compensateScope: inicia a compensação de escopos que já foram completados com sucesso;

- exit: finaliza imediatamente a instância do processo;

- empty: não faz nenhuma ação significativa. Pode ser usada como ponto de sincronização;

- rethrow: lança novamente falhas que foram capturadas;

- validate: assegura que os valores armazenados nas variáveis sejam válidos;

- extensionActivity: define novas atividades.

\section{Atividades estruturadas}

Seguem as atividades estruturadas providas por BPEL. Mais detalhes podem ser encontrados no Apêndice A.

- sequence: contém uma ou mais atividades, fazendo com que sejam executadas seqüencialmente;

- flow: contém um conjunto de atividades, fazendo com que sejam executadas concorrentemente;

- pick: contém um conjunto de pares evento-atividade, executando a atividade associada a um evento ocorrido; 
- while: repete a execução de uma atividade enquanto uma condição for verdadeira;

- repeatUntil: repete a execução de uma atividade até que uma condição se torne verdadeira;

- scope: agrupa atividades em blocos;

- if: especifica um comportamento condicional dentro do processo;

- forEach: repete a execução de uma atividade por um número previamente calculado de vezes.

\section{Manipuladores}

Em BPEL, existem quatro tipos de manipuladores. São os manipuladores de eventos, falhas, compensações e terminações.

Os manipuladores de eventos são formados por pares evento-atividade. Eles são considerados habilitados quando seu escopo associado (ver atividade scope no Apêndice A) está em execução. Quando a ocorrência de um evento descrito é registrada, a atividade associada ao evento é, então, disparada e executada concorrentemente à atividade principal. Pode ser considerado evento o término de um período de tempo, funcionando como um alarme, ou ainda uma mensagem externa.

Os manipuladores de falhas são utilizados pela linguagem para tratar as falhas internas e externas que podem acontecer durante a execução de atividades contidas em um escopo. Existem maneiras de gerar falhas de modo explícito, por meio da utilização de atividades específicas (ver atividade throw no Apêndice A). Diferentemente do que ocorre nos manipuladores de eventos, aqui o fluxo principal é interrompido antes que a atividade especificada no interior do manipulador seja executada.

Os manipuladores de compensações são um modo de desfazer as atividades de um escopo que já foi executado. Quando uma atividade compensatória (ver atividade compensate e compensateScope no Apêndice A) é executada para um determinado escopo, o manipulador de compensações desse escopo será executado (caso exista), disparando a execução da atividade especificada no seu interior. Essa é a maneira existente em BPEL de reverter o que foi feito em partes do processo que necessitam de compensação.

Quando um manipulador de falhas de um escopo é acionado, todas as atividades ativas do fluxo principal desse escopo devem ser finalizadas antes que o manipulador comece a tratar a falha. Algumas atividades são simplesmente interrompidas, terminando prematuramente, como é o caso de atividades do tipo wait, receive, reply e invoke. Já outras têm permissão para acabar o que estão fazendo (assign, por exemplo). No caso de atividades estruturadas, ocorre a interrupção e a propagação da finalização para as atividades aninhadas que 
estão em execução. Para algumas atividades, existe a possibilidade (ou obrigatoriedade) de se aplicar uma rotina de terminação ao final (forçado) da sua execução. Nesse contexto entra o manipulador de terminação. Os manipuladores de terminação permitem determinar a terminação das atividades. Para isso, é necessário associar, ao escopo devido, uma atividade usada pelo manipulador de terminação. Depois que a atividade primária do escopo é finalizada, a atividade do manipulador é executada. Caso não exista, é executada uma terminação padrão.

\section{Estrutura de grafos}

Disponibilizando as atividades estruturadas, a linguagem fornece um meio de representar as dependências entre atividades de forma hierárquica. Além disso, BPEL proporciona outros artifícios para controlar o fluxo de atividades, por meio da utilização de ligações de controle, condições de junção e condições de transição.

Em BPEL, as ligações de controle (control links) são utilizadas na sincronização de atividades concorrentes, ocorrendo dentro de atividades do tipo flow. Uma ligação de controle possui uma atividade origem e uma atividade destino. Uma atividade pode ser origem de várias ligações. A cada ligação que "sai" de uma atividade, pode ser atribuída uma expressão Booleana denominada condição de transição. Uma atividade também pode ser destino de várias ligações. Ao conjunto de ligações que "chegam" em uma atividade, pode ser atribuída uma expressão Booleana chamada de condição de junção. A toda ligação de controle está associado um estado. Esse estado pode ter os valores: verdadeiro, falso e indefinido. Logo no início da execução da atividade flow, os valores das ligações de controle são iniciadas com o valor indefinido. Ao longo da execução das atividades, as ligações de controle recebem os valores verdadeiro ou falso. Existem diversas regras complexas em BPEL para associar um valor ao estado de uma ligação (ver [14]). Em linhas gerais, para uma ligação receber um estado verdadeiro, sua atividade de origem deve terminar de maneira bem-sucedida e, caso exista, a sua condição de transição deve ser avaliada como verdadeira. De outro modo, o estado da ligação de controle terá o valor falso. Para uma atividade estar habilitada para execução, duas condições devem ser satisfeitas: em primeiro lugar, a atividade deve estar pronta para executar, levando em consideração o contexto da estrutura hierárquica da qual faz parte; em segundo lugar, a condição de junção associada à atividade deve ser avaliada como verdadeira. Caso não haja uma declaração explícita de uma condição de junção, basta que uma das ligações que chegam na atividade seja verdadeira para satisfazer a condição implícita.

Combinando essa abordagem baseada em grafos com o controle de fluxo por blocos, tem-se, adicionalmente às restrições impostas pelo modelo estruturado, as dependências condicionais, de precedência e sincronização provenientes das ligações de controle especificadas. 


\subsubsection{Manipulação de dados em BPEL}

A manipulação de dados em BPEL é feita com a intuito de influenciar o fluxo dos processos e tratar os dados provenientes das mensagens recebidas ou enviadas. BPEL parte do princípio de que ela não deve ser utilizada como uma linguagem própria para tratamento de dados, pois espera que os dados sejam tratados e armazenados dentro dos serviços web que o processo BPEL utiliza. Assim, ela provê funções limitadas para este fim, com o intuito de servir apenas para manipular os dados relevantes para o controle de fluxo e possibilitar a passagem de dados via mensagens.

Para exercer as suas funções, BPEL utiliza vários recursos. Dentre eles estão as variáveis e as expressões. O uso de variáveis BPEL ocorre da mesma maneira que na maioria das linguagens de programação. Elas podem guardar dados relacionados ao estado do processo, guardar valores temporários, ser parte de expressões, ou ainda armazenar mensagens recebidas ou que serão enviadas.

BPEL utiliza três tipos de declaração de variáveis: WSDL message type, XML Schema type e XML Schema element. Cada variável é declarada dentro de um escopo (ver atividade scope no Apêndice A), pertencendo, assim, a ele. Uma variável declarada dentro do escopo global do processo pode ser vista em todo o processo, sendo chamada de variável global. Uma variável declarada em algum escopo que não seja global, será visível somente no escopo na qual foi definida, ou nos escopos definidos internamente. Nesse caso, ela recebe o nome de variável local. O acesso às variáveis é feito do escopo mais restrito para o mais abrangente, da mesma forma que ocorre na maioria das linguagens de programação.

As variáveis globais não são iniciadas no começo do processo. Da mesma maneira, as variáveis locais não são iniciadas no começo do escopo aos quais elas pertencem. Para sair desse estado, elas devem ser iniciadas utilizando, por exemplo, a atribuição de valores ou mensagens. Se uma leitura de uma variável não-iniciada for feita, uma falha é gerada. As variáveis BPEL também possuem um mecanismo de validação. Por meio da atividade validate, pode-se garantir que os valores das variáveis sejam sempre válidos, comparados às definições que foram feitas em algum arquivo XML auxiliar. Se um problema relativo a validação é encontrado, uma falha é gerada.

Somente a utilização de variáveis não é suficiente para controlar o comportamento de um processo. É necessária alguma maneira de extrair e combinar esses dados. Dessa forma, surge a necessidade de algum mecanismo de expressões. BPEL optou por não "reinventar a roda" nesse aspecto, deixando que a linguagem utilizada para descrever as expressões seja escolhida na hora da especificação do processo. Apesar da capacidade de escolha, BPEL sugere a utilização da linguagem XPath 1.0 [32] para a descrição de expressões, determinando que as implementações de BPEL devem oferecer a interpretação dessa linguagem como fun- 
cionalidade obrigatória. BPEL usa vários tipos de expressões, tais como expressões Booleanas, expressões que devolvem uma data de expiração, expressões que devolvem uma duração, expressões que devolvem um número inteiro e outras de uso geral.

Por meio da atividade assign, os dados podem ser copiados de uma variável para outra. Além disso, ela permite a atribuição de novos dados às variáveis, com o uso de expressões.

Detalhes sobre a manipulação de dados em BPEL podem ser encontrados em [14].

\subsubsection{Instâncias de processos: identificação e ciclo de vida}

Um processo descrito em BPEL é construído baseado em um modelo de serviço definido pela especificação WSDL. Todas as interações externas realizadas pelo processo ocorrem por meio de interfaces WSDL de serviços web. Porém, o modelo de interação de WSDL não armazena estados, sendo baseado em interações curtas. Entretanto, os processos de negócio em BPEL representam interações longas, que requerem o armazenamento de estados, sendo que cada interação possui um começo, um determinado comportamento durante a execução do processo e um fim. Tem-se então uma divergência entre os paradigmas de WSDL e dos processos BPEL. Para resolver essa questão, decidiu-se fazer o gerenciamento implícito do ciclo de vida do processo. Dessa maneira, o cliente do serviço web não tem consciência da existência de um processo subjacente ao serviço web acessado por ele. Quando uma mensagem é recebida por meio de determinadas operações que o serviço web disponibiliza, uma nova instância do processo é automaticamente criada. Uma instância é finalizada quando suas atividades finais acabam de executar ou então quando é executada uma atividade que explicitamente termina a execução da instância do processo (ver atividade exit no Apêndice A).

Existe ainda a questão da identificação das instâncias de um processo. De alguma maneira, BPEL precisa lidar com o roteamento das mensagens que chegam ao serviço web. É necessário saber onde a mensagem será entregue e se o seu destino será uma nova instância do processo ou uma instância já existente. É essa identificação que permite aos processos participarem de interações longas. Em muitos sistemas existentes, esse problema é resolvido por meio da criação de um identificador para cada instância. Ao chegar uma mensagem, ela é examinada em busca de um identificador que indique qual é o seu destino. Em BPEL, esta questão é resolvida de uma maneira levemente diferente: por meio do uso de correlações. Com o mecanismo de correlações, dados específicos da aplicação, que ficam disponíveis nas mensagens trocadas, são utilizados para manter referências para instâncias específicas do processo. Fazendo uma analogia com os Sistemas Gerenciadores de Banco de Dados, esse processo de identificação seria semelhante à identificação unívoca de uma tupla de uma relação a partir de uma chave primária pré-definida. A localização exata dos dados usados pela 
correlação variam de mensagem para mensagem dentro de um mesmo processo. Para especificar quais dados devem ser utilizados na correlação, utiliza-se o arquivo WSDL associado ao processo, no qual são definidas as estruturas responsáveis por fazer estas associações, essenciais para o funcionamento do mecanismo.

\subsubsection{BPEL e outras linguagens}

Assim como BPEL, existem várias outras linguagens de representação de processos. Algumas são linguagens proprietárias, embutidas em Sistemas Gerenciadores de Workflows existentes no mercado, enquanto outras são linguagens de composição de serviços web, como é o caso da própria BPEL. Várias tentativas de desenvolver uma linguagem que seja bastante representativa vêm sendo feitas, como é o caso da recente YAWL [17]. Apesar disso, pouco esforço foi feito para compará-las utilizando como base uma referência comum. Apesar de já existirem algumas comparações entre linguagens, elas não utilizaram uma base mais formal para isto. Apenas com o surgimento dos Workflow Patterns (ver Seção 3.1), comparações utilizando uma base comum começaram a surgir.

Em [1], foi feita uma comparação entre os principais produtos de workflows existentes no mercado, bem como das linguagens de composição de serviços web, utilizando, para isto, alguns padrões de controle de fluxo dos Workflow Patterns e também alguns padrões referentes a comunicação. Nesse trabalho comparativo, conclui-se que as linguagens de composição de serviços web são mais expressivas do que os tradicionais sistemas de workflow. Observando a comparação entre as linguagens de composição de serviços web feita pelo artigo, pode-se chegar a algumas conclusões importantes. A primeira delas é que nenhuma linguagem mostra-se perfeita, pois nenhuma delas consegue cobrir integralmente todos os padrões apresentados no artigo. A segunda conclusão a que se pode chegar é que, de fato, BPEL consegue representar a união dos padrões representados pela XLANG e pela WSFL, conforme era esperado, devido à própria origem da linguagem. Por fim, pode-se notar, por meio da comparação entre os padrões cobertos pela linguagem (ver [1]), que BPEL é a linguagem mais representativa dentre as analisadas.

Com a sustentação de grandes empresas, como a IBM e a Microsoft, BPEL parece ganhar cada vez mais espaço. Com o seu poder de representatividade, aliado à adesão da OASIS ao projeto, ela vem se destacando no cenário atual. Já existem muitas ferramentas disponíveis no mercado que fazem os mapeamentos de seus processos para BPEL e, inclusive, permitem que se desenvolva graficamente os processos, passando-os posteriormente para BPEL. Isso facilita o uso da linguagem e alavanca ainda mais o seu crescimento. 


\subsubsection{Exemplo de especificação de processo}

Para ilustrar a maneira como o controle de fluxo está inserido em uma especificação BPEL, o exemplo da Seção 2.1.5 será descrito agora por meio da sintaxe de BPEL.

Exemplo. Segue o trecho de código referente à especificação na linguagem BPEL. Várias simplificações foram feitas, deixando apenas a estrutura essencial para o entendimento do fluxo do processo. Em BPEL, as tarefas do exemplo são desempenhadas por serviços web. Portanto, na especificação, as tarefas são mapeadas para interações com esses serviços, feitas por meio de atividades BPEL. Nessa estrutura, pode-se verificar a presença de uma atividade receive, que recebe uma mensagem inicial, criando uma instância do processo. Em seguida, duas atividades invoke são responsáveis pelo cálculo inicial do preço e escolha da transportadora. A partir daí, a atividade flow entra para aninhar duas outras atividades, paralelizando-as. A primeira delas é uma atividade invoke, responsável pelo término do cálculo do preço. A outra atividade é uma sequiência que contém outras duas atividades invoke, das quais uma notifica a transportadora e a outra termina o agendamento da entrega. Terminada a atividade flow, segue, então a resposta ao cliente feita pela atividade reply.

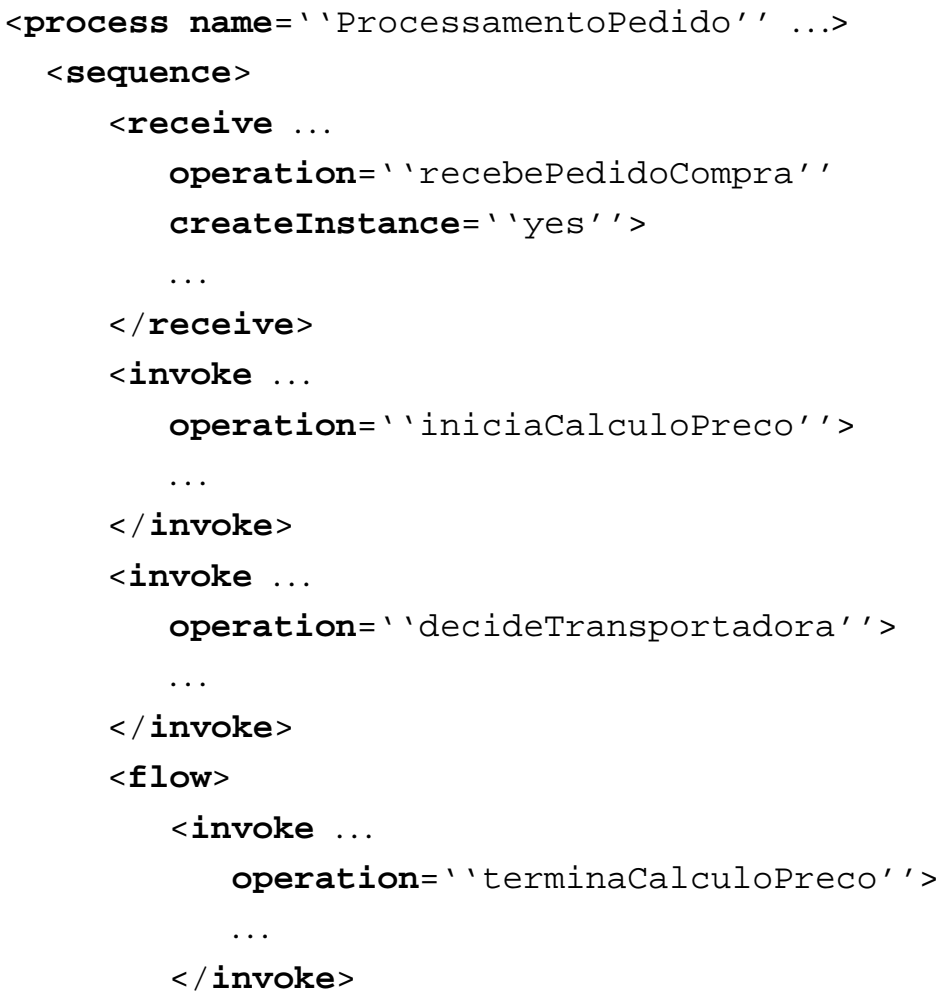




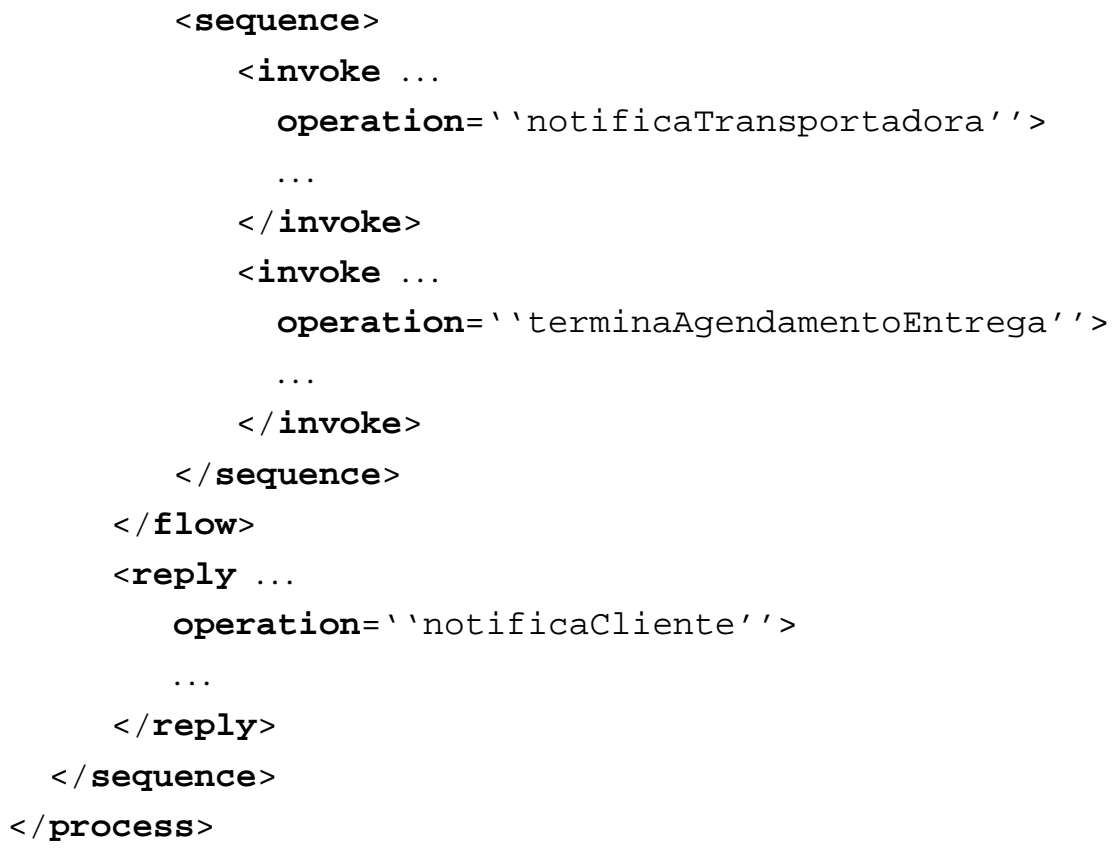

\subsection{NPDL}

Tradicionalmente, os ambientes de representação e execução de processos de negócio utilizam redes de Petri como arcabouço formal. Recentemente, surgiram algumas iniciativas que utilizam extensões de álgebra de processos para este fim. Dentre elas, está a NPDL [9].

A NPDL (Navigation Plan Definition Language) é uma linguagem de definição de processos de negócio baseada na ACP e foi desenvolvida como uma extensão da linguagem SQL. Seu principal objetivo é facilitar a representação das estruturas de controle de fluxo utilizadas nos processos de negócio.

\subsubsection{Linguagem para representação e execução de processos}

A NPDL é uma linguagem construída como uma extensão de SQL [33]. Porém, SQL não possui estruturas de dados apropriadas para a representação de processos. Por este motivo, NPDL define comandos que adicionam à SQL a capacidade de representar processos. A NPDL é baseada no conceito de Plano de Navegação da arquitetura Riverfish [34,35] e na ACP [21].

Em NPDL, os processos são definidos por meio de expressões algébricas. As expressões algébricas de NPDL são construídas utilizando-se ações atômicas, operadores NPDL e processos. Ações atômicas NPDL 
são indivisíveis, sendo executadas sempre na íntegra. Elas são equivalentes a transações que respeitam as propriedades ACID (atomicidade, consistência, isolamento e durabilidade). Os operadores são utilizados para encadear ações ou (sub)processos. Inicialmente, a NPDL foi criada apenas com 3 operadores: os operadores de composição seqüencial, composição alternativa e composição paralela. Para conseguir especificar de maneira mais direta os Padrões de Controle de Fluxo, outros operadores foram adicionados à linguagem. Atualmente, ela apresenta os operadores descritos a seguir. Esta descrição foi extraída de [9]. A palavra "termo" é utilizada com o mesmo significado da teoria de álgebra de processos (ver Seção 2.1).

1. Composição Seqüencial (operador “.”): o termo de processo $A \cdot B$ significa que inicialmente somente o termo $A$ está habilitado para execução. $\mathrm{O}$ termo $B$ será habilitado para execução somente após o fim da execução do termo $A$;

2. Composição Alternativa (operador “ + ”): o termo de processo $A+B$ significa que inicialmente ambos os termos $A$ e $B$ estarão habilitados para execução;

3. Composição Paralela (operador “ " ”): o termo de processo $A \| B$ significa que os termos $A$ e $B$ podem ser executados paralelamente, dividindo a linha de execução em duas;

4. Composição Paralela Entrelaçada (operador “ $\mid *$ ”): o termo de processo $A \mid * B$ significa que os termos $A$ e $B$ podem ser executados em qualquer ordem (i.e., $A \cdot B+B \cdot A$ ), mas não paralelamente;

5. Composição Multi-Convergente (operador “ \& ”): o termo de processo $A \& B$ significa que o termo $B$ será habilitado para execução após o término da execução de cada linha de execução do termo $A$. Por exemplo, o processo $P=(X \| Y) \& Z$ indica que $Z$ será habilitado duas vezes: uma após o término da execução de $X$ e outra após o término da execução de $Y$, mas no processo $P=(X+Y) \& Z, Z$ será habilitado apenas uma vez, após a execução da atividade escolhida na composição alternativa $(X$ ou $Y)$;

6. Composição Discriminatória (operador “ $\wedge$ ”): o termo de processo $A \wedge B$ significa que o termo $B$ será habilitado para execução após o primeiro término de uma linha de execução do termo $A$. Por exemplo, o processo $P=(X \| Y) \wedge Z$ indica que $Z$ será habilitado para execução somente uma vez; se a atividade $Y$ terminar primeiro, então $Z$ será habilitado depois da execução de $Y$. Neste caso, quando $X$ terminar, $Z$ não será habilitado novamente - esse comportamento diferencia do operador “ $\wedge$ ” do operador "\&";

7. Repetição Ilimitada (operador “ ?* ”): o termo de processo $A$ ?* significa que o termo $A$ pode ser executado, de forma paralela, uma ou mais vezes; 
8. Repetição Numericamente Limitada (operador “?n”, sendo n um número inteiro positivo e não nulo): o termo de processo $A ? 5$ significa que o termo $A$ deve ser executado, de forma paralela, 5 vezes;

9. Repetição Limitada por Função (operador “?f ”, sendo f uma função atômica que retorna um número inteiro positivo e não nulo): o termo de processo $A$ ? $f_{1}$ significa que o termo $A$ deve ser executado, de forma paralela, o número de vezes retornado pela função $f_{1}$ em tempo de execução;

10. Execução Condicional (operador "\%r", sendo r uma regra, ou seja, uma função atômica que retorna um valor Booleano - verdadeiro ou falso): o termo de processo \% $r_{1} A$ significa que o termo $A$ será habilitado para execução se o valor de retorno da regra $r_{1}$ (avaliada em tempo de execução) for verdadeiro. Sendo assim, uma regra na NPDL pode ser entendida como uma condição para a execução de uma atividade;

11. Execução Condicional Negativa (operador “\%!r”, sendo $r$ uma regra, ou seja, uma função atômica que retorna um valor Booleano - verdadeiro ou falso): o termo de processo $\% ! r_{1} A$ significa que o termo $A$ será habilitado para execução se o valor de retorno da regra $r_{1}$ (avaliada em tempo de execução) for falso.

A precedência desses operadores é mostrada na Figura 3.1.

\begin{tabular}{|c|c|c|c|c|c|c|c|}
\hline & \multicolumn{7}{|c|}{ Alta $\longleftrightarrow$ Precedência $\longrightarrow$ Baixa } \\
\hline Operador & $\begin{array}{c}\% r \\
\% ! r\end{array}$ & $\begin{array}{l}?^{*} \\
? n \\
? f\end{array}$ & • & $\|$ & $\left.\right|^{*}$ & $\hat{\&}$ & + \\
\hline
\end{tabular}

Figura 3.1: Precedência de operadores em NPDL. Extraída de [9].

Para maiores detalhes com relação à sintaxe da linguagem, pode-se consultar o texto existente em http: //www.ime.usp.br/ jef/kelly/bnf_NPDL.pdf.

\subsubsection{Especificação dos Padrões de Controle de Fluxo em NPDL}

NPDL tem como um de seus objetivos garantir que as diferentes abstrações de controle de fluxo que são encontradas em um processo de negócio possam ser especificadas. Para tanto, NPDL busca, por meio de seus operadores, representar os Padrões de Controle de Fluxo identificados por Aalst [19]. Para cada padrão, há, em NPDL, expressões que o especificam. Utilizando esse mapeamento, pelo aspecto composicional da linguagem, é possível montar expressões que especifiquem um processo integralmente. Para a concisão deste 
texto, o mapeamento dos padrões em expressões NPDL será apresentado na Seção 4.1, juntamente com os mapeamentos para ACP e LOTOS. Maiores detalhes podem ser encontrados em [9].

\subsubsection{Exemplo de especificação de processo}

Dadas as correspondências entre os padrões e a linguagem NPDL (ver Seção 4.1), é possível retomar o exemplo descrito pela Figura 2.2 da Seção 2.1.5, descrevendo-o, agora, por meio da sintaxe de NPDL.

Exemplo. Para esse exemplo, não há diferenças significativas entre as especificações em ACP e NPDL. Da mesma forma que na ACP, as tarefas do exemplo foram mapeadas para ações NPDL. Basicamente, três padrões foram utilizados: o padrão de seqüência (Padrão 1), a divisão paralela (Padrão 2) e a sincronização (Padrão 3). Utilizando os mapeamentos descritos, chega-se na seguinte especificação:

\section{CREATE ACTION A 'ReceberPedido'; \\ CREATE ACTION B 'IniciarCalculoPreco'; \\ CREATE ACTION C 'EscolherTransportadora'; \\ CREATE ACTION D 'TerminarCalculoPreco'; \\ CREATE ACTION E 'NotificarTransportadora'; \\ CREATE ACTION $F$ 'AgendarEntrega'; \\ CREATE ACTION G 'NotificarCliente';}

\section{CREATE PROCESS P 'ProcessamentoPedido';}

$$
\text { SET } P=A \cdot B \cdot C \cdot(D \| E \cdot F) \cdot G
$$

Os comandos CREATE ACTION são responsáveis pela criação das ações e associações de descrições (por exemplo, ReceberPedido) a um identificador de uma ação (por exemplo, A). O comando CREATE PROCESS cria um processo e o identifica e descreve, da mesma forma que as ações. Por fim, tem-se a definição do processo.

\subsection{Conclusão}

Neste capítulo, foram apresentados os Padrões de Controle de Fluxo, a NPDL e BPEL. No capítulo seguinte, os Padrões de Controle de Fluxo e os principais conceitos de BPEL serão usados para comparar as capacidade de representação da ACP e de LOTOS. Nesse contexto serão apresentados os padrões e seus mapeamentos para ACP, NPDL e LOTOS. Os conceitos de BPEL serão retomados e mapeados para ACP e LOTOS. 



\section{Capítulo 4}

\section{Comparando ACP e LOTOS}

Neste capítulo, é feita uma comparação de expressividade dos formalismos algébricos ACP e LOTOS. Para tanto, são utilizadas duas bases comparativas: a primeira delas, refere-se aos Padrões de Controle de Fluxo de Workflow (ver Seção 3.1); a segunda, refere-se aos principais conceitos da linguagem BPEL (ver Seção 3.2).

Na primeira seção, para cada um dos padrões, três especificações são apresentadas. A primeira delas corresponde à especificação utilizando a linguagem ACP (descrita na Seção 2.1); a segunda corresponde à especificação utilizando a linguagem LOTOS (descrita na Seção 2.2). Além dessas, é apresentada a especificação em NPDL. Depois das especificações, seguem os comentários a respeito da comparação. As especificações dos padrões referentes a LOTOS constituem parte das contribuições deste trabalho. Já as especificações referentes a ACP e a NPDL foram, em sua maioria, extraídas do mesmo trabalho que especifica a linguagem NPDL [9].

Embora as especificações dos Padrões de Controle de Fluxo em NPDL também estejam presentes nesta seção, elas não fazem parte da comparação proposta por este trabalho, pois o objetivo é comparar a álgebra base da NPDL, que é a ACP, com LOTOS. Elas estão presentes aqui apenas para ressaltar a dificuldade que NPDL enfrentou para tentar solucionar parte das deficiências de expressividade do arcabouço algébrico no qual foi baseada.

Na segunda seção deste capítulo, os arcabouços algébricos ACP e LOTOS são comparados com relação aos principais conceitos presentes na linguagem BPEL. Para cada conceito, são discutidas as características da ACP e LOTOS que permitem ou impedem a sua representação, abordando, assim, os limites representativos das álgebras. 
Para cada padrão, as álgebras serão classificadas de acordo a sua capacidade de representá-lo. A álgebra representará o padrão quando estiverem presentes na álgebra as estruturas e conceitos teoricamente necessários para isso. A álgebra não representará o padrão quando faltarem no formalismo estruturas ou conceitos necessários para a sua representação. Entende-se que a não representatividade de um padrão não deve ser propagada para outros. Assim, se determinado padrão depende da representatividade de outro, o fato de este último não ser representável não deve influenciar na representatividade do primeiro. Diz-se que a álgebra $r e-$ presenta parcialmente o padrão quando as estruturas e conceitos existentes na álgebra são suficientes apenas para representar parte das situações compreendidas pelo padrão. Para os conceitos BPEL, os mesmos critérios serão considerados.

Após as duas comparações, os resultados obtidos são analisados e sintetizados em tabelas que facilitam a visualização dos resultados.

Antes de iniciar os mapeamentos, uma importante observação sobre o operador de entrelaçamento ("I|") da ACP deve ser feita. O operador de entrelaçamento representa duas funções distintas: o paralelismo e a comunicação (ver Seção 2.1.2). Considerando o axioma $x \| y=(x \downarrow y+y \llbracket x)+x \mid y$, entende-se por paralelismo a parte do comportamento do operador equivalente ao termo $(x \downarrow y+y \llbracket x)$. O termo $x \mid y$ representa a comunicação. A função de comunicação do operador é bastante utilizada nos axiomas da ACP, bem como em análises teóricas sobre o formalismo algébrico. Entretanto, para a especificação de processos de negócio utilizando essa álgebra, o operador de entrelaçamento com o seu significado original não é aplicável. Como o operador de entrelaçamento permite optar pela realização do paralelismo entre termos de processo e a realização da comunicação por meio de um sincronismo das primeiras ações atômicas desses termos, não é possível usar esse operador quando se quer definir um processo que use apenas uma das suas funcionalidades. Para viabilizar o uso desse operador na especificação de processos de negócio, torna-se necessário restringir o seu significado, retirando a sua função de comunicação. Portanto, para os mapeamentos a seguir, ele será considerado como um operador de paralelismo. Isto não gerará perdas nos mapeamentos seguintes, visto que nenhum dos padrões ou conceitos requerem a sincronização entre ações iniciais pertencentes a ramos paralelos. Essa mesma decisão foi tomada na definição da NPDL [9].

\subsection{Representação dos Padrões de Controle de Fluxo}

Para começar a especificar, em LOTOS, os Padrões de Controle de Fluxo, é necessário estabelecer alguns mapeamentos iniciais, visando reproduzir, em LOTOS, alguns conceitos utilizados nos padrões e no mapeamento dos padrões para ACP. 
Nos padrões, existe a idéia de atividade elementar. Uma atividade elementar pode ser vista como um passo de negócio, isto é, uma unidade atômica de trabalho. No mapeamento em ACP, esta idéia estava representada pelo conceito de ação atômica. Em LOTOS, porém, não existe uma "unidade" que expresse essa idéia. A ação ou evento presente em LOTOS representa simplesmente um sincronismo. Com o intuito de criar em LOTOS uma unidade que represente essa idéia, a seguinte estrutura será utilizada:

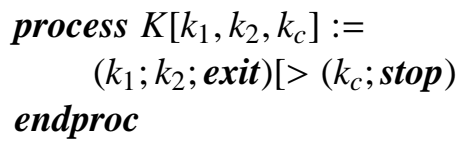

Nessa estrutura, a idéia de atividade elementar de nome $K$ é representada por meio de um processo com $\mathrm{o}$ mesmo nome da atividade. O funcionamento de $K$ consiste em coordenar a execução de um processo externo $S$, responsável pela realização do trabalho da atividade. Esse processo $S$ pode ser, por exemplo, uma interface entre a especificação LOTOS e um serviço web. A ação simbolizada por $k_{1}$ tem o papel de iniciar a atividade elementar. Uma vez que $K$ sincroniza, por meio de $k_{1}$, com o processo $S$, a atividade inicia a sua execução. Nesse instante, $S$ começa a desempenhar o trabalho interno da atividade. Depois que o trabalho é desempenhado pelo processo $S$, ele sincroniza com $K$ usando a porta $k_{2}$, indicando o término do trabalho da atividade. Por fim, a terminação bem sucedida é sinalizada pela palavra reservada exit. Durante a execução da atividade, é interessante poder sinalizar o seu cancelamento ou a ocorrência de alguma espécie de erro que a invalide. Para esse fim, usa-se o operador de desativação. O cancelamento pode ser indicado por meio da sincronização com a porta $k_{c}$. Se ocorrer essa sincronização, o fluxo principal (à esquerda do operador) é interrompido. Para indicar o término de maneira não usual, stop é utilizado em vez do exit. No restante da seção, o termo atividade elementar, no contexto de LOTOS, será usado como representante dessa estrutura apresentada.

Além do conceito de atividade elementar, o termo atividade também é usado tanto nos padrões como no mapeamento padrões-ACP. Uma atividade pode ser vista tanto como uma atividade elementar como também como um conjunto de atividades com uma ordem de execução (em ACP, um subprocesso). Em LOTOS, o termo atividade será utilizado para representar uma atividade elementar conforme descrita anteriormente e também processos, cujas expressões de comportamento representam uma execução ordenada de diversas atividades elementares. As expressões de comportamento desses processos também podem ser usadas como atividades, substituindo os processos representados por elas.

Para facilitar a leitura dos padrões, permitindo uniformizá-la, será utilizada uma notação simplificada para a representação de processos. Para instanciar um processo em uma expressão de comportamento, apenas o 
nome dele será utilizado. A representação das portas será omitida. Para a definição de processos, a forma "nome do processo = expressão de comportamento" será usada, uma vez que já contém todas as informações necessárias, pois o enfoque dos padrões é o controle de fluxo representado pelas expressões de comportamento.

Para cada um dos padrões, será dada uma definição sucinta e um exemplo, que será usado para o desenvolvimento das expressões nas álgebras e na NPDL. Para a maioria deles, uma ilustração do exemplo é também apresentada. Para facilitar a comparação, a maior parte dos exemplos que serão mapeados são exatamente os mesmos do trabalho de mapeamento padrões-ACP, presentes em [9]. Alguns deles foram levemente modificados, com o intuito de facilitar o entendimento.

\subsubsection{Padrões básicos de controle de fluxo}

\section{Padrão 1: Seqüiência}

Definição. Série ordenada de atividades, em que uma atividade é habilitada para executar somente após a execução da atividade anterior.

Exemplo. A atividade $B$ só é habilitada para execução após o término da execução da atividade $A$.

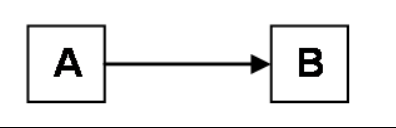

Figura 4.1: Seqüência. (Extraída de [9]).

ACP:

$$
P=A \cdot B
$$

LOTOS:

$$
P=A>>B
$$

NPDL:

$$
\text { SET } P=A \cdot B
$$


Nesse padrão, não há diferenças significativas entre as representações em ACP e LOTOS. O operador de composição seqüencial de LOTOS equivale ao operador de composição seqüencial de ACP no mapeamento.

\section{Padrão 2: Divisão Paralela}

Definição. Um ponto no processo em que uma linha de execução única é dividida em duas ou mais linhas de execução, de forma que duas ou mais atividades possam começar simultaneamente ou em qualquer ordem. Dessa forma, atividades podem ser executadas concorrentemente, em vez de seriadamente.

Exemplo. A atividade $A$ é executada, habilitando a execução paralela de $B$ e $C$.

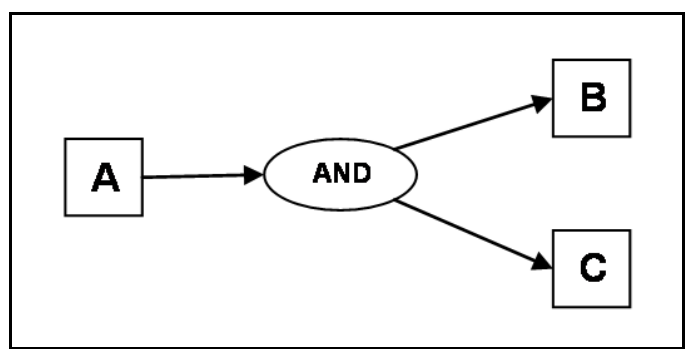

Figura 4.2: Divisão Paralela. (Extraída de [9]).

ACP:

$$
P=A \cdot(B \| C)
$$

LOTOS:

$$
P=A>>(B \mid \| C)
$$

NPDL:

$$
\text { SET } P=A \cdot(B \| C)
$$

O operador de intercalação em LOTOS desempenha o papel do paralelismo na ACP, isto é, as atividades $B$ e $C$ são executadas concorrentemente de maneira independente. 


\section{Padrão 3: Sincronização}

Definição. Um ponto no processo em que múltiplas atividades paralelas convergem para uma única linha de execução. Essas atividades são sincronizadas nesse ponto, pois todas elas precisam estar completas para que o processo possa continuar.

Exemplo. A atividade $C$ é habilitada somente depois do término da execução das atividades $A$ e $B$.



Figura 4.3: Sincronização. (Extraída de [9]).

ACP:

$$
P=(A \| B) \cdot C
$$

LOTOS:

$$
P=(A \| B)>>C
$$

NPDL:

$$
\text { SET } P=(A \| B) \cdot C
$$

A sincronização entre os ramos paralelos é garantida, em LOTOS, pela sincronização das terminações bem-sucedidas presentes nas atividades $A$ e $B$.

\section{Padrão 4: Escolha Exclusiva}

Definição. Um ponto no processo em que, baseado em uma decisão interna ao sistema ou nos dados de controle do workflow, um dentre os diversos ramos é escolhido. Assim, o caminho divide-se em alternativas 
exclusivas.

Exemplo. As atividades $B$ e $C$ são habilitadas após a execução da atividade $A$, mas somente uma delas ( $B$ ou $C)$ será escolhida implicitamente para execução.

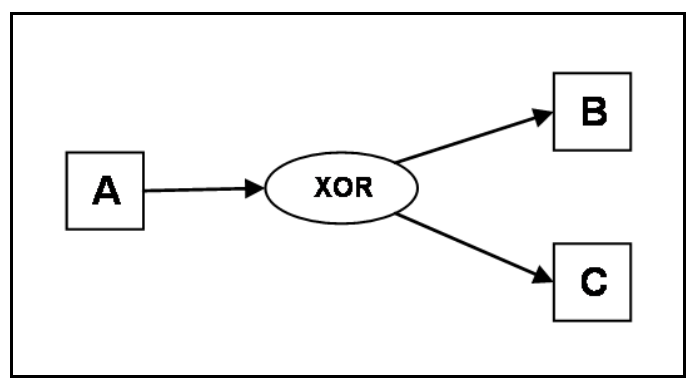

Figura 4.4: Escolha Exclusiva. (Extraída de [9]).

ACP:

Não é possível a especificação desse padrão.

LOTOS:

$$
P=A>>(([\text { cond } 1] \rightarrow B)[]([\text { cond } 2] \rightarrow C))
$$

NPDL:

$$
\text { SET } P=A \cdot(\% r B+\% ! r C)
$$

em que $r$ é uma regra NPDL associada à escolha exclusiva (ver operadores NPDL, na Seção 3.3.1) e [condl], [cond2] são condições de guarda (ver Seção 2.2.4). [cond1] e [cond2] devem ser, nesse caso, mutuamente exclusivas.

Apesar de a ACP representar todas as possibilidades de escolha, suas especificações impossibilitam a tomada de decisão sobre qual ramo será escolhido em tempo de execução pelo sistema, devido à ausência de condições nessa álgebra. Assim, o padrão não é representado. Nesse aspecto, surge a primeira grande vantagem da utilização de LOTOS. Por possuir a representação de tipos de dados e condições que usam esses 
tipos, juntamente com o operador de escolha, LOTOS preenche essa deficiência da ACP e representa, por completo, o padrão.

A NPDL, para preencher a lacuna da ACP, utiliza atividades que implementam regras associadas às escolhas. Ainda assim, em NPDL, não existe um meio de colocar, de modo explícito e direto, uma expressão condicional na especificação do processo. Em vez disso, as regras são embutidas em atividades definidas para esse fim.

\section{Padrão 5: Junção Simples}

Definição. Um ponto no processo em que dois ou mais ramos alternativos se juntam, sem ser necessária a sincronização. Observação: assume-se, nesse padrão, que não ocorre execução em paralelo nos diversos caminhos alternativos.

Exemplo. Inicialmente, as atividades A e B estão habilitadas. Após a execução de uma delas (ou A ou B), a atividade $\mathrm{C}$ é habilitada.

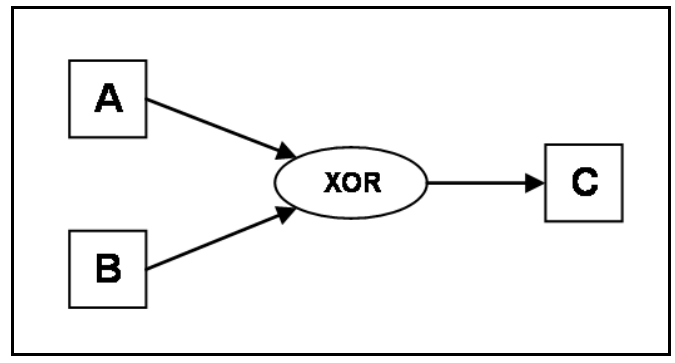

Figura 4.5: Junção Simples. (Extraída de [9]).

ACP:

$$
P=(A+B) \cdot C
$$

\section{LOTOS:}

$$
\begin{aligned}
P & =(A[] B)>>C \\
& \text { ou } \\
P & =(([\text { cond } 1] \rightarrow A)[]([\text { cond } 2] \rightarrow B))>>C
\end{aligned}
$$


NPDL:

$$
\begin{aligned}
\text { SET P } & =(A+B) \cdot C \\
& \text { ou } \\
\text { SET P } & =(\% r A+\% ! r B) \cdot C
\end{aligned}
$$

em que $r$ é uma regra NPDL associada à escolha exclusiva e [cond1], [cond2] são condições de guarda mutuamente exclusivas.

Considerando os padrões de escolha existentes, a junção simples deverá ocorrer posteriormente a uma escolha exclusiva ou a uma escolha postergada (ver Padrão 16: Escolha Postergada). Na ACP, apesar de a junção simples poder ser representada sem impedimentos teóricos, na prática, somente os casos provenientes de uma escolha postergada poderão ser representados, visto que não é possível representar uma escolha exclusiva e, portanto, uma junção resultante dela. Porém, para fins de comparação de expressividade, este padrão será considerado como representável na ACP, pelo fato de que a restrição se dá devido ao padrão de escolha, e não devido à junção. O mesmo vale para outros padrões com situações similares a essa. Em LOTOS, o padrão é perfeitamente representável, bem como na NPDL.

\subsubsection{Padrões avançados de ramificação e sincronização}

\section{Padrão 6: Escolha Múltipla}

Definição. Um ponto no processo em que, baseado em uma decisão ou nos dados de controle do workflow, um ou mais ramos são escolhidos. A diferença para a escolha exclusiva é justamente a quantidade de caminhos que, neste padrão, se pode escolher na hora da execução (desde um até todos os caminhos).

Exemplo. Após a execução da atividade $A$, uma das três opções fica habilitada: $B, C$, ou $B$ e $C$ em paralelo.

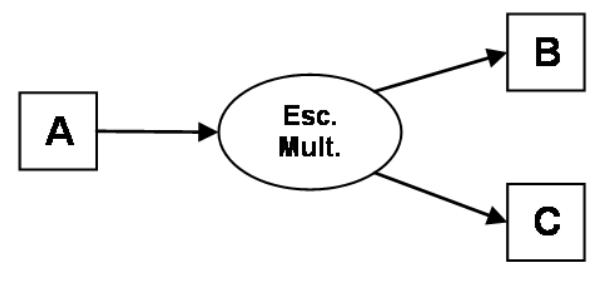

Figura 4.6: Escolha Múltipla. (Extraída de [9]). 
ACP:

Não é possível a especificação desse padrão.

LOTOS:

$$
P=A>>(([\text { cond } 1] \rightarrow B[][\neg \text { cond } 1] \rightarrow \text { exit }) \mid \|([\text { cond } 2] \rightarrow C[][\neg \text { cond } 2] \rightarrow \text { exit }))
$$

NPDL:

$$
\text { SET } P=A \cdot\left(\% r_{1}(B \| C)+\% ! r_{1}\left(\% r_{2} B+\% ! r_{2} C\right)\right)
$$

em que $r_{1}$ e $r_{2}$ são regras NPDL associadas às escolhas exclusivas e [cond1], [cond2] são condições de guarda. $[\neg$ condl] e $[\neg$ cond 2$]$ são, respectivamente, as negações das duas condições.

$\mathrm{Na} \mathrm{ACP}$, não existe uma maneira de se especificar este padrão, pelo mesmo motivo apresentado no Padrão 4: Escolha Exclusiva. Em NPDL, a especificação é feita por meio da combinação de todas as possíveis maneiras de se executar as diferentes atividades. Se fosse acrescentada apenas mais uma atividade às opções paralelas, a expressão já se tornaria bastante extensa $\left(\boldsymbol{S E T P}=A \cdot\left(\% r_{1}(B\|C\| D)+\% ! r_{1}\left(\% r_{2}(B \| C)+\right.\right.\right.$ $\left.\left.\% ! r_{2}\left(\% r_{3}(B \| D)+\% ! r_{3}\left(\% r_{4}(C \| D)+\% ! r_{4}\left(\% r_{5} B+\% ! r_{5}\left(\% r_{6} C+\% ! r_{6} D\right)\right)\right)\right)\right)\right)$. Com $n$ opções paralelas, são necessários $2^{n}-1$ termos para serem compostos por meio do operador de composição alternativa $(+)$. A NPDL herda esse problema da sua álgebra base, necessitando fazer uma explosão do número de termos para representar o padrão. Em LOTOS, isso não ocorre, já que o número de termos aumenta linearmente com relação ao número de opções paralelas. Esta facilidade pode ser apontada como outra vantagem significativa da utilização de LOTOS.

\section{Padrão 7: Junção Sincronizada}

Definição. Um ponto no processo em que múltiplos ramos convergem para um único ramo. Se mais de um ramo estiver com atividades ativas, é preciso esperar o término de todas elas, sincronizando-as, para continuar. Se apenas um ramo for escolhido, o processo deve convergir sem sincronização.

Exemplo. Após a execução da atividade $A$, na escolha múltipla, se as duas atividades $(B$ e $C$ ) forem disparadas, a junção sincronizada espera pela finalização de $B$ e $C$ para habilitar $D$. Caso só a atividade $B$ ou somente a atividade $C$ for disparada, a atividade $D$ será habilitada após o término da atividade disparada. 


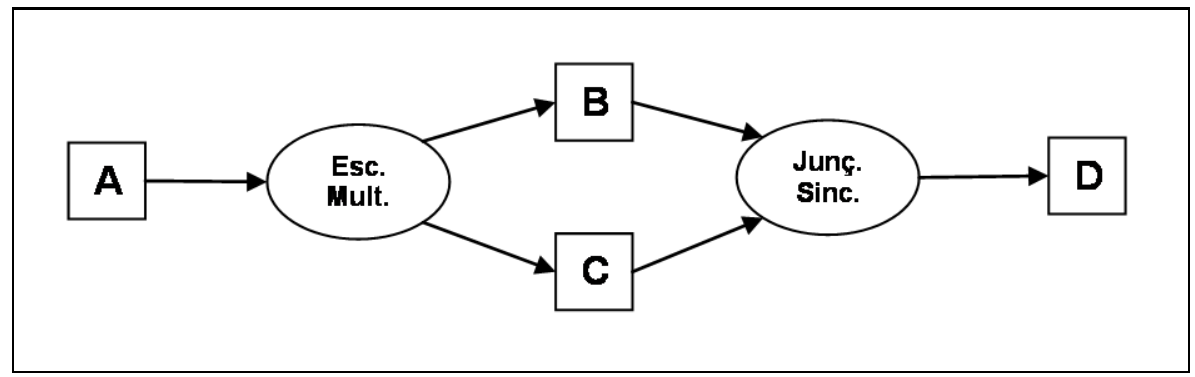

Figura 4.7: Junção Sincronizada. (Extraída de [9]).

ACP:

$$
P=A \cdot((B \| C)+B+C) \cdot D
$$

LOTOS:

$$
P=A>>(([\text { cond } 1] \rightarrow B[][\neg \text { cond } 1] \rightarrow \text { exit }) \|([\text { cond } 2] \rightarrow C[][\neg \text { cond } 2] \rightarrow \text { exit }))>>D
$$

NPDL:

$$
\text { SET P }=A \cdot\left(\% r_{1}(B \| C)+\% ! r_{1}\left(\% r_{2} B+\% ! r_{2} C\right)\right) \cdot D
$$

em que $r_{1}$ e $r_{2}$ são regras NPDL associadas às escolhas exclusivas e [condl], [cond2] são condições de guarda. $[\neg$ cond1] e [ $\neg$ cond2] são, respectivamente, as negações das duas condições.

Em ACP, a situação que ocorre aqui é similar ao Padrão 5: Junção Simples. Se a escolha múltipla fosse representável, não haveria nenhum problema para representar este padrão, visto que não há empecilhos na linguagem que impedem a junção. Esse padrão será, portanto, considerado como representável em ACP. A expressão ACP mostrada anteriormente apenas ilustra como seria especificado o padrão, ignorando a existência de condições. Em LOTOS, o padrão é perfeitamente representável, bem como na NPDL.

\section{Padrão 8: Junção Múltipla}

Definição. Um ponto no processo em que dois ou mais ramos convergem sem sincronização. Se mais de um ramo foi escolhido anteriormente para executar, a atividade seguinte à junção será iniciada várias vezes, com a chegada de cada uma das atividades provenientes dos diversos ramos. 
Exemplo. Após a execução da atividade $A$, na escolha múltipla, se as duas atividades $(B$ e $C$ ) forem disparadas, a junção múltipla executará $D$ a cada vez que uma linha de execução da divisão paralela é finalizada. Caso só a atividade $B$ ou somente a atividade $C$ for disparada, então $D$ será habilitado uma única vez, após o término da execução da atividade disparada.

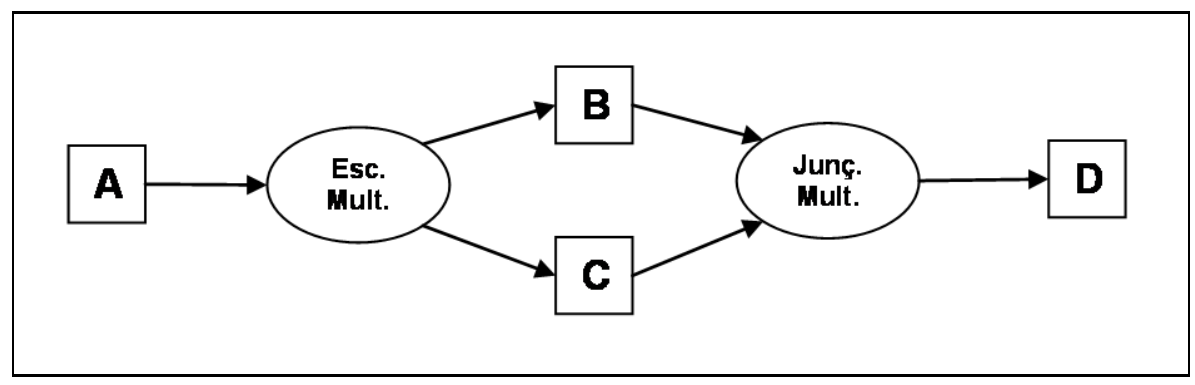

Figura 4.8: Junção Múltipla. (Extraída de [9]).

ACP:

$$
P=A \cdot((B \cdot D) \|(C \cdot D)+B \cdot D+C \cdot D)
$$

\section{LOTOS:}

$$
P=A>>(([\text { cond } 1] \rightarrow(B>>D)[][\neg \text { condl }] \rightarrow \text { exit })\|\|([\text { cond } 2] \rightarrow(C>>D)[][\neg \text { cond } 2] \rightarrow \text { exit }))
$$

NPDL:

$$
\text { SET } P=A \cdot\left(\% r_{1}(B \| C)+\% ! r_{1}\left(\% r_{2} B+\% ! r_{2} C\right)\right) \& D
$$

em que $r_{1}$ e $r_{2}$ são regras NPDL associadas às escolhas exclusivas e [cond1], [cond2] são condições de guarda. $[\neg$ cond1] e [ $\neg$ cond2] são, respectivamente, as negações das duas condições.

Para este padrão, a análise é a mesma feita no padrão anterior. Portanto, é considerada representável tanto em ACP (ver Padrão 7: Junção sincronizada) como também em LOTOS e na NPDL. É interessante notar que, na NPDL, foi criado um novo operador ("\&"), que evita ter que repetir, em cada termo, a atividade posterior à junção, facilitando a representação deste padrão. 


\section{Padrão 9: Discriminador}

Definição. Um ponto no processo que espera pelo término de um dos seus ramos de entrada antes de habilitar a atividade subseqüente. A partir daí, ele espera o fim da execução dos outros ramos ativos, ignorando-os. Depois disso, ele se reinicia. É importante notar que, diferentemente da junção múltipla, o número de vezes que a atividade subseqüente é executada não depende do número de ramos ativos de entrada do discriminador.

Exemplo. Após a execução da atividade $A$, na escolha múltipla, se as duas atividades $(B$ e $C$ ) forem disparadas, o discriminador habilita a execução de $D$ após o término da linha de execução que terminar primeiro. Se $B$ terminar primeiro, então $D$ será habilitada para execução. Após o término de $C$, diferentemente do que ocorre na junção múltipla, $D$ não será habilitada novamente. Caso só a atividade $B$ ou somente a atividade $C$ for disparada, então $D$ será habilitada uma única vez, após a execução da atividade disparada.



Figura 4.9: Discriminador. (Extraída de [9]).

ACP:

$$
P=A \cdot((B \cdot D)\|C+B\|(C \cdot D)+(B \| C) \cdot D+B \cdot D+C \cdot D)
$$

LOTOS:

$$
\begin{aligned}
P= & \text { hide } q \text { in } P_{1} \\
P_{1}= & A>>(([\text { cond } l] \rightarrow(B>>q)[][\neg \text { cond } l] \rightarrow \text { exit }) \| \\
& ([\text { cond } 2] \rightarrow(C>>q)[][\neg \text { cond } 2] \rightarrow \text { exit })) \mid[q] \| \\
& \left(q ;\left(D \| P_{2}\right)\right) \\
P_{2}= & \left(q ; P_{2}\right)[] \text { exit }
\end{aligned}
$$

NPDL: 


$$
\text { SET } P=A \cdot\left(\% r_{1}(B \| C)+\% ! r_{1}\left(\% r_{2} B+\% ! r_{2} C\right)\right) \wedge D
$$

em que $r_{1}$ e $r_{2}$ são regras NPDL associadas às escolhas exclusivas e [cond1], [cond2] são condições de guarda. $[\neg$ cond1] e [ $\neg$ cond2] são, respectivamente, as negações das duas condições. $q$ é uma ação LOTOS (porta).

Para este padrão, a análise é a mesma feita nos dois padrões anteriores. É considerada representável tanto em ACP como também em LOTOS e na NPDL. Na ACP, a representação do padrão (ignorando as condições) faz com que ocorra uma explosão de termos ainda maior do que aquela resultante unicamente pela escolha múltipla. Na NPDL, foi criado um novo operador (“ $\wedge$ ”), com o intuito de facilitar a representação. Usando esse operador, o número de termos volta a ser aquele originado pela escolha exclusiva, ainda muito grande, porém mais aceitável do que o originado pela ACP.

Para descrever o padrão em LOTOS, é necessário utilizar uma porta adicional $(q)$ e um processo adicional $P_{2}$ (apesar de existirem $P, P_{1}$ e $P_{2}$, somente dois deles são necessários, sendo que o processo $P_{1}$ foi definido apenas para facilitar a visualização de $P$ ). A porta $q$ será a responsável por, após o término de $B$ ou $C$, disparar o subprocesso $q ;\left(D \| P_{2}\right)$. Após o seu disparo, a atividade $D$ estará habilitada para execução. Em paralelo, o processo $P_{2}$ é executado. O processo $P_{2}$ tem a função de esperar o término da outra atividade no caso em que ela tenha sido habilitada. Na especificação LOTOS, o número de termos aumenta linearmente com relação aos ramos paralelos do discriminador, gerando expressões bem mais enxutas do que em ACP ou NPDL.

\subsubsection{Padrões estruturais}

\section{Padrão 10: Ciclo Arbitrário}

Definição. Um ponto no processo em que uma ou mais atividades (partes do processo) podem ser executadas repetidamente, formando um laço. Este padrão permite laços não estruturados. Assim, o laço pode ter mais de um ponto de entrada ou ponto de saída.

Exemplo. Neste exemplo, um laço se forma no processo. Após a execução da atividade $F$, dependendo dos ramos escolhidos no decorrer do processo, pode ocorrer a repetição cíclica de algumas atividades do processo, caracterizando, assim, um laço. 


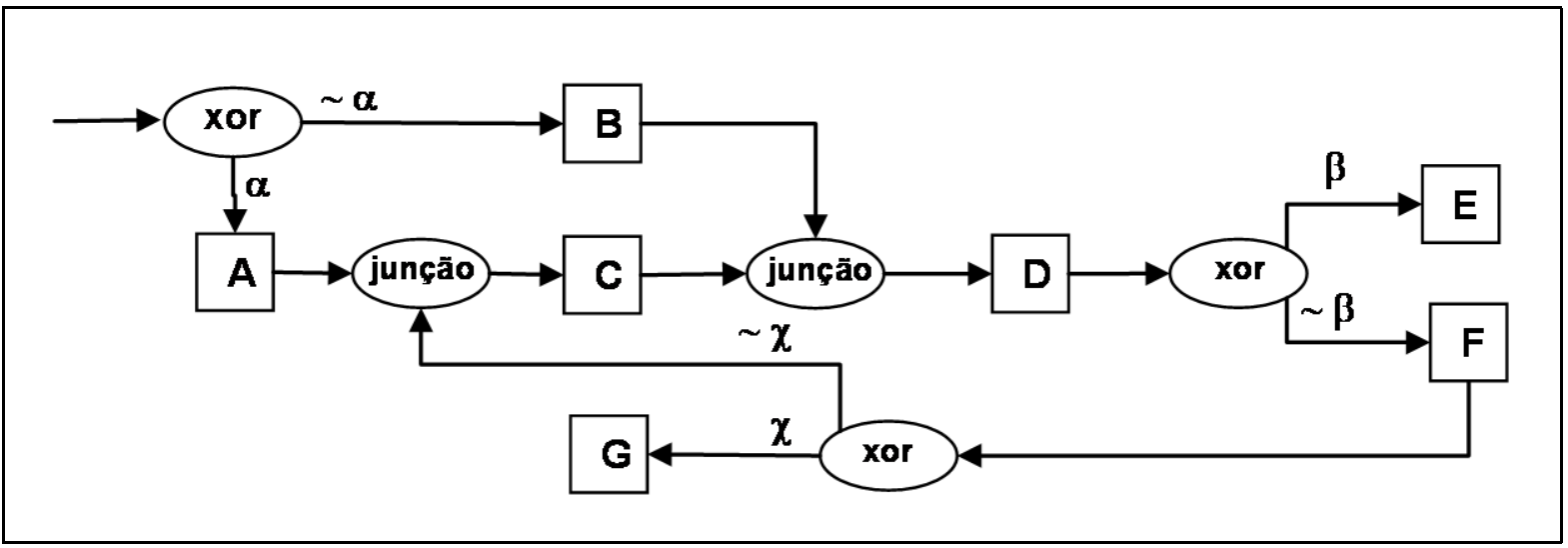

Figura 4.10: Ciclo Arbitrário. (Extraída de [9]).

$\mathrm{ACP}$ :

$$
\begin{aligned}
& P_{1}=A \cdot P_{2}+B \cdot P_{3} \\
& P_{2}=C \cdot P_{3} \\
& P_{3}=D \cdot\left(E+F \cdot\left(G+P_{2}\right)\right)
\end{aligned}
$$

LOTOS:

$$
\begin{aligned}
P_{1} & =\left(A>>P_{2}\right)[]\left(B>>P_{3}\right) \\
P_{2} & =C>>P_{3} \\
P_{3} & =D>>\left(E[]\left(F>>\left(G[] P_{2}\right)\right)\right) \\
& \text { ou } \\
P_{1} & =\left([\text { cond } 1] \rightarrow\left(A>>P_{2}\right)\right)[]\left([\neg \text { cond } 1] \rightarrow\left(B>>P_{3}\right)\right) \\
P_{2} & =C>>P_{3} \\
P_{3} & =D>>\left(([\text { cond } 2] \rightarrow E)[]\left([\neg \text { cond }] \rightarrow\left(F>>\left([\text { cond }] \rightarrow G[][\neg \text { cond }] \rightarrow \rightarrow P_{2}\right)\right)\right)\right)
\end{aligned}
$$

NPDL: 


$$
\begin{aligned}
\text { SET P1 } & =(A \cdot P 2)+(B \cdot P 3) \\
\text { SET P2 } & =C \cdot P 3 \\
\text { SET P3 } & =D \cdot(E+(F \cdot(G+P 2))) \\
& \text { ou } \\
\text { SET P1 } & =\% r_{3}(A \cdot P 2)+\% ! r_{3}(B \cdot P 3) \\
\text { SET P2 } & =C \cdot P 3 \\
\text { SET P3 } & =D \cdot\left(\% r_{1} E+\% ! r_{1}\left(F \cdot\left(\% r_{2} G+\% ! r_{2} P 2\right)\right)\right)
\end{aligned}
$$

em que $r_{1}, r_{2}$ e $r_{3}$ são regras NPDL associadas às escolhas exclusivas e [cond1], [cond2] e [cond3] são condições de guarda. [ $\neg$ cond1] , [ $\neg$ cond2] e [ $\neg$ cond3] são, respectivamente, as negações das condições.

Em ACP, NPDL e LOTOS, este padrão é representável, devido à presença de processos recursivos tanto na ACP como em LOTOS.

Para que um processo que contenha laços seja finito, é necessária a existência de maneiras de se sair dos laços, isto é, seja possível escolher entre continuar a repetição ou sair dela, dando continuidade ao processo. Como visto anteriormente, essas escolhas podem ou não ser representáveis na ACP. Em se tratando de escolhas postergadas, não haverá problemas para representar o padrão. O mesmo não ocorre quando escolhas exclusivas estão presentes no laço. Entretanto, essa deficiência já foi apontada pela não-representatividade da escolha exclusiva. Aqui, ela não será considerada, por não haver impedimentos teóricos para a representação de laços na ACP. Em LOTOS e na NPDL, o padrão é perfeitamente representável.

\section{Padrão 11: Terminação Implícita}

Definição. Uma instância de um processo (ou subprocesso) deve ser finalizada quando não há mais nada a ser feito, isto é, quando já não há atividades ativas no (sub)processo.

$\mathrm{Na}$ ACP, não existe uma estrutura que indique uma terminação. Fica a cargo do controlador de execução de processos saber se um processo chegou ao seu fim. O único caso representável pela ACP é o impasse, para o qual existe uma constante especial " $\delta$ " que o representa. Já no caso de LOTOS, essa idéia é representada por meio da palavra reservada stop, que indica a inatividade e também a situação de impasse. Mesmo nos casos em que ocorre terminação bem-sucedida do processo, o stop é gerado depois da emissão de um evento especial, simbolizando que o processo encontra-se inativo no momento. Assim, para este padrão, a ACP 
representa apenas uma parte dos possíveis casos, enquanto LOTOS o representa por completo. A NPDL se comporta da mesma forma que a ACP, representando o impasse com o caractere "\#”.

\subsubsection{Padrões envolvendo múltiplas instâncias}

\section{Padrão 12: Múltiplas Instâncias Sem Sincronização}

Definição. Ponto do processo em que, dentro do contexto de uma mesma instância do processo, várias instâncias de uma atividade podem ser criadas por meio de novas linhas de execução (threads), independentes umas das outras. Não existe a necessidade de sincronizar essas linhas de execução. A criação dessas instâncias não depende de regras.

Exemplo. A atividade $A$ é executada, podendo ter múltiplas instâncias. Independentemente da execução de $A$, o subprocesso $(B \cdot C)$ deve poder executar, sem sincronia com as instâncias da atividade A.

ACP:

$$
\begin{aligned}
& P=P_{1} \| B \cdot C \\
& P_{1}=\left(P_{1} \| A\right)+A
\end{aligned}
$$

LOTOS:

$$
\begin{aligned}
& P=P_{1} \mid \|(B>>C) \\
& P_{1}=\left(P_{1} \| A\right)[] A
\end{aligned}
$$

NPDL:

$$
\operatorname{SET} P=A ? * \| B \cdot C
$$

Não existe problemas para representar este padrão nas álgebras. Na NPDL, o operador "?*” foi criado somente com o objetivo de facilitar a representação dessa situação.

\section{Padrão 13: Múltiplas Instâncias Com Conhecimento Prévio em Tempo de Projeto}

Definição. Um ponto do processo em que, dentro do contexto de uma mesma instância do processo, uma atividade é habilitada várias vezes. O número de instâncias de uma dada atividade em uma dada instância de um processo é previamente conhecido em tempo de projeto do processo. Após o término de todas as instâncias 
da atividade, uma outra atividade fica habilitada para execução.

Exemplo. A atividade $A$ é executada, habilitando a atividade $B$. Serão executadas 3 instâncias da atividade $B$. Após a execução de todas as instâncias de $B, C$ estará habilitada para executar.

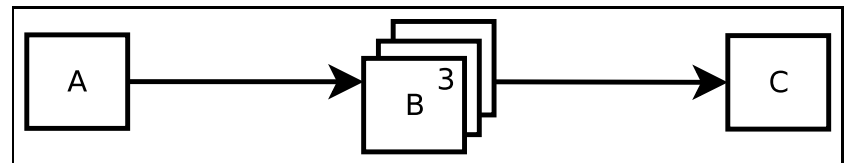

Figura 4.11: MI com Conhecimento Prévio em Tempo de Projeto.

ACP:

$$
\begin{aligned}
& P=A \cdot P_{1} \cdot C \\
& P_{1}=B\|B\| B
\end{aligned}
$$

LOTOS:

$$
\begin{aligned}
& P=A>>P_{1}>C \\
& P_{1}=B\|\mid B\| B
\end{aligned}
$$

NPDL:

$$
\text { SET } P=A \cdot(B ? 3) \cdot C
$$

Este padrão é representado tanto em ACP (e NPDL) como também em LOTOS. Em NPDL, o operador “?n", em que $n$ é o número de instâncias, foi criado apenas para facilitar a representação do padrão.

\section{Padrão 14: Múltiplas Instâncias Com Conhecimento Prévio em Tempo de Execução}

Definição. Um ponto do processo em que, dentro do contexto de uma mesma instância do processo, uma atividade é habilitada várias vezes. O número de instâncias dessa atividade pode variar dependendo da instância do processo, podendo depender de características da instância ou ainda da disponibilidade de recursos. Este número é conhecido em algum momento em tempo de execução, antes que as instâncias dessa atividade sejam criadas. Após o término de todas as instâncias da atividade, uma outra atividade fica habilitada para execução. Exemplo. A atividade $A$ é executada, habilitando a atividade $B$. Em tempo de execução é determinada a 
quantidade de instâncias da atividade $B$ que serão executadas. Após a execução de todas as instâncias de $B, C$ estará habilitada para executar.

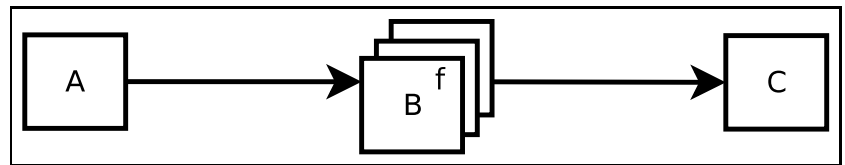

Figura 4.12: MI com Conhecimento Prévio em Tempo de Execução.

ACP:

Não é possível a especificação desse padrão.

LOTOS:

$$
\begin{aligned}
& P=A>>P_{1}(n)>>C \\
& P_{1}(x)=([x<=0] \rightarrow \text { exit })[]\left([x>0] \rightarrow\left(B \mid \| P_{1}(x-1)\right)\right)
\end{aligned}
$$

NPDL:

$$
\text { SET } P=A \cdot(B ? f) \cdot C
$$

em que $f$ é uma função NPDL que devolve um número inteiro e maior que zero.

Utilizando apenas a ACP, não é possível a especificação desse padrão, pois a ausência de dados no controle de fluxo inviabiliza colocar no processo, em tempo de execução, o número de instâncias que devem ser criadas. A NPDL, para viabilizar a sua representação, criou o operador "? $f$ ", que permite determinar, por meio de uma função $f$, a quantidade de instâncias. Em LOTOS, a presença de dados permite a especificação. Basta passar como parâmetro do processo $P_{1}$, um número $n$ indicando a quantidade de instâncias que se quer criar. A recursão presente em $P_{1}$ faz com que as $n$ instâncias sejam criadas.

\section{Padrão 15: Múltiplas Instâncias Sem Conhecimento Prévio em Tempo de Execução}

Definição. Um ponto do processo em que, dentro do contexto de uma mesma instância do processo, uma atividade é habilitada várias vezes. O número de instâncias de uma dada atividade não é conhecido nem durante 
o projeto do processo (como no Padrão 13) nem em tempo de execução antes da criação das instâncias (como no Padrão 14). Mesmo enquanto algumas das instâncias da atividade são executadas ou até mesmo depois de completadas, outras instâncias podem ser criadas. Após o término de todas as instâncias da atividade, uma outra atividade fica habilitada para execução.

Exemplo. A atividade $A$ é executada, habilitando a atividade $B$. A quantidade de instâncias da atividade $B$ não é conhecida nem em tempo de projeto nem em tempo de execução. Assim, as instâncias a serem executadas surgem durante a execução da atividade. Após a execução de todas as instâncias de $B$, que foram criadas ao longo da execução, $C$ estará habilitada para executar.

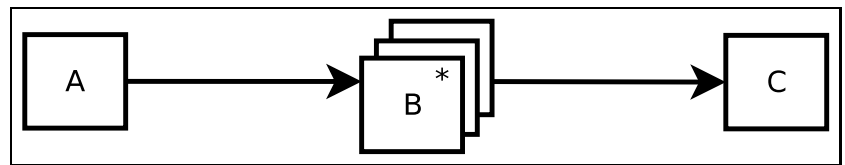

Figura 4.13: MI sem Conhecimento Prévio em Tempo de Execução.

$\mathrm{ACP}:$

$$
\begin{aligned}
P & =A \cdot P_{1} \cdot C \\
P_{1} & =\left(P_{1} \| B\right)+B
\end{aligned}
$$

LOTOS:

$$
\begin{aligned}
& P=A>>P_{1}>>C \\
& P_{1}=\left(P_{1}|| B\right)[] B
\end{aligned}
$$

NPDL:

$$
\operatorname{SETP}=A \cdot(B ? *) \cdot C
$$

Não existem problemas para representar este padrão nas álgebras. Na NPDL, o operador “?*” também é utilizado para facilitar a representação deste padrão. 


\subsubsection{Padrões baseados em estados}

\section{Padrão 16: Escolha Postergada}

Definição. Um ponto no processo em que um entre vários ramos é escolhido. A escolha não é feita baseada em dados existentes ou regras (como ocorre no padrão Escolha Exclusiva), mas sim baseada em uma escolha oferecida ao ambiente. Apenas uma alternativa é escolhida para execução.

Exemplo. A atividade $A$ é executada. Após a execução de $A$, as atividades $B$ e $C$ são habilitadas, sendo que apenas uma delas será escolhida para execução. Esta escolha é feita de maneira explícita pelo ambiente.

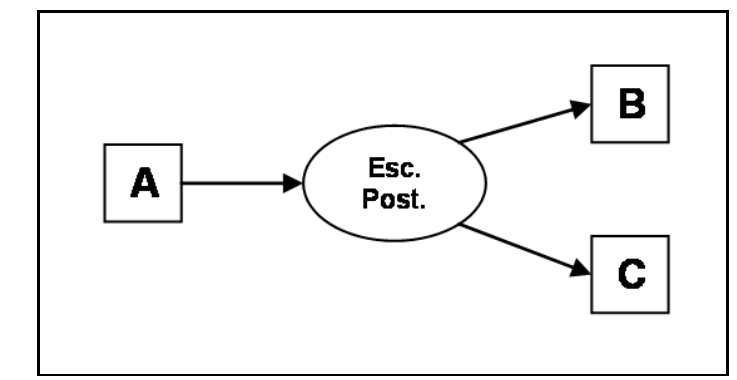

Figura 4.14: Escolha Postergada. (Extraída de [9]).

ACP:

$$
P=A \cdot(B+C)
$$

LOTOS:

$$
P=A>>(B[] C)
$$

NPDL:

$$
\text { SET } P=A \cdot(B+C)
$$

Este padrão é representável em ACP, NPDL e LOTOS. 


\section{Padrão 17: Roteamento Paralelo Entrelaçado}

Definição. Conjunto de atividades que é executado em uma ordem arbitrária. A ordem é definida em tempo de execução e, para uma mesma instância de workflow, duas atividades não podem ser executadas no mesmo momento. Todas as atividades do conjunto serão executadas.

Exemplo. A atividade $A$ é executada, habilitando a execução de $B$ seguida pela execução de $C$, ou a execução de $C$ seguida pela execução de $B$. Esta ordem é decidida em tempo de execução. As duas atividades nunca são executadas ao mesmo tempo. Após o término da execução de $B$ e $C$ ou $C$ e $B$, a atividade $D$ é habilitada para execução.



Figura 4.15: Roteamento Paralelo Entrelaçado. (Extraída de [9]).

ACP:

$$
P=A \cdot(B \cdot C+C \cdot B) \cdot D
$$

LOTOS:

$$
\begin{aligned}
& P=A>>P_{1}>>D \\
& P_{1}=\text { hide } q, r \text { in }\left((((q ; B)>>(r ; \text { exit }))\|\|((q ; C)>>(r ; \text { exit }))) \|[q, r] \mid P_{2}\right) \\
& P_{2}=q ; r ; P_{2}[] \text { exit }
\end{aligned}
$$

NPDL:

SETP $=A \cdot(B \mid * C) \cdot D$

em que $q$ e $r$ são ações LOTOS. 
LOTOS, ACP e NPDL representam este padrão. Em ACP, todas as possibilidades de execução devem ser explicitamente descritas. Em LOTOS, a utilização de duas ações $q$ e $r$, forçam a execução de apenas uma das atividades por vez, garantindo a implementação do padrão. $O$ processo $P_{2}$ faz com que todas as atividades possam executar, independentemente do número de atividades existentes.

LOTOS apresenta uma vantagem comparada a ACP com relação ao tamanho da expressão. Na ACP, com $n$ atividades paralelas são necessários $n$ ! termos para serem compostos por meio do operador de composição alternativa (+). Em LOTOS, entretanto, o número de termos aumenta linearmente com relação ao número de opções paralelas. Devido ao grande número de termos da ACP, NPDL criou o operador “|*”, facilitando a representação dessa situação.

\section{Padrão 18: Marco}

Definição. Um ponto no processo em que a execução de uma atividade depende de uma instância de um processo estar em um estado específico. A atividade é habilitada somente se um certo marco foi atingido, mas ainda não tiver expirado. Este padrão será exemplificado por meio de dois casos distintos, que refletem diferentes situações.

Exemplo. A atividade $A$ somente será habilitada depois da execução da atividade $B$, mas somente se $C$ não tiver sido executada ainda. Assim, a atividade $A$ não estará habilitada antes da execução de $B$ e nem depois da execução da atividade $C$. O estado entre as atividades $B$ e $C$ é modelado pelo lugar $M$. $M$ é chamado de marco para $A$.

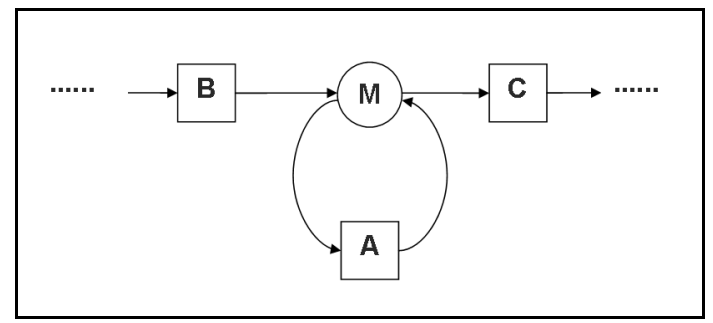

Figura 4.16: Marco. (Extraída de [9]).

ACP:

$$
\begin{aligned}
P & =B \cdot P_{1} \\
P_{1} & =A \cdot P_{1}+C
\end{aligned}
$$


LOTOS:

$$
\begin{aligned}
& P=B>>\left(\text { hide } p \text { in }\left(P_{1}|[p]| P_{2}\right)\right) \\
& P_{1}=p ; P_{1}[] C \\
& P_{2}=\left(p ; A>>P_{2}\right)[] \text { exit }
\end{aligned}
$$

NPDL:

$$
\begin{aligned}
& \text { SET } P=B \cdot P_{1} \\
& \text { SET } P_{1}=A \cdot P_{1}+C
\end{aligned}
$$

em que $p$ é uma ação LOTOS.

Este primeiro caso pode ser representado tanto em ACP (e NPDL) como também em LOTOS. Em LOTOS, uma ação $p$ é usada com o intuito de "simular" o marco. A ação $A$ só poderá ser executada enquanto $p$ for oferecida pelo subprocesso $P_{1}$, isto é, enquanto $C$ não começar a sua execução.

Exemplo. Neste segundo exemplo, tem-se um segundo caso de utilização do padrão. A diferença deste para o primeiro exemplo é a existência de linhas de execução paralelas, conforme ilustrado pela Figura 4.17. Uma das linhas de execução contém o marco $M$, que modela o estado compreendido entre o término da execução da atividade $B$ e o início da execução da atividade $C$. Já na outra linha de execução, paralela à primeira, está a atividade $F$, dependente do marco e que só poderá ser executada após o término da atividade $E$. É importante notar que neste caso, diferentemente do exemplo anterior, se a atividade dependente do marco não for executada nenhuma vez, o processo entra em um impasse, pois as atividades $F, G$ e $H$ nunca serão executadas.

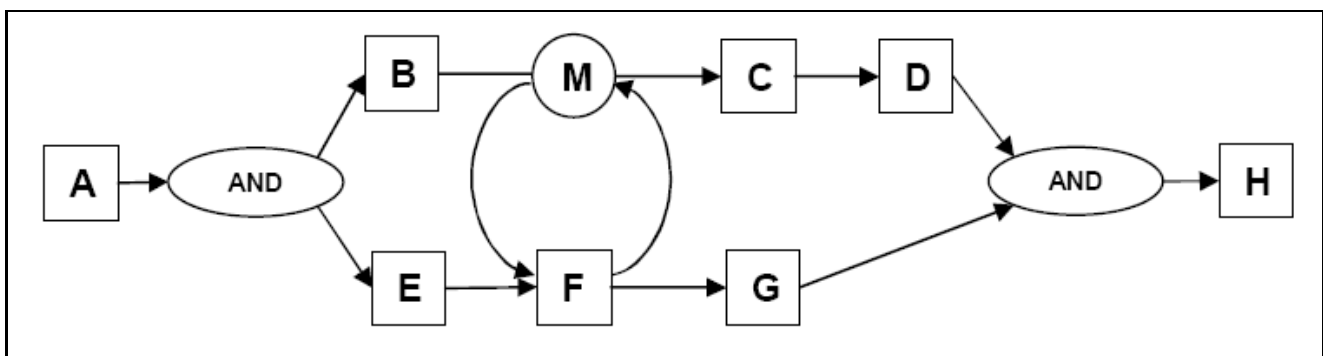

Figura 4.17: Marco envolvendo duas linhas paralelas. (Extraída de [9]).

ACP: 


$$
\begin{aligned}
& P=A \cdot(B \| E) \cdot P_{1} \cdot H+A \cdot(B \cdot C \cdot D \| E \cdot \delta \cdot G) \cdot H \\
& P_{1}=F \cdot P_{1}+F \cdot C \cdot(D \| G)
\end{aligned}
$$

LOTOS:

$$
\begin{aligned}
& P=A>>\left(\text { hide } p \text { in }\left(P_{1}|[p]| P_{2}\right)\right)>>H \\
& P_{1}=B>>P_{3} \\
& P_{2}=E>>\left(\left(P_{4}>>G\right)[] \text { stop }\right) \\
& P_{3}=\left(p ; P_{3}\right)[](C>>D) \\
& P_{4}=p ; F>>\left(P_{4}[] \text { exit }\right)
\end{aligned}
$$

NPDL:

$$
\begin{aligned}
& \boldsymbol{S E T P}=A \cdot(B \| E) \cdot P_{1} \cdot H+A \cdot(B \cdot C \cdot D \| E \cdot \# \cdot G) \cdot H \\
& \boldsymbol{S E T P} P_{1}=F \cdot P_{1}+F \cdot C \cdot(D \| G)
\end{aligned}
$$

em que $p$ é uma ação LOTOS.

Neste segundo caso, nota-se que não há uma regra geral para se especificar este padrão usando a ACP. Cada caso deve ser analisado separadamente. Porém, sempre é possível representá-lo em ACP, visto que é possível descrever a expressão como uma conjunção de todos os cenários possíveis. Devido a isso, a expressão resultante pode se tornar muito extensa, o que constitui um problema. A NPDL herda essa característica da ACP e funciona da mesma maneira. Já, em LOTOS, a especificação é possível, usando um mecanismo semelhante ao do caso anterior.

\subsubsection{Padrões de cancelamento}

\section{Padrão 19: Atividade Cancelável}

Definição. Ocorre quando uma atividade habilitada é cancelada antes do começo da sua execução. Quando a atividade é cancelada, é necessário remover a linha de execução que controla a atividade. Caso a execução da atividade já tenha começado, ela é cancelada e, quando possível, a instância em execução é paralisada e removida.

Exemplo. Se o cancelamento da atividade $B$ não for utilizado, após a execução da atividade $A$, habilita-se a 
atividade $B$ para a execução. Após a execução de $B$, a atividade $C$ torna-se habilitada para execução. Porém, antes da execução da atividade $B$, é possível cancelá-la. O cancelamento de $B$ faz com que a linha de execução que a controla seja removida, ou seja, $C$ não poderá mais ser executada. Este comportamento é reproduzido por meio do símbolo de impasse.

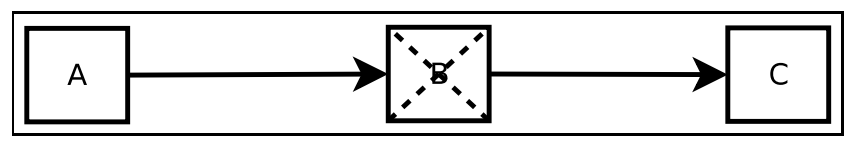

Figura 4.18: Atividade Cancelável.

ACP:

$$
P=A \cdot(B+\delta) \cdot C
$$

LOTOS:

$$
P=A>>B>>C
$$

NPDL:

$$
\operatorname{SET} P=A \cdot(B+\#) \cdot C
$$

Tanto em ACP (e NPDL) quanto em LOTOS, é possível especificar um possível cancelamento de uma atividade. Porém, existe uma diferença importante: na ACP, a atividade cancelável deve ser explicitamente definida como tal, pois as atividades usuais de ACP não estão preparadas para um cancelamento. Já em LOTOS, as atividades foram construídas de modo que elas possam ser canceladas. É por esse motivo que, em LOTOS, a especificação desse padrão não fica explícita na definição do processo $P$. Basta lembrar que a atividade $B$ é definida como $B=k_{1} ; k_{2} ;$ exit [ $>k_{c} ;$ stop (ver início desta seção) e que, portanto, já está preparada para um possível cancelamento.

\section{Padrão 20: Caso Cancelável}

Definição. Ocorre quando uma instância do processo é completamente removida. Esta remoção inclui todas as atividades que estão executando no momento, aquelas que ainda poderiam ser executadas e todos os subprocessos. A instância do processo é armazenada como completada de modo malsucedido.

Esta característica está relacionada ao serviço de execução do workflow e não à definição de um processo. 
Tanto processos escritos em ACP (e NPDL) como em LOTOS podem, portanto, ser cancelados pelo controle de execução, pois as linguagens não impedem o cancelamento.

\subsection{Representação dos conceitos de BPEL}

Esta seção contém idéias de mapeamento dos principais conceitos da linguagem BPEL para as álgebras ACP e LOTOS. Os mapeamentos dos conceitos BPEL em LOTOS vêm complementar um trabalho já existente sobre mapeamento BPEL-LOTOS [36], mostrando os limites de LOTOS na representação dos conceitos e, principalmente, comparar a ACP com LOTOS, com relação ao que é ou não representável. Seguem os conceitos.

\subsubsection{Serviços web}

Um processo BPEL é o responsável por coordenar os trabalhos de diversos serviços web, que são responsáveis por realizar as tarefas propriamente ditas. Mapear esse conceito para LOTOS é bastante natural, considerando que LOTOS já trabalha com sincronizações entre vários processos. É possível enxergar cada serviço web de BPEL como se fosse um processo LOTOS. Bastaria, portanto, que os processos LOTOS responsáveis por coordenar o controle de fluxo (fazendo o papel do processo BPEL) fizessem as sincronizações com os processos que representam os serviços web, utilizando, para isso, o sincronismo entre as ações LOTOS. Esses sincronismos entre ações seriam equivalentes às interações presentes em um processo BPEL. Portanto, LOTOS representa esse conceito. Em ACP, esse conceito não é representável. Uma descrição de processo ACP, por não haver a idéia de sincronismo, acaba representando a real execução do trabalho nas próprias atividades do controle de fluxo.

\subsubsection{Atividades}

No mapeamento dos padrões para LOTOS, ficou estabelecido que o conceito de atividade elementar dos padrões seria mapeado para um processo LOTOS. Nos padrões, só existe um tipo de conceito de atividade elementar, possibilitando esse mapeamento único. Em BPEL, porém, as atividades básicas fazem o papel de unidades atômicas de trabalho em um processo. Diferentemente do que ocorre nos padrões, existem diversos tipos de atividades básicas, cada qual com o seu comportamento. Desse modo, a tradução das atividades básicas de BPEL para LOTOS resultará em diversos mapeamentos, originando diferentes tipos de processos LOTOS. Nessa seção, o termo atividade básica, no contexto de LOTOS, será usada para designar tais processos. As principais idéias referentes a esses mapeamentos serão vistas a seguir, na seção que trata das atividades básicas. 
Da mesma maneira que nos padrões existem as atividades complexas, ou simplesmente atividades, em BPEL existem as atividades estruturadas. As atividades estruturadas de BPEL referem-se a conjuntos de atividades, sejam básicas ou estruturadas, com uma ordem de execução estabelecida. As atividades estruturadas de BPEL também serão mapeadas para processos LOTOS. Esses mapeamentos terão suas idéias explicitadas na seção que trata das atividades estruturadas. O termo atividade estruturada será usado, no contexto de LOTOS, para designar tais processos. Nesse mesmo contexto, o termo atividade será usado para se referir tanto a atividades básicas, como também a atividades estruturadas.

\section{Atividades básicas}

Seguem, abaixo, algumas idéias sobre os mapeamentos das principais atividades básicas BPEL para ACP e para LOTOS.

\section{1. invoke}

A atividade básica invoke é utilizada para fazer uma chamada a um serviço web. Essa chamada pode ser realizada de dois modos: requisição-resposta ou somente requisição. No modo somente requisição, usa-se uma variável para enviar mensagens ao serviço web. Na requisição-resposta, além do envio de dados, a atividade possui uma outra variável para guardar a resposta obtida.

Exemplo. Atividade invoke no modo somente requisição. A variável $i v$ é usada para o envio de mensagens.

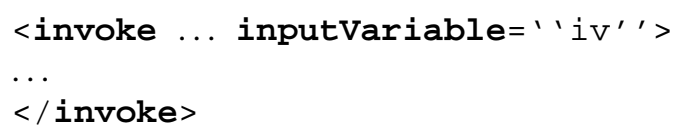

ACP:

Não é possível a representação desse conceito.

LOTOS:

$$
P=p ! i v ; \text { exit }
$$

em que $p$ é uma porta LOTOS. 
Exemplo. Atividade invoke no modo requisição-resposta. A variável iv é usada para o envio de mensagens e a variável $o v$, para recepção.

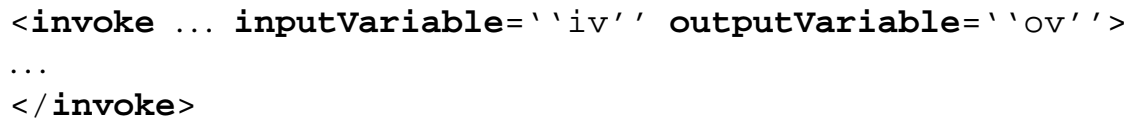

ACP:

Não é possível a representação desse conceito.

\section{LOTOS:}

$$
P=p ! i v ; q ? \text { ov:t; exit (ov) }
$$

em que $p$ e $q$ são portas LOTOS e $t$ é um tipo de dados LOTOS.

Em ACP, não existe a idéia de sincronização com passagem de dados entre processos. Logo, não é possível fazer o mapeamento. Em LOTOS, entretanto, é possível a comunicação utilizando as suas portas, que serão sincronizadas com um processo $S$ que representa um serviço web. Assim, no primeiro caso, há uma porta responsável pela sincronização inicial correspondente a uma chamada ao serviço web. Já no segundo caso, após a chamada inicial, haverá outra sincronização para capturar a resposta proveniente do serviço.

\section{2. receive}

A atividade receive, responsável por receber uma mensagem proveniente de um serviço web, possui uma variável usada para armazenar os dados recebido.

Exemplo. Atividade receive com variável var que guardará a mensagem recebida.

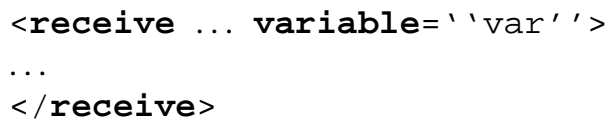

ACP: 
Não é possível a representação desse conceito.

\section{LOTOS:}

$$
P=p ? \text { var:t; exit }(\text { var })
$$

em que $p$ é uma porta LOTOS e $t$ é um tipo de dados LOTOS.

Em ACP, pelo mesmo motivo da atividade invoke, não é possível a representação deste conceito. Em LOTOS, a representação é possível usando uma porta $p$ que sincronizará a um serviço web, recebendo na variável var os dados provenientes do serviço.

\section{3. reply}

A atividade reply é responsável por enviar mensagens a serviços web. Seu uso é posterior a utilização de alguma atividade de recebimento de mensagens, como é o caso do receive.

Exemplo. Atividade reply com variável var que conterá mensagens a serem enviadas.

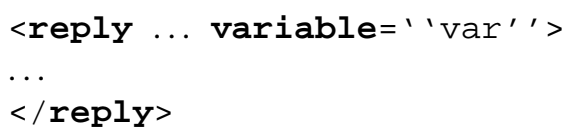

ACP:

Não é possível a representação desse conceito.

LOTOS:

$$
P=p ! \text { var } \text { exit }
$$

em que $p$ representa uma porta LOTOS.

Pelos mesmos motivos dos dois conceitos anteriores, a ACP não consegue representá-lo. Em LOTOS, a representação é feita normalmente, utilizando uma porta $p$ para a sincronização com o serviço web. 


\section{4. wait}

A atividade básica wait é responsável pela especificação de um atraso em um processo. Assim, essa atividade "segura" um processo por um tempo determinado, ou até que uma data específica seja atingida. Esse tipo de comportamento não é representável nem em LOTOS nem em ACP.

\section{5. assign}

A atividade assign é responsável pela cópia de dados entre variáveis ou pelo seu armazenamento nas variáveis por meio de expressões.

Exemplo. Nesta atividade assign, o valor da expressão exprl é inserido na variável var.

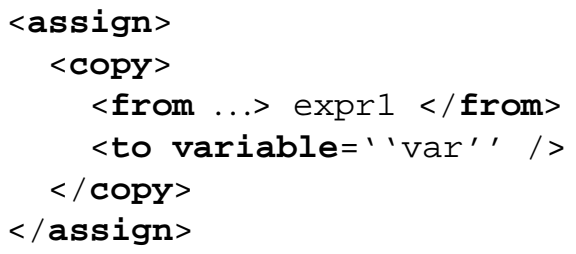

ACP:

Não é possível a representação desse conceito.

LOTOS:

$$
P_{1}>>\text { accept var:t in } P_{2}
$$

em que $P_{1}$ é um processo que produz a expressão exprl, repassando-a como saída pelo comando exit e $P_{2}$ é um processo que consome a expressão, armazenando o seu valor na variável var do tipo $t$.

Em ACP, este conceito não é representado, devido a ausência de dados e variáveis nessa álgebra. Em LOTOS, o conceito é representado, existindo várias maneiras de fazer a cópia de dados ou a inserção de valores de expressões em variáveis. Isso pode ser feito, por exemplo, utilizando processos paramétricos, a palavra reservada let, ou ainda por meio do accept. Entretanto, em LOTOS, esta atividade não comporá um processo em si, mas alterará a expressão de comportamento dos processos envolvidos com a finalidade de passar os dados entre os processos. 
6. exit

A atividade exit existe para indicar explicitamente que uma instância do processo deve ser imediatamente terminada, abortando todas as atividades em execução da instância. Tanto ACP como LOTOS representam esse conceito. Em ACP, o operador de impasse $(\delta)$ pode ser usado com essa finalidade. Em LOTOS, a expressão stop cumpre esse papel. Vale lembrar que o controle de instâncias e, portanto, a implementação da finalização da instância é responsabilidade do controlador de execução do processo. As álgebras apenas oferecem um sinalizador de que a instância deve ser finalizada.

\section{7. empty}

Esta atividade não realiza trabalho. Por esse motivo, será considerada aqui a sua principal utilização em BPEL: a de fornecer pontos de sincronização entre fluxos paralelos. Tendo como base essa finalidade, é possível representá-la, em LOTOS, por meio de ações de LOTOS básica de mesmo nome colocadas em expressões paralelas, com o intuito de sincronizá-las. Assim, a expressão hide $p$ in $(\ldots ; p ; \ldots|[p]| \ldots ; p ; \ldots)$ fará com que $p$ seja um ponto de sincronização entre as expressões paralelas, que é o papel da atividade empty. Em ACP, não é possível representar essa sincronização.

\section{Atividades estruturadas}

Seguem, abaixo, algumas idéias sobre os mapeamentos das atividades estruturadas BPEL para ACP e para LOTOS. Apesar de, como visto anteriormente, não ser possível mapear algumas atividades básicas para LOTOS e, principalmente, para ACP, esse fato será desconsiderado nessa seção, para possibilitar o mapeamento das atividades estruturadas e a análise da representatividade dos conceitos a seguir.

\section{Sequence}

A atividade sequence é responsável por executar as atividades contidas nela em ordem léxica, definindo uma sequiência. Uma determinada atividade só será executada depois do término da execução da atividade imediatamente anterior.

Exemplo. Nesta seqüência, a atividade ativ $C$ só será executada após o término da ativ $B$, que, por sua vez, só poderá ser executada após o término da ativA.

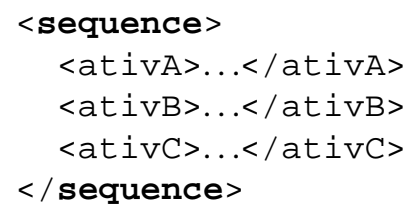


ACP:

$$
P=\operatorname{ativ} A \cdot \operatorname{ativ} B \cdot \operatorname{ativ} C
$$

\section{LOTOS:}

$$
P=\operatorname{ativ} A>>\operatorname{ativ} B>>\operatorname{ativ} C
$$

Esse conceito, pela sua semelhança com o Padrão 1: Seqüência, apresentado na Seção 4.1, é facilmente representado nas duas álgebras.

\section{2. flow}

A atividade flow contém um conjunto de atividades que serão executadas concorrentemente e sincronizadas no término das suas execuções.

Exemplo. Nesta atividade flow, a atividade ativA será executada concorrentemente com a atividade ativB.

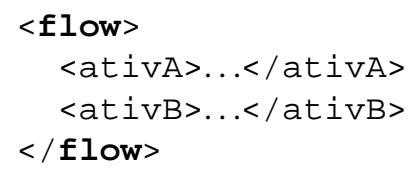

ACP:

$$
P=\operatorname{ativ} A \| \operatorname{ativ} B
$$

LOTOS:

$$
P=\operatorname{ativ} A \| \operatorname{ativ} B
$$

Considerando o paralelismo introduzido pela estrutura flow, ambas as álgebras são capazes de representálo. É importante notar que, aqui, não está sendo considerada uma possível introdução de dependências entre atividades concorrentes especificadas pelo uso de ligações de controle. Esse conceito será abordado mais adiante, na Seção 4.2.3.

\section{3. pick}

A atividade pick contém vários pares evento-atividade. Ela espera pela ocorrência de exatamente um dentre os eventos especificados, executando a atividade associada a ele. 
Exemplo. Nesta atividade pick, mensagens de dois tipos distintos, diferenciadas pelos seus atributos, podem ser recebidas. Uma mensagem do primeiro tipo habilita a execução da atividade ativA. A atividade ativB é habilitada pela chegada de uma mensagem do outro tipo.

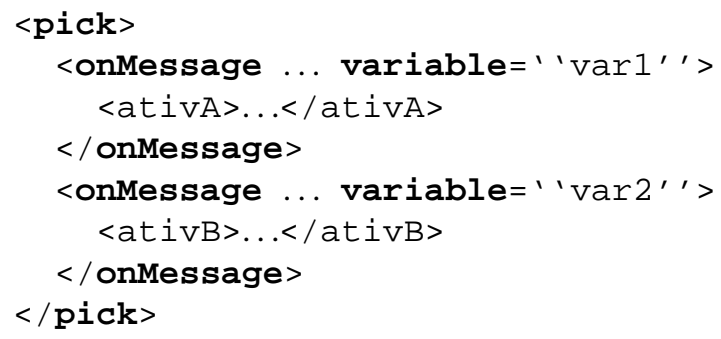

ACP:

Não é possível a representação desse conceito.

LOTOS:

$$
P=p ? \text { varl:t1; ativA }[] q \text { ?var2:t2; ativB }
$$

Em ACP, este conceito não pode ser representado devido a ausência de troca de mensagens e da inexistência de tratamento de dados. Já em LOTOS, esse conceito é representável. Para isso, basta considerar um recebimento de evento como uma sincronização em uma porta LOTOS. Entretanto, existe um tipo de evento que LOTOS não consegue representar: se, em vez de um evento "<onMessage>", fosse esperado um evento "<onAlarm>", isto é, um evento que é disparado por uma contagem regressiva de tempo. Não existe nos formalismos algébricos pesquisados nenhum mecanismo que tenha uma funcionalidade dessas.

\section{4. while}

A atividade while é responsável por executar repetidamente uma atividade definida em seu interior enquanto uma condição especificada for verdadeira. Essa verificação ocorre antes de cada execução da atividade interna.

Exemplo. Neste while, enquanto a condição cond for satisfeita, a atividade ativA será executada. 


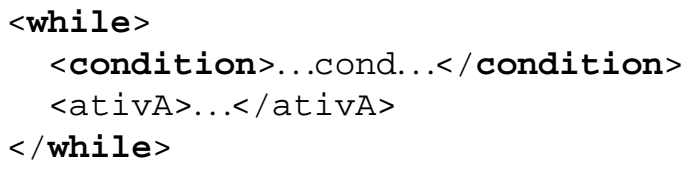

ACP:

Não é possível a representação desse conceito.

\section{LOTOS:}

$$
P=([\text { cond }] \rightarrow(\text { ativA }>>P))[]([\neg \text { cond }] \rightarrow \text { exit })
$$

em que $\neg$ cond refere-se à negação da condição cond.

Em LOTOS, um processo recursivo é usado para mapear esse conceito de laço, e as condições de guarda para representar a condição de parada do while. Já a ACP, apesar de possuir processos recursivos, não possui uma maneira de especificar a condição de parada do laço, o que torna impossível a representação.

\section{5. repeatUntil}

A atividade repeatUntil funciona de maneira muito semelhante ao while. A diferença é que, aqui, a checagem da condição é feita posteriormente à execução da atividade interna.

Exemplo. Neste repeatUntil, a atividade ativA é executada até que a condição cond não seja mais satisfeita.

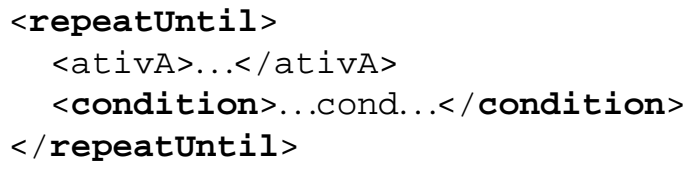

ACP:

Não é possível a representação desse conceito. 


\section{LOTOS:}

$$
P=\operatorname{ativA}>>(([\text { cond }] \rightarrow P)[]([\neg \text { cond }] \rightarrow \text { exit }))
$$

em que $\neg$ cond refere-se à negação da condição cond.

A análise deste caso é semelhante a do caso anterior. A não existência de uma representação em ACP se dá pelos mesmos motivos.

\section{6. scope}

A atividade scope é usada para agrupar atividades em blocos. É possível associar a esses blocos algumas estruturas como manipuladores de eventos, manipuladores de falhas e variáveis.

Em LOTOS, um escopo pode ser definido por meio de um processo. Os tipos de dados definidos localmente, bem como os processos locais, não são visíveis fora do escopo do processo. Definindo um escopo como um processo, é possível definir as variáveis locais dentro dele. Os manipuladores de eventos, falhas e compensações também podem ser definidos como processos locais, influenciando somente no escopo desejado. Em ACP, não é possível definir escopos, dado que faltam elementos que encapsulam essas estruturas.

7. if

A atividade if é usada para, dado um conjunto de atividades, selecionar uma delas para execução. Essa escolha é baseada em condições (ver atividade if no Apêndice A).

Exemplo. Para esta atividade if, se a condição condA for satisfeita, a atividade ativA será executada. Caso contrário, a condição $c o n d B$ é testada. Se for satisfeita, a atividade ativB será executada. Caso contrário, a atividade ativ $C$ será executada. A execução do if encerra-se após o término da execução de uma das três atividades. 


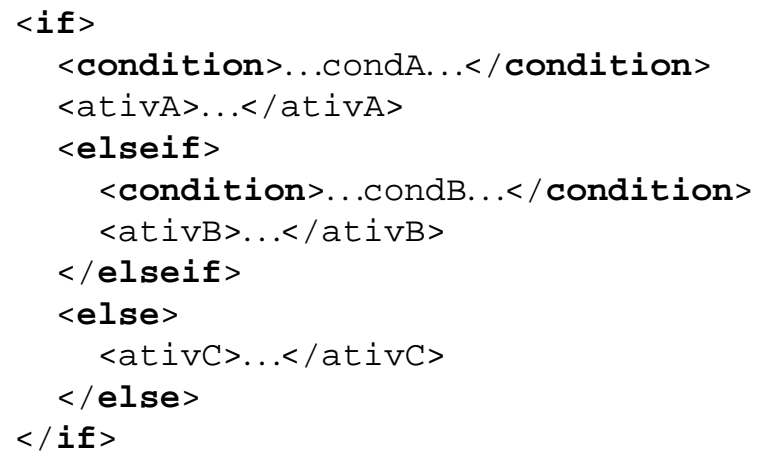

ACP:

Não é possível a representação desse conceito.

LOTOS:

$$
P=([\operatorname{cond} A] \rightarrow \operatorname{ativ} A)[]([\neg \operatorname{cond} A] \rightarrow(([\operatorname{cond} B] \rightarrow \operatorname{ativ} B)[]([\neg \operatorname{cond} B] \rightarrow \operatorname{ativ} C))
$$

em que $\neg \operatorname{cond} A$ e $\neg \operatorname{cond} B$ são as negações das condições $c o n d A$ e $\operatorname{cond} B$, respectivamente.

Em ACP, a representação é impossível devido à ausência de uma maneira de representar condições. Em LOTOS, o conceito é completamente representável utilizando condições de guarda.

\section{8. forEach}

A atividade forEach executa a atividade especificada em seu interior exatamente $n+1$ vezes, em que $n$ = finalCounterValue - startCounterValue. Se o atributo parallel tiver valor "yes", as instâncias da atividade serão executadas em paralelo. Caso o valor seja "no", cada instância da atividade começará somente depois que a repetição anterior foi completada.

Exemplo. Nesta atividade forEach, a atividade ativA será executada exprF - exprI +1 vezes.




ACP:

Não é possível a representação desse conceito.

LOTOS:

$$
P=P^{\prime}[\ldots](\operatorname{exprI}, \operatorname{exprF})
$$

Se parallel $=$ "no":

process $P^{\prime}[\ldots]($ contI:int, contF:int): exit :=

$\left([\operatorname{cont} F-\operatorname{contI}>=0] \rightarrow\left(\operatorname{ativ} A>>P^{\prime}[\ldots](\operatorname{contI}+1, \operatorname{cont} F)\right)\right)[]([\operatorname{cont} F-\operatorname{cont} I<0] \rightarrow$ exit $)$ endproc

Se parallel $=$ “yes":

process $P^{\prime}[\ldots]($ contI:int, contF:int $):$ exit $:=$

$\left([\operatorname{cont} F-\operatorname{contI}>=0] \rightarrow\left(\operatorname{ativ} A \| P^{\prime}[\ldots](\operatorname{contI}+1, \operatorname{cont} F)\right)\right)[]([\operatorname{cont} F-\operatorname{contI}<0] \rightarrow$ exit $)$ endproc

em que $P^{\prime}$ é um processo paramétrico LOTOS, com contI e contF parâmetros pertencentes aos números inteiros.

Em ACP, a representação é impossível devido à ausência de uma maneira de representar expressões e condições. Em LOTOS, foi necessária a definição de um processo paramétrico. Inicialmente, as variáveis são iniciadas com as expressões passadas. O contador inicial é incrementado até que todas as instâncias do processo sejam criadas. Quando parallel = "no", o forEach executa as instâncias do processo em série. Caso parallel $=$ "yes", os processos são executados em paralelo.

\subsubsection{Grafos e BPEL}

Além das atividades estruturadas, alguns conceitos de grafos como ligações de controle, condições de junção e condições de transição são responsáveis por definir o controle de fluxo de um processo. Basicamente, 
o papel dessas ligações e suas condições vinculadas é o de estabelecer dependências entre atividades definidas em fluxos paralelos.

A dependência entre atividades de ramos paralelos é um dos problemas enfrentados na ACP. Não há uma maneira de se representar diretamente a dependência inserida por uma ligação de controle na definição do processo. A solução, nesse caso, é escrever a expressão como uma conjunção de cenários possíveis, abrangendo todas as possíveis ordens de execução que o processo pode assumir dada aquela restrição da dependência. Isso pode resultar em expressões bastante extensas. Somando-se a essa dificuldade, a ausência de variáveis e dados na ACP não possibilita a criação e verificação de condições atreladas às ligações de controle. Assim, só é possível representar em ACP as dependências que não possuem condições atreladas. Por esse motivo, a ACP representa parcialmente esse conceito. Em LOTOS, a existência da sincronização entre ações possibilita estabelecer as dependências entre atividades em ramos paralelos, fazendo o papel das ligações de controle. As condições de junção e transição podem ser mapeadas por meio das condições LOTOS, o que resulta em uma representação completa do conceito.

Exemplo. Para ilustrar, simplificadamente, como seria uma utilização de um processo LOTOS para representar uma dependência BPEL, segue um exemplo. Nesse exemplo, duas sequiências de atividades estão rodando em paralelo. Uma delas, é composta pelas atividades ativA, ativB e ativC. A outra, é composta pelas atividades ativD, ativE e ativF. Existem duas ligações de controle entre os fluxos paralelos. Uma delas faz com que a execução da ativE dependa da execução da ativA. A outra faz com que a execução da ativE também dependa da execução da $a t i v B$. Na atividade ativE, ainda existe uma condição de junção que deve ser satisfeita para que o fluxo continue normalmente.

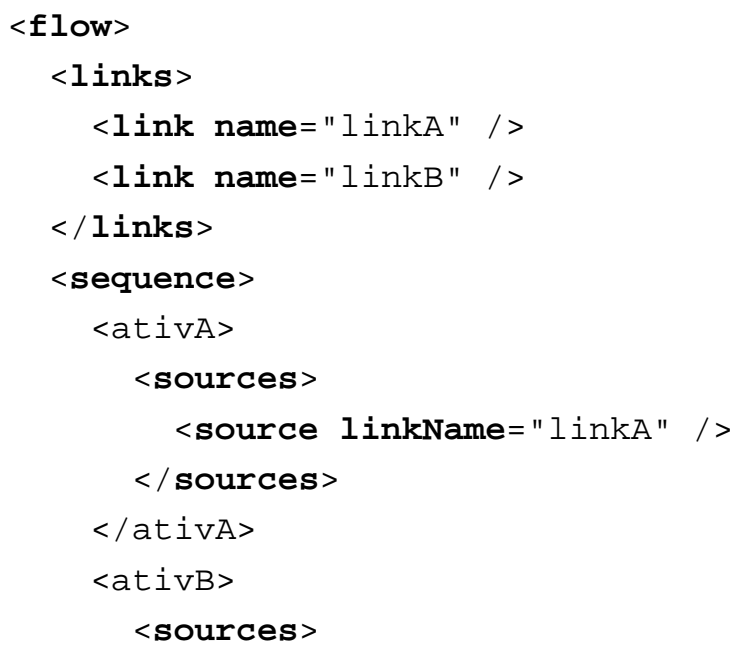




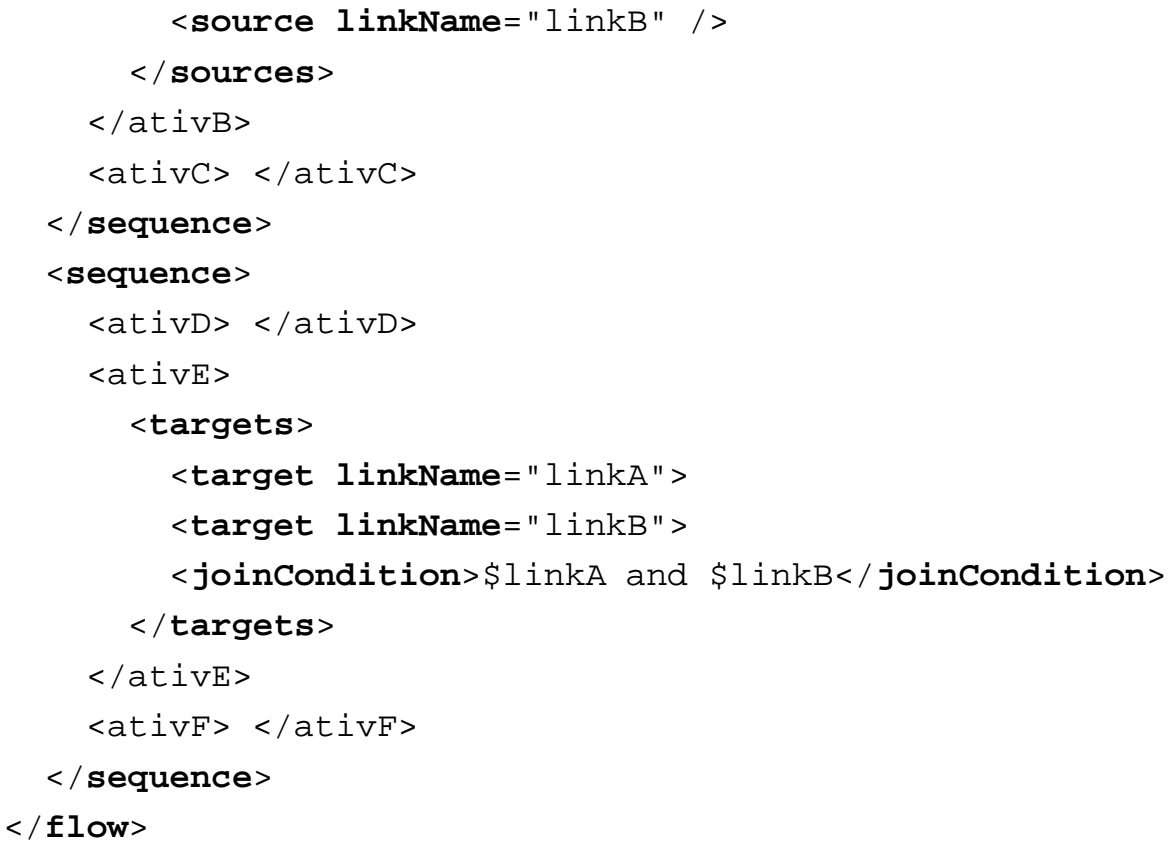

$\mathrm{ACP}:$

Não é possível a representação desse conceito.

\section{LOTOS:}

$A>>p$ !link $A>>B>>q$ !link $B>>C$

$|[p, q]|$

$p$ ?linkA:bool; $q$ ?linkB:bool; $r$ !linkA !linkB; exit

$|[r]|$

$D>>r$ ?linkA:bool ?linkB:bool $>>([$ linkA AND linkB $] \rightarrow(E>>F)[][\neg($ linkA AND linkB $)] \rightarrow$ stop $)$

em que $p, q$ e $r$ são portas LOTOS e linkA e linkB são variáveis Booleanas.

A notação usada no exemplo acima foi simplificada para facilitar o entendimento do processo. Assim, elementos como hide que deveria ser usado para isolar as portas e accept, para a passagem de dados, não 
foram colocados. O intuito desse exemplo é mostrar que é possível a especificação das dependências em LOTOS. Para isso, basta usar algumas portas adicionais e condições presentes nessa álgebra.

\subsubsection{Manipulação de dados}

A manipulação de dados em BPEL é um assunto abrangente e complexo. Parte dessa complexidade vem da flexibilidade que BPEL proporciona na escolha da linguagem usada para representar expressões. As variáveis, que podem ser declaradas de várias formas distintas, também contribuem para a dificuldade. Entretanto, simplificando as notações utilizadas e se atendo aos conceitos, a manipulação de dados de BPEL pode ser resumida a variáveis e a expressões. Juntamente a esses conceitos básicos, são importantes: o escopo de atuação dessas variáveis, seus tipos, um mecanismo de cópia e também de validação. A falta de tratamento de variáveis e expressões é uma das grandes deficiências da ACP. Assim, a saída encontrada na NPDL foi criar alguns operadores básicos para atrelar condições à ACP e fazer o tratamento e o controle desses dados no interior das atividades. Em LOTOS, existem os conceitos de expressões e variáveis. Para criar os tipos de dados, LOTOS possui à sua disposição os tipos abstratos de dados. Assim, é possível determinar os tipos dos valores resultantes das expressões e os tipos das variáveis, permitindo que validações de tipos sejam feitas. Além disso, é possível fazer verificações, por meio de condições, dos valores atribuídos às variáveis. Caso haja um valor não esperado, um comportamento diferente pode ser disparado com a finalidade de tratar o caso especial. A idéia de escopo também pode ser mapeada em LOTOS. A existência de processos que encapsulam portas, variáveis, tipos de dados e até subprocessos garantem a delimitação de escopos para a atuação das variáveis.

\subsubsection{Manipuladores de falhas, eventos, compensações e terminações}

Em BPEL, existem quatro tipos de manipuladores: de falhas, eventos, compensações e terminações. Esses manipuladores estão diretamente relacionados com a idéia de escopo de BPEL. Além de um comportamento considerado normal (chamado de atividade primária), um escopo contém variáveis, manipuladores de eventos, falhas, compensações, terminações, entre outras estruturas. Os manipuladores de eventos são responsáveis por capturar possíveis eventos que possam ocorrer durante a execução do escopo ao qual está associado. Quando um evento é capturado, a atividade associada a ele é executada juntamente com a atividade principal, de modo concorrente. São considerados eventos as mensagens e os "alarmes". Os manipuladores de falhas são utilizados para tratar as falhas que possam ocorrer durante a execução normal das atividades contidas dentro do escopo. Eles interrompem o fluxo principal antes de executar a atividade especificada no manipulador. $\mathrm{O}$ manipulador de compensações serve para desfazer as atividades de seu escopo quando este já foi executado 
com sucesso. Um manipulador de terminações, em linhas gerais, estabelece rotinas de terminação para atividades. São usadas nas atividades em execução no momento da detecção de uma falha (ver Seção 3.2.3).

Para mapear esses conceitos, é necessária a presença de eventos e tipos de dados. Como em ACP esses requisitos não são satisfeitos, é impossível representar essas estruturas. Em LOTOS, entretanto, o mapeamento é possível. Considerando que um escopo é representado por um processo LOTOS e que, dentro dele, estão presentes a atividade principal e os manipuladores, bastaria então definir um processo com algumas peculiaridades. Um mapeamento bastante interessante foi proposto por [36] e será agora explicado de maneira bem sucinta.

Um processo LOTOS é definido fazendo o papel do escopo. Nele, uma atividade principal, mapeada por um processo interno ao escopo, tem a sua execução rodando paralelamente com um processo recursivo que representa manipuladores de eventos. Sempre que um evento é recebido, este último processo é responsável por identificá-lo (por meio de uma variável) disparando a expressão de comportamento responsável pelo tratamento do evento, de forma paralela à atividade principal. Ainda paralelamente a esses processos, existe um outro, responsável pela manipulação das falhas. Ao receber uma falha, este processo interrompe o fluxo principal e também os manipuladores de eventos. Em seguida, identifica a falha, executando o tratamento adequado. É importante notar que a interrupção do fluxo principal pelo manipulador de falhas não é trivial, exigindo inclusive interação com o controle de execução para poder saber o momento exato que se deve interromper cada uma das atividades do fluxo. Para os manipuladores de compensação, um outro processo é criado, podendo ser ativado de duas maneiras: implicitamente dentro de um tratamento de uma falha ou por meio da chamada de uma atividade compensate. Nesse contexto, uma atividade compensate ou compensateScope pode ser vista como um processo LOTOS que, com a posse do nome de um escopo, contém uma simples sincronização que ativa um processo de um manipulador de compensação correspondente àquele escopo. Já um manipulador de terminações pode ser mapeado por meio de expressões de comportamento associadas às atividades pelo operador de desativação (“ [>”). Se uma atividade $A$ puder ser interrompida para a execução de uma terminação $T$, é possível representá-la como $A[>(t ; T)$, em que $t$ é a porta responsável por disparar a terminação $T$, desabilitando a execução de $A$.

\subsubsection{Identificação e ciclo de vida de instâncias de processos}

A identificação e ciclo de vida de instâncias de processos são assuntos que saem do escopo de definição de processos, sendo relacionados ao controle de execução que utilizará a definição dos processos para instanciálos e, após instanciados, identificá-los. Portanto, a linguagem não favorece ou impede a aplicabilidade desse conceito. Na ferramenta NavigationPlanTool, por exemplo, baseada na NPDL e, portanto, na ACP, um con- 
junto de tabelas relacionais é responsável por guardar as diferentes instâncias dos processos e identificá-las univocamente.

\subsection{Conclusão}

Dadas as análises individuais dos Padrões de Controle de Fluxo e dos conceitos de BPEL, as tabelas desta seção resumem as comparações apresentadas. A Tabela 4.1 refere-se aos padrões, e a Tabela 4.2 refere-se aos conceitos BPEL. Nelas, a seguinte legenda será usada:

- “+” : álgebra representa o padrão/conceito em questão;

- “_” : álgebra não representa o padrão/conceito em questão;

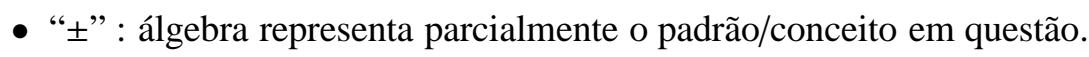

Observando a Tabela 4.1, nota-se que a linguagem LOTOS se mostra mais apropriada para a representação dos padrões apresentados, conseguindo representar um conjunto de padrões que engloba os padrões representados pela ACP. Da análise dos mapeamentos, é possível apontar quais são os fatores que contribuem para essa desigualdade da capacidade representativa:

- Ausência de tipos de dados, variáveis e expressões no controle de fluxo da ACP:

$\mathrm{O}$ fato de a ACP não ter uma maneira de inserir dados de controle de fluxo na especificação de processos constitui o principal problema no mapeamento dos padrões. A ausência de tipos de dados, variáveis e expressões não permite a essa álgebra especificar condições ou regras que podem influenciar o fluxo do processo. Com isso, certos padrões que envolvem escolha (como o Padrão 4: Escolha Exclusiva e o Padrão 6: Escolha Múltipla) não podem ser representados. Além da impossibilidade de produzir condições, a ausência de dados de controle de fluxo limita a flexibilidade da especificação de processos com relação a informações obtidas em tempo de execução. Isso é notado na impossibilidade de representação do Padrão 14: Múltiplas Instâncias Com Conhecimento Prévio em Tempo de Execução.

- Ausência de um indicador de inatividade do processo na ACP:

$\mathrm{Na} \mathrm{ACP}$, não existe um meio de indicar quando a instância do processo chegou ao seu fim. Essa característica faz com que um controlador de execução de processos ACP tenha que monitorar constantemente 
a situação das instâncias dos processos para detectar o seu término, que será associado à falta de atividades habilitadas para execução. Essa deficiência culmina na impossibilidade de representar o Padrão 11: Terminação Implícita.

- Representação exaustiva de alternativas nos processos ACP:

Em ACP, pela própria estrutura da linguagem, ao mapear alguns padrões, as expressões resultantes acabam ficando muito extensas, pois necessitam especificar todas as possibilidades resultantes da escolha envolvida. Isso ocorre no Padrão 6: Escolha Múltipla, no Padrão 9: Discriminador e no Padrão 17: Roteamento Paralelo Entrelaçado. Teoricamente, o tamanho da expressão resultante não interfere na representatividade da álgebra, e assim foi considerado neste trabalho. Porém, em se tratando de casos práticos, o tamanho da expressão resultante constitui um problema sério. Processos reais são, em geral, complexos. Se situações como essas apontadas nos padrões estiverem presentes nesses processos, as expressões geradas serão grandes demais para serem especificadas e entendidas, tornando o processo de modelagem mais propenso a erros.

Na representação dos conceitos BPEL, devido às características dessa linguagem, as deficiências da ACP aparecem de maneira mais acentuada, sendo poucos os conceitos representáveis por ela. Grande parte do problema se deve às características já apontadas nas observações anteriores. Assim, a ausência de tipos de dados, variáveis e expressões interfere na representação das atividades assign, while, pick, repeatUntil, scope, if, forEach, além dos manipuladores de eventos, falhas, compensações e terminações. Outra restrição importante imposta pela ausência de condições é a impossibilidade de mapear as dependências geradas pelas ligações de controle quando associadas a condições de junção e transição. Entretanto, pode-se apontar também como fatores importantes para a desigualdade de representatividade:

- Ausência de troca de mensagens na ACP:

Em BPEL, mensagens são muito utilizadas, pois a execução de tarefas por meio de serviços web assim exige. Essa ausência na ACP impede que vários conceitos possam ser representados, como é o caso das atividades invoke, receive, reply, pick e dos manipuladores.

- Ausência de sincronização entre ações:

$\mathrm{Na}$ ACP, não existe uma maneira de sincronizar ações. A representação da dependência entre atividades em ramos paralelos é um dos problemas enfrentados na ACP. Teoricamente, essa deficiência não influencia a representatividade da álgebra, pois é possível representar um processo que tenha esse tipo de dependência 
por meio da conjunção de todos os cenários possíveis. Porém, em processos reais, o tamanho da expressão resultante dificulta a sua especificação, sendo um impedimento real na utilização do formalismo. Isso afeta diretamente os processos que têm dependências especificadas por ligações de controle. É importante notar que, apesar de ficar bem evidente no contexto de BPEL, esse problema também é detectado na representação do Padrão 18: Marco. Além disso, o fato de não haver pontos de sincronização impede a representação da atividade empty.

Essas são as principais razões detectadas que justificam a baixa capacidade representativa da ACP. Devido a ausência dessas deficiências em LOTOS, ela mostra-se superior a ACP quando são tomados como bases comparativas os conceitos de BPEL e os Padrões de Controle de Fluxo. 


\begin{tabular}{|l|c|c|}
\hline Padrões de Controle de Fluxo & ACP & LOTOS \\
\hline \hline 01. Sequiência & + & + \\
02. Divisão paralela & + & + \\
03. Sincronização & + & + \\
04. Escolha exclusiva & - & + \\
05. Junção simples & + & + \\
06. Escolha múltipla & - & + \\
07. Junção sincronizada & + & + \\
08. Junção múltipla & + & + \\
09. Discriminador & + & + \\
10. Ciclo arbitrário & + & + \\
11. Terminação implícita & \pm & + \\
12. MI sem sincronização & + & + \\
13. MI com conhec. prévio projeto & + & + \\
14. MI com conhec. prévio execução & - & + \\
15. MI sem conhec. prévio execução & + & + \\
16. Escolha postergada & + & + \\
17. Roteamento paralelo entrelaçado & + & + \\
18. Marco & + & + \\
19. Atividade cancelável & + & + \\
20. Caso cancelável & + & + \\
\hline
\end{tabular}

Tabela 4.1: ACP e LOTOS: comparação baseada nos padrões. 


\begin{tabular}{|l|c|c|}
\hline Conceitos de BPEL & ACP & LOTOS \\
\hline \hline Serviços web & - & + \\
Invoke & - & + \\
Receive & - & + \\
Reply & - & + \\
Wait & - & - \\
Assign & - & + \\
Exit & + & + \\
Empty & - & + \\
Sequence & + & + \\
Flow & + & + \\
Pick & - & \pm \\
While & - & + \\
RepeatUntil & - & + \\
Scope & - & + \\
If & - & + \\
ForEach & - & + \\
Dependências entre ramos paralelos & \pm & + \\
Manipulação de dados & - & + \\
Manipuladores & - & + \\
\hline
\end{tabular}

Tabela 4.2: ACP e LOTOS: comparação baseada nos conceitos BPEL. 



\section{Capítulo 5}

\section{Conclusão}

Este trabalho apresenta um estudo comparativo entre ACP e LOTOS tendo como base os principais conceitos da linguagem BPEL e os Padrões de Controle de Fluxo de Workflow. Para a sua realização, detalhes da ACP e LOTOS foram revisitados de modo a permitir uma comparação entre esses arcabouços teóricos. Essa comparação foi necessária para que fosse possível avaliar quais seriam os ganhos de representatividade provenientes da troca da base algébrica da NPDL.

Inicialmente, a principal motivação do trabalho foi avaliar uma possível extensão ou troca da base algébrica da NPDL. Com o andamento da pesquisa, ficou evidente que estender a NPDL seria infrutífero, tendo em vista as limitações intrínsecas da ACP.

As tabelas 4.1 e 4.2 evidenciam importantes limitações da ACP. Assim, estender a NPDL, embora possível, seria um trabalho tão exaustivo quanto criar um novo arcabouço algébrico. Essas mesmas tabelas evidenciam

que o arcabouço algébrico LOTOS consegue cobrir satisfatoriamente os Padrões de Controle de Fluxo e os principais conceitos de BPEL. Portanto, constitui-se um forte candidato a arcabouço algébrico da NPDL.

\subsection{Principais contribuições}

Como principais contribuições deste trabalho, pode-se citar:

- Caracterização dos principais limites da ACP: ausência de tipos de dados, variáveis e expressões no controle de fluxo; a ausência de um indicador de inatividade do processo; a representação exaustiva de alternativas nos processos; a ausência de troca de mensagens; e a ausência de sincronização entre ações. Esses limites foram descritos na Seção 4.3.

- Representação dos Padrões de Controle de Fluxo de Workflow em LOTOS. Todos os principais 
padrões de controle de fluxo apresentados por Aalst em [19] foram cobertos pelo mapeamento realizado e comparados com a ACP. Detalhes do mapeamento podem ser vistos na Seção 4.1.

- Estudo da representação dos conceitos de BPEL em LOTOS e ACP. Como apresentado na Seção 4.2, as principais características de BPEL foram estudadas com relação a sua representatividade em LOTOS e em ACP, caracterizando a superioridade de LOTOS quanto ao poder de expressividade quando comparada à $\mathrm{ACP}$.

- Um texto que sintetiza os fundamentos e principais operadores da ACP, LOTOS, NPDL e conceitos de BPEL.

\subsection{Sugestões para pesquisas futuras}

Como atividades sugeridas para pesquisas futuras, incluem-se:

- Estudar outras álgebras existentes, comparando seu poder de representação em relação a LOTOS, ratificando seus pontos positivos e identificando possíveis limitações;

- Avaliar a reimplementação de NPDL tendo LOTOS como arcabouço algébrico;

- Propor um projeto de implementação de NPDL com seu novo arcabouço algébrico;

- Validar essa nova versão da NPDL usando estudos de caso. 


\section{Apêndice A}

\section{Atividades BPEL}

Este apêndice tem o objetivo de descrever um pouco mais detalhadamente as atividades presentes na linguagem BPEL. Ainda assim, trata-se de uma visão geral, sem entrar em detalhes de especificação da linguagem. Para informações mais aprofundadas, [14] traz a especificação completa da versão mais recente de BPEL.

\section{Atividades básicas:}

1. invoke: é utilizada para fazer uma chamada a algum dos serviços web disponibilizados. É através dela que se pode fazer uma chamada a alguma operação de um serviço. Estas operações podem ser do tipo requisição-resposta, na qual espera-se uma mensagem de resposta após o envio da mensagem requisitante, ou ainda do tipo somente requisição, no qual simplesmente ocorre o envio da mensagem requisitante, o que faz esse tipo de mensagem ser assíncrona;

2. receive: essa atividade espera por uma mensagem de um agente externo. Esta é uma das maneiras do processo de negócio prover serviços, que são chamados por meio de mensagens solicitantes. Pode ser utilizada para a criação de novas instâncias de processos. Ela é vista como uma atividade bloqueante, que faz a instância do processo esperar pela chegada de uma mensagem;

3. reply: é utilizada para mandar uma resposta referente a uma requisição previamente aceita através de uma outra atividade (como o receive). Essa resposta só tem sentido se for utilizada em uma interação do tipo requisição-resposta;

4. wait: essa atividade especifica uma espera, aguardando por um tempo determinado ou então até que determinado marco final seja atingido. Uma das utilidades dela é fazer com que outra atividade seja executada 
no momento correto;

5. assign: é utilizada para inserir dados em variáveis, por meio do uso de expressões. Também pode ser utilizada para copiar dados de uma variável para outra e outros fins (Ver [14]);

6. throw: é utilizada para sinalizar explicitamente uma falha interna na execução. A falha é identificada por meio de um nome e pode inclusive conter dados com mais informações sobre ela. Essa falha pode ser utilizada por um manipulador de falhas, que saberá tratá-la e informar outros serviços com as mensagens necessárias;

7. compensate: essa atividade é utilizada para iniciar a compensação de escopos (ver scope) que já foram completados com sucesso. Ela faz a compensação de todos os escopos internos que foram completados;

8. compensateScope: da mesma maneira que a atividade compensate, essa atividade serve para iniciar o processo de compensação de escopo que foi completado com sucesso. Porém, aqui, ela faz a compensação de um escopo interno que foi previamente especificado;

9. exit: essa atividade dá um fim imediato à instância do processo. Ela finaliza imediatamente todas as atividades que estejam rodando no momento, sem qualquer tipo de tratamento de falhas ou atividades compensatórias;

10. empty: essa atividade não faz nenhuma ação significativa. Ela é utilizada para fins como servir de ponto de sincronização para linhas de execução paralelas e para um tratamento de falhas no qual nenhuma ação é necessária;

11. rethrow: é utilizada dentro dos manipuladores de falhas para lançar novamente as falhas que foram capturadas. As modificações feitas anteriormente com relação aos dados presentes na falha são ignoradas e a mensagem original é lançada;

12. validate: essa atividade foi introduzida na especificação WS-BPEL 2.0. Durante a execução de um processo, os valores armazenados nas variáveis podem mudar. Essa atividade assegura que esses valores sejam válidos, comparando-os com o que foi definido previamente através de arquivos XML relacionados, como o arquivo WSDL ou ainda um XML Schema;

13. extensionActivity: introduzida na especificação WS-BPEL 2.0, essa atividade tem a funcionalidade de encapsular novas atividades (inclusive atividades estruturadas) que não foram definidas na especificação de BPEL. Essas novas atividades devem obedecer a algumas restrições impostas pela linguagem. Com isso, a especificação busca deixar a linguagem bastante extensível. 


\section{Atividades estruturadas:}

1. sequence: contém uma ou mais atividades, fazendo com que sejam executadas seqüencialmente, na ordem léxica em que aparecem dentro do bloco sequence. A atividade é dita completa quando a última atividade da seqüência acabar de ser executada;

2. flow: a atividade flow contém um conjunto de atividades. Sua função é fazer com que essas atividades sejam executadas concorrentemente. Além disso, ela é responsável pela sincronização destas atividades, pois o flow somente termina quando todas as atividades contidas nele estiverem finalizadas. A execução dessas atividades podem depender umas das outras. Essa dependência é expressa por meio do conceito de ligações de controle;

3. switch: esta atividade deixou de existir na especificação WS-BPEL 2.0, sendo substituída pelo if. Ela consiste em uma lista ordenada de um ou mais blocos condicionais definidos por elementos case. Opcionalmente, existe um bloco final do tipo otherwise. De acordo com a ordem em que aparecem, o primeiro bloco cuja condição for verdadeira será executado. Caso não haja tal bloco, o bloco otherwise será executado caso exista. Ao término da execução das atividades do bloco selecionado, a atividade é considerada completa;

4. pick: essa atividade é formada por um conjunto de blocos, cada um contendo um par evento-atividade. Ela espera pela ocorrência de exatamente um dos eventos do seu conjunto de eventos e então executa a atividade associada ao evento ocorrido. Quando um evento ocorre, os outros eventos, caso ocorram, não são mais aceitos pelo pick. O pick é considerado completo quando a atividade selecionada é completada;

5. while: a atividade while contém uma atividade especificada no seu interior. Sua função é repetir a execução da atividade interna contanto que a condição associada ao while seja verdadeira. A verificação sempre ocorre no começo de cada iteração, ao contrário do repeatUntil;

6. repeatUntil: foi introduzido na especificação WS-BPEL 2.0. O seu funcionamento é similar ao while, no sentido de ficar iterando a atividade presente no seu interior. Porém, ao contrário do while, a atividade interna é executada até que a condição se torne verdadeira. Quando a condição é satisfeita, a atividade é dita completa. É importante notar que pelo menos uma iteração sempre é executada, dado que o teste aqui é feito ao final da iteração;

7. scope: é utilizada para agrupar atividades em blocos. Com isso, é possível associar a esses blocos alguns objetos como manipuladores de eventos, manipuladores de falhas e variáveis. Esses blocos podem ser 
aninhados hierarquicamente;

8. if: substituindo o switch de BPEL4WS 1.1, essa atividade foi introduzida na especificação WS-BPEL 2.0. Especifica um comportamento condicional dentro do processo. Ela é formada por uma lista ordenada de um ou mais blocos condicionais definidos pelos elementos if ou elseif e seguidos por um elemento else. A existência de blocos elseif e else são opcionais. O primeiro bloco na ordem em que aparecem cuja condição associada for verdadeira tem suas atividades internas consideradas para o prosseguimento da execução. Se nenhuma condição for verdadeira, o bloco else é escolhido para o prosseguimento, caso esteja presente. Ela é considerada completa quando as atividades do bloco que foi selecionado completarem, ou quando nenhuma condição associada aos blocos for verdadeira e nenhum bloco else for especificado;

9. forEach: essa atividade está associada a duas expressões: startCounterValue e finalCounterValue. Ela possui no seu interior uma atividade do tipo scope. A sua função é a de executar esta atividade interna $N+1$ vezes, em que $N$ significa finalCounterValue - startCounterValue. Estas expressões são calculadas no início da atividade forEach e os seus valores permanecem constantes. As $N+1$ execuções podem ocorrer de duas maneiras, de acordo com o que for especificado: serial e paralela. Na serial, cada instância do scope começará somente depois da repetição anterior ter sido completada. Na paralela, a execução é equivalente a um flow com $N+1$ cópias do scope no seu interior. Existe ainda a possibilidade de inserir uma condição de término, que pode diminuir o número de execuções se a condição for satisfeita, ou ainda pode terminar execuções em andamento, no caso paralelo. 


\section{Apêndice B}

\section{Processo LOTOS}

Neste apêndice está a especificação em LOTOS completa do exemplo visto na Seção 2.1.5. Essa especificação ainda está em uma forma simplificada, na qual foram omitidas as definições dos tipos de dados, bem como algumas portas e parâmetros. Entende-se por $S A[\ldots], S B[\ldots], \ldots, S G[\ldots]$, processos que simbolizam serviços web, responsáveis pela realização das tarefas do exemplo. Existem diversas maneiras de especificar um processo LOTOS. A maneira utilizada aqui busca seguir os mapeamentos BPEL-LOTOS vistos na Seção 4.2 .

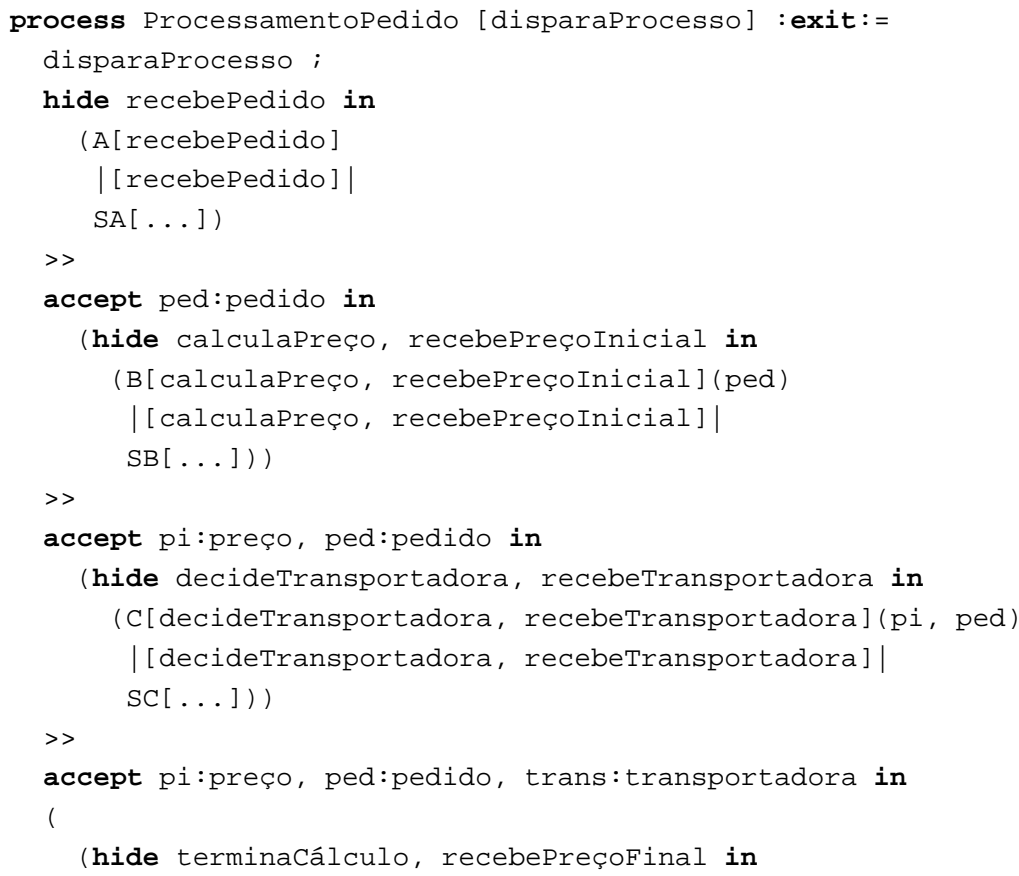




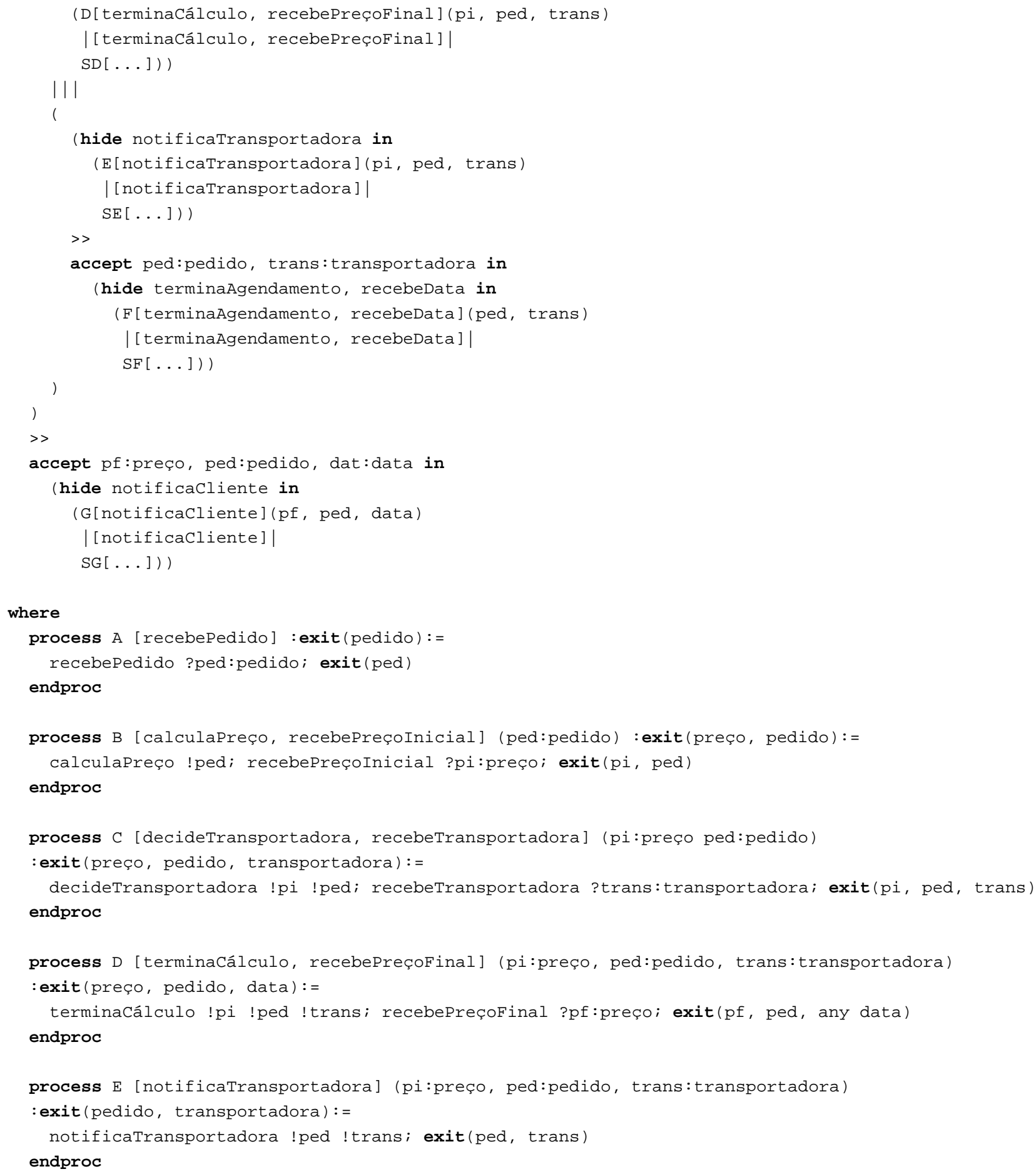




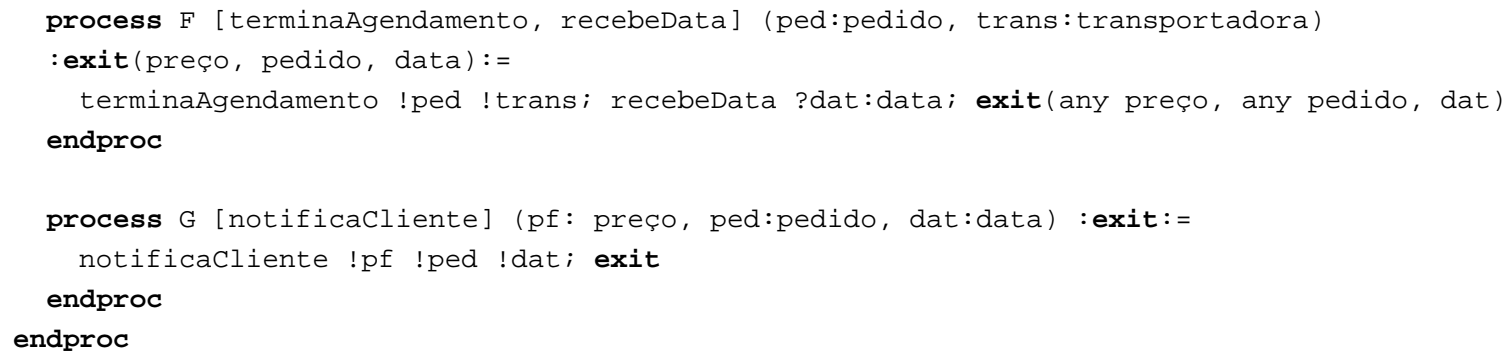





\section{Referências Bibliográficas}

[1] AALST, W. M. P. van der; DUMAS, M.; HOFSTEDE, A. H. M. ter. Web service composition languages: Old wine in new bottles? In: EUROMICRO '03: Proceedings of the 29th Conference on EUROMICRO. Washington DC, EUA: IEEE Computer Society, 2003. p. 298-305. ISBN 0-7695-1996-2.

[2] MURATA, T. Petri nets: Properties, analysis and applications. In: Proceedings of the IEEE. [S.1.]: IEEE Computer Society, 1989. v. 77, n. 4, p. 541-580.

[3] FOKKINK, W. Introduction to Process Algebra. Secaucus, NJ, EUA: Springer-Verlag New York, Inc., 2000. (Texts in Theoretical Computer Science (An EATCS Series)). ISBN 3-540-66579-X.

[4] BAETEN, J. C. M.; WEIJLAND, W. P. Process algebra. Essex, UK: Cambridge University Press, 1990.

[5] MILNER, R. Communication and Concurrency. Hertfordshire, UK: Prentice Hall, 1989.

[6] HOARE, C. A. R. Communicating Sequential Processes. New York, EUA: Prentice Hall, 1985.

[7] MILNER, R.; PARROW, J.; WALKER, D. A calculus of mobile processes, part i/ii. Journal of Information and Computation, Academic Press, Inc., Duluth, EUA, v. 100, n. 1, p. 1-77, 1992. ISSN 0890-5401.

[8] BOLOGNESI, T.; BRINKSMA, E. Introduction to the ISO specification language LOTOS. Comput. Netw. ISDN Syst., Elsevier Science Publishers B. V., Amsterdam, Holanda, v. 14, n. 1, p. 25-59, 1987. ISSN 0169-7552.

[9] BRAghetTO, K. R. Padrões de Fluxos de Processos em Banco de Dados Relacionais. Dissertação (Mestrado) - Instituto de Matemática e Estatística da Universidade de São Paulo, 2006.

[10] ARKIN, A. et al. Web Service Choreography Interface (WSCI 1.0). Ago. 2002. Disponível em: <http://www.w3.org/TR/2002/NOTE-wsci-20020808>. Acesso em: jan. 2007.

[11] ARKIN, A. Business Process Modeling Language. November 2002.

[12] CURBERA, F. et al. Business Process Execution Language for Web Services (Version 1.0). Jul. 2002. Disponível em: <ftp://www6.software.ibm.com/software/developer/library/ws-bpel1.pdf>. Acesso em: jan. 2007. 
[13] ANDREWS, T. et al. Business Process Execution Language for Web Services (Version 1.1). Mai. 2003. Disponível em: <http://www-106.ibm.com/developerworks/webservices/library/ws-bpel/>. Acesso em: jan. 2007.

[14] ALVES, A. et al. Web Services Business Process Execution Language Version 2.0. (OASIS Standard). Abr. 2007. Disponível em: <http://docs.oasis-open.org/wsbpel/2.0/>. Acesso em: set. 2007.

[15] THATTE, S. XLANG, Web Services for Business Process Design. Microsoft Corporation. 2001. Disponível em: <http://www.gotdotnet.com/team/xml_wsspecs/xlang-c/>. Acesso em: jan. 2007.

[16] LEYMANN, F. Web Services Flow Language (WSFL 1.0). 2001.

[17] AALST, W. M. P. van der; HOFSTEDE, A. H. M. ter. YAWL: Yet Another Workflow Language (Revised Version). Brisbane, Austrália, 2003.

[18] BOOTH, D. et al. Web Services Architecture. fev. 2004. Disponível em: <http://www.w3.org/TR/2004/NOTE-ws-arch-20040211/>. Acesso em: jan. 2007.

[19] AALST, W. M. P. van der et al. Workflow patterns. Distributed and Parallel Databases, v. 14, n. 1, p. 5-51, jul. 2003.

[20] BAETEN, J. C. M. A brief history of process algebra. Theor. Comput. Sci., Elsevier Science Publishers Ltd., Essex, UK, v. 335, n. 2-3, p. 131-146, 2005. ISSN 0304-3975.

[21] BERGSTRA, J. A.; KLOP, J. W. Process algebra for synchronous communication. Information and Control, v. 60, n. 1-3, p. 109-137, 1984.

[22] MILNER, R. A Calculus of Communicating Systems. Secaucus, EUA: Springer-Verlag New York, Inc., 1982. ISBN 0387102353.

[23] MOLLER, F. The importance of the left merge operator in process algebras. In: Proceedings of the seventeenth international colloquium on Automata, languages and programming. New York, NY, EUA: Springer-Verlag New York, Inc., 1990. p. 752-764. ISBN 0-387-52826-1.

[24] EHRIG, B. M. H. Fundamentals of Algebraic Specification - 1. Secaucus, NJ, EUA: Springer-Verlag, 1985.

[25] LOGRIPPO, L.; FACI, M.; HAJ-HUSSEIN, M. An introduction to LOTOS: learning by examples. Comput. Netw. ISDN Syst., Elsevier Science Publishers B. V., Amsterdam, Holanda, v. 23, n. 5, p. 325-342, 1992. ISSN 0169-7552.

[26] TURNER, K. The Formal Specification Language LOTOS: A Course for Users. Escócia, Ago 1989.

[27] GAMMA, E. et al. Design Patterns: Elements of Reusable Object-Oriented Software. Massachusetts, EUA: Addison-Wesley, 1995. ISBN 0201633612. 
[28] LEYMANN, F.; ROLLER, D.; THATTE, S. Goals of the BPEL4WS Specification. 2003. Disponível em: $<$ http://xml.coverpages.org/BPEL4WS-DesignGoals.pdf>. Acesso em: jan. 2007.

[29] BRAY, T. et al. Extensible Markup Language (XML) 1.0. Ago. 2006. Disponível em: <http://www.w3.org/TR/2006/REC-xml-20060816/>. Acesso em: jan. 2007.

[30] CHRISTENSEN, E. et al. Web Services Description Language (WSDL) 1.1. Mar. 2001. Disponível em: <http://www.w3.org/TR/2001/NOTE-wsdl-20010315>. Acesso em: jan. 2007.

[31] OUYANG, C. et al. Formal Semantics and Analysis of Control Flow in WS-BPEL. Amsterdam, Holanda, 2005. Disponível em: <http://www.bpmcenter.org/reports/2005/BPM-05-13.pdf>.

[32] CLARK, J.; DEROSE, S. XML Path Language (XPath) Version 1.0. Nov. 1999. Disponível em: <http://www.w3.org/TR/1999/REC-xpath-19991116>. Acesso em: jan. 2007.

[33] ULLMAN, J. D.; WIDOM, J. A First Course in Database Systems. Segunda edição. Upper Saddle River, NJ, EUA: Prentice Hall, 1997.

[34] FERREIRA, J. E.; TAKAI, O. K.; PU, C. Integration of collaborative information system in internet applications using RiverFish architecture. In: Annals International Conference on Collaborative Computing: Networking, Applications and Worksharing. San Jose, EUA: IEEE Computer Society, 2005.

[35] FERREIRA, J. E.; TAKAI, O. K.; PU, C. Integration of business processes with autonomous information systems: A case study in government services. In: 7th International IEEE Conference on E-Commerce Technology. Munique: IEEE Computer Society, 2005. p. 471-478.

[36] FERRARA, A. Web services: a process algebra approach. In: ICSOC '04: Proceedings of the 2nd international conference on Service oriented computing. New York, NY, EUA: ACM Press, 2004. p. 242251. ISBN 1581138717. 